\title{
Effect of Potassium on \\ Uptake of 137Cs in Food Crops Grown on Coral Soils: Annual Crops at Bikini Atoll
}

E.L. Stone, W.L. Robison

U.S. Department of Energy

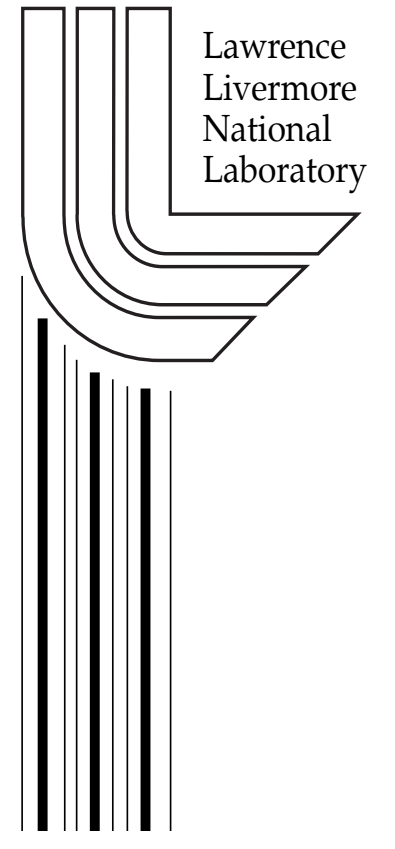

February 2002 


\section{DISCLAIMER}

This document was prepared as an account of work sponsored by an agency of the United States Government. Neither the United States Government nor the University of California nor any of their employees, makes any warranty, express or implied, or assumes any legal liability or responsibility for the accuracy, completeness, or usefulness of any information, apparatus, product, or process disclosed, or represents that its use would not infringe privately owned rights. Reference herein to any specific commercial product, process, or service by trade name, trademark, manufacturer, or otherwise, does not necessarily constitute or imply its endorsement, recommendation, or favoring by the United States Government or the University of California.

The views and opinions of authors expressed herein do not necessarily state or reflect those of the United States Government or the University of California, and shall not be used for advertising or product endorsement purposes.

This work was performed under the auspices of the U.S. Department of Energy by the University of California, Lawrence Livermore National Laboratory under Contract No. W-7405Eng-48.

This report has been reproduced directly from the best available copy.

Available to DOE and DOE contractors from the Office of Scientific and Technical Information

P.O. Box 62, Oak Ridge, TN 37831

Prices available from (423) 576-8401

http://apollo.osti.gov/bridge/

Available to the public from the

National Technical Information Service

U.S. Department of Commerce 5285 Port Royal Rd., Springfield, VA 22161 http:/ / www.ntis.gov/

OR

Lawrence Livermore National Laboratory

Technical Information Department's Digital Library

http://www.llnl.gov/tid/Library.html 


\title{
Effect of Potassium on Uptake of 137Cs in Food Crops Grown on Coral Soils: Annual Crops at Bikini Atoll
}

\author{
Earl L. Stonet \\ William L. Robison \\ tAdjunct Professor \\ University of Florida \\ Gainesville, FL
}

Manuscript Date: February 2002

\section{Lawrence Livermore National Laboratory \\ University of California • Livermore, CA • 94551}




\section{Table of Contents}

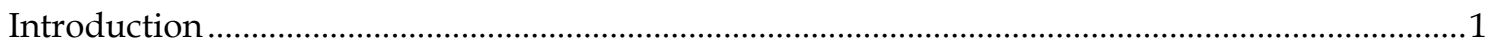

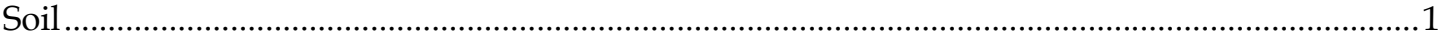

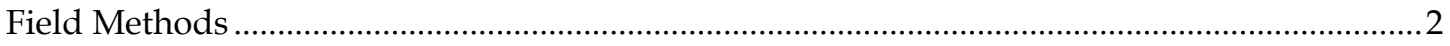

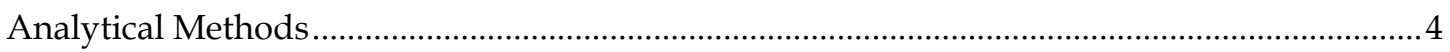

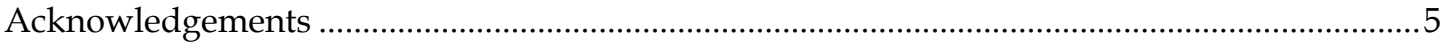

Experiment 1: Potassium and Stable Cesium Reduce Uptake of Radiocesium by

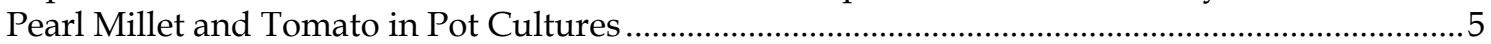

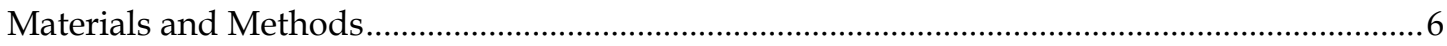

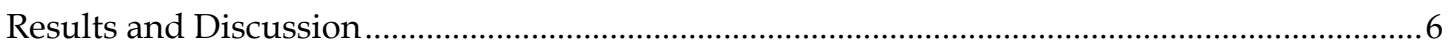

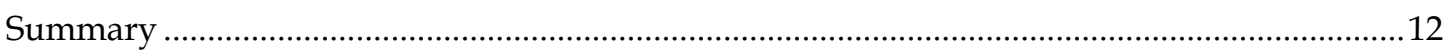

Experiment 2: Potassium Reduces ${ }^{137} \mathrm{Cs}$ in Annual Crops Grown on an Atoll Soil.......................15

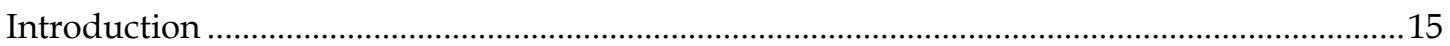

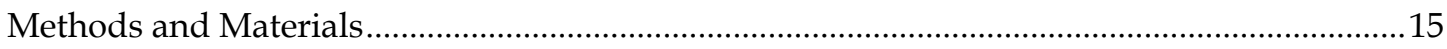

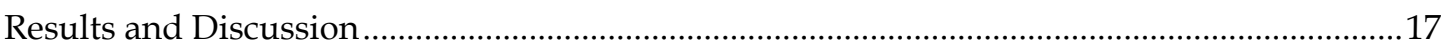

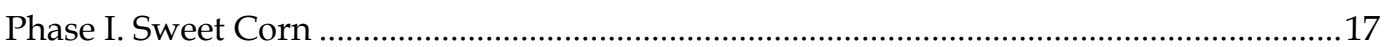

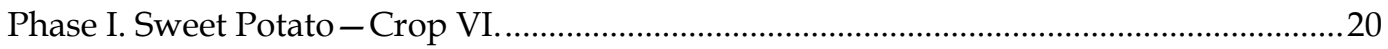

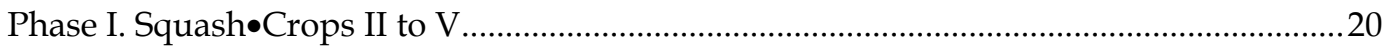

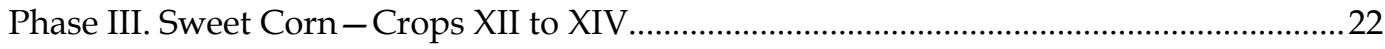

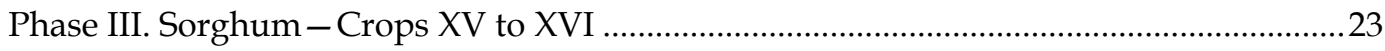

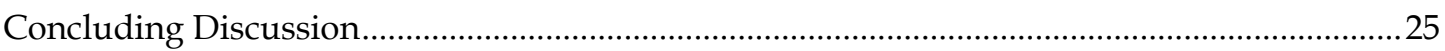

Experiment 3: Effect of large K and Na Applications on ${ }^{137}$ Cs Uptake by Annual

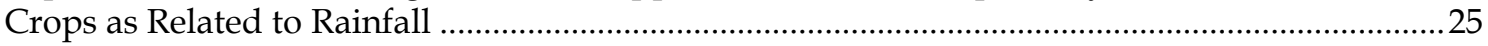

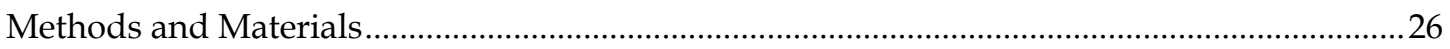

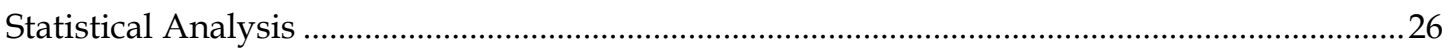

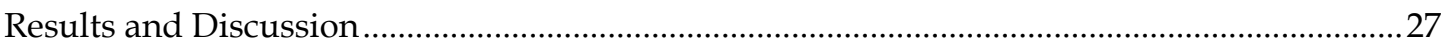

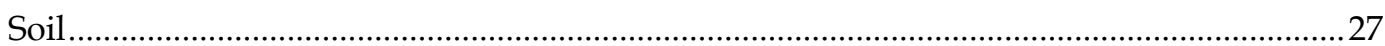

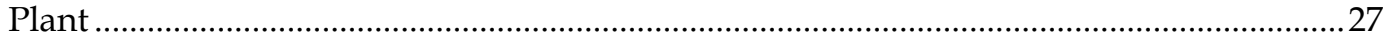

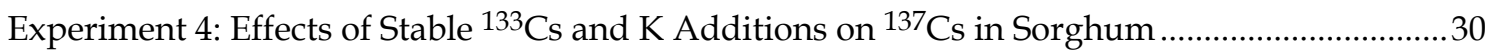

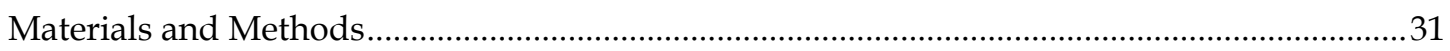

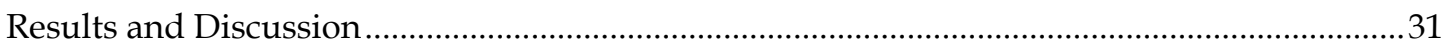

Experiment 5: Effect of Applied K on ${ }^{137} \mathrm{Cs}$ and $\mathrm{K}$ Concentrations in Sorghum .............................35

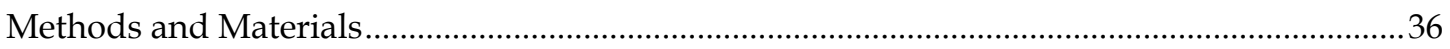

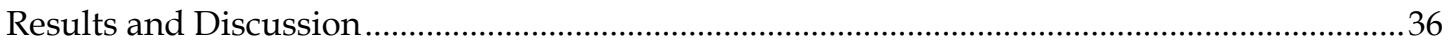

Experiment 6: Spatial Distribution of Applied Potassium and the Uptake of ${ }^{137} \mathrm{Cs}$

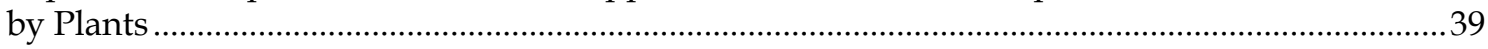

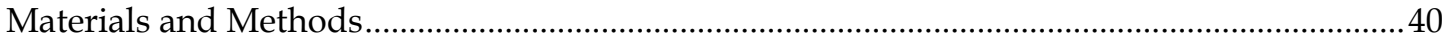

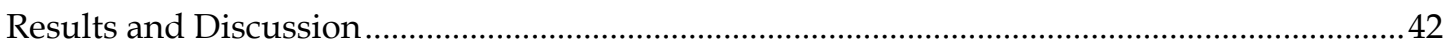

Experiment 7: Potassium Release from Clinoptilolite Reduces ${ }^{137}$ Cs in Food Crops......................4 45

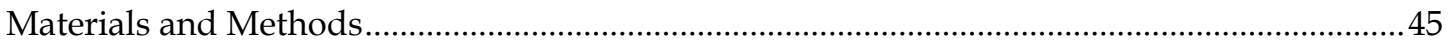

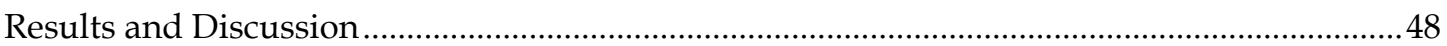

Experiment 8: Soil Fumigation Increase s ${ }^{137}$ Cs Concentration in Sweet Corn.................................52

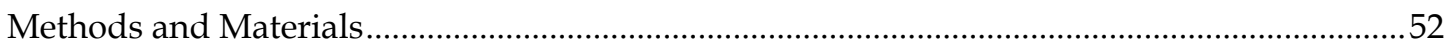




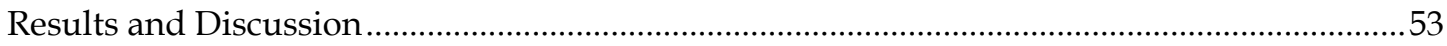

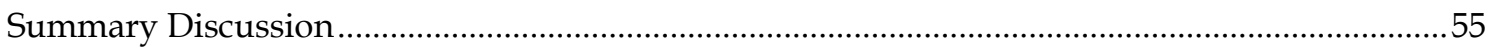

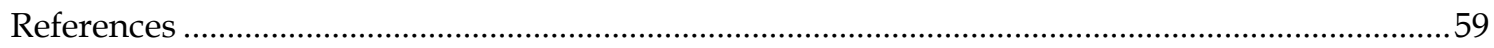

\section{List of Tables}

Table 1-1. Soil mass, ${ }^{137} \mathrm{Cs}$ activity, and derived parameters used in this study. .............................

Table 1-2. Average plant/soil concentration ratios (dry weight) of ${ }^{137} \mathrm{Cs}$ in cultures......................9

Table 1-3. Comparison of radiocesium/stable cesium ratios $\frac{{ }^{137} \mathrm{Cs}^{133} \mathrm{~Bq} \mathrm{~g} \mathrm{~g} \mathrm{~g}^{-1}}{{ }^{-1}}$, in soil and plants..........14

Table 2-1. Properties of soils sampled at various times after beginning of study............................16

Table 2-2. Crops II to V. Effect of potassium rate on two successive collections of

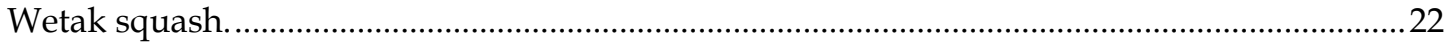

Table 3-1. Cropping sequence, rainfall, and $\mathrm{K}$ addition to all plots.................................................2

Table 3-2. Significance of treatment differences by Scheffe's test, Crops I-V ................................29

Table 4-1. Treatments, growth features, and dry matter content of tops at harvest for five

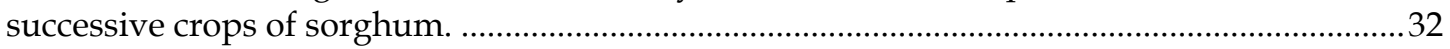

Table 4-2. ANOVA: Effect of potassium application on least squares ${ }^{137} \mathrm{Cs}$ mean

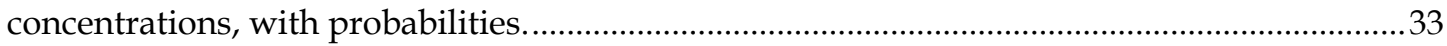

Table 5-1. Potassium treatment, growth conditions, and dry matter content of tops at

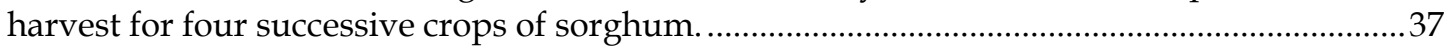

Table 6-1. Potassium added per treated row to Crops I and II, and assumed distribution............42

Table 6-2. Details of four successive cropping periods of same row-plots described in

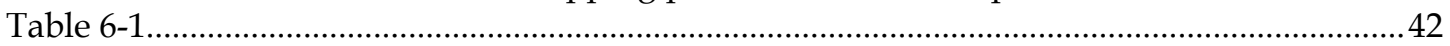

Table 6-3. Green weight yields of three successive crops..................................................................43

Table 6-4. Removal of ${ }^{137} \mathrm{Cs}$ from soil in three harvested crops from the same plots. ....................44

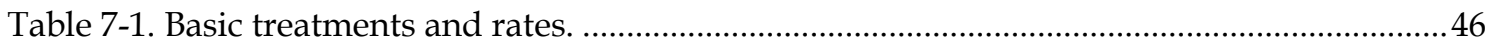

Table 7-2. Organic matter and extractable elements in soil.............................................................46

Table 7-3. Sequence of crops, fertilizer addition, and growth conditions for all plots...................48

Table 7-4. ANOVA means of green weight, ${ }^{137} \mathrm{Cs}$ concentration of whole plant or index component, and total ${ }^{137} \mathrm{Cs}$ in harvested crop, together with significance of differences from control by Fisher's PLSD test.

Table 7-5. Total potassium in Crop III, IV, V, and VI harvests as compared with added K, and with $\mathrm{K}$ contained in clinoptilolite before cropping.................................................................

Table 8-1. Effect of methyl bromide fumigation on harvested mass of young sweet corn............54

Table 8-2. Effect of methyl bromide fumigation on ${ }^{137} \mathrm{Cs}$ concentration in sweet corn..................54

\section{List of Figures}

Figure 0-1. Schematic location of the seven field experiments described in this

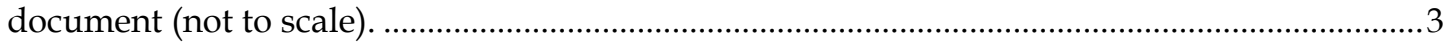

Figure 0-2. The annual rainfall at Bikini Island............................................................................

Figure $0-3$. The mean monthly rainfall ( \pm 1 standard deviation) at Bikini Island............................ 4

Figure 1-1A. The effect of added $\mathrm{K}$ on plant mass of pearl millet....................................................

Figure 1-1B. The effect of added $\mathrm{K}$ on $\mathrm{K}$ concentration in pearl millet............................................. 8 
Figure 1-2A. The effect of added $\mathrm{K}$ on plant mass of tomato.

Figure 1-2B. The effect of added $\mathrm{K}$ on $\mathrm{K}$ concentration in tomato. .................................................

Figures 1-3A \& 3B. The ${ }^{137} \mathrm{Cs}$ concentration as a function of $\mathrm{K}$ concentration in pearl millet (A) with no stable Cs added, and (B) with $10 \mathrm{n} \mathrm{mg}{ }^{133} \mathrm{Cs}$ per pot.

Figures 1-4A \& 4B. The correlation between ${ }^{137} \mathrm{Cs}$ concentration and $\mathrm{K}$ concentration

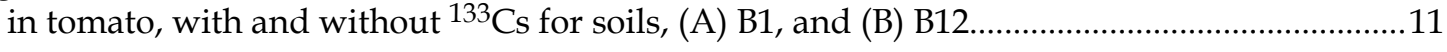

Figures 1-5A \& 5B. The correlation between ${ }^{137} \mathrm{Cs}$ and ${ }^{133} \mathrm{Cs}$ concentrations in

(A) pearl millet, and (B) tomato. ..................................................................................................13

Figure 1-6A. Potassium in plants (tops only) versus added K per pot with no added ${ }^{133}$ Cs........14

Figure $1-6 \mathrm{~B} .{ }^{137} \mathrm{Cs}$ in plants (tops only) versus added $\mathrm{K}$ per pot with no added ${ }^{133} \mathrm{Cs}$..................14

Figure $1-6 \mathrm{C} .{ }^{133} \mathrm{Cs}$ in plants (tops only) versus added $\mathrm{K}$ per pot when $10 \mathrm{mg}$ of ${ }^{133} \mathrm{Cs}$ was added to each pot.

Figure 1-6D. ${ }^{137} \mathrm{Cs}$ in plants (tops only) versus added $\mathrm{K}$ per pot when $10 \mathrm{mg}$ of ${ }^{133} \mathrm{Cs}$

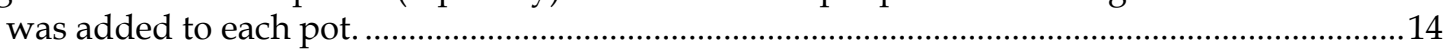

Figure $2-1 .{ }^{137} \mathrm{Cs}$ concentration in corn versus the amount of added $\mathrm{K}$ for Crop I..........................18

Figure 2-2. Green weight and ${ }^{137} \mathrm{Cs}$ concentration in corn versus the amount of added $\mathrm{K}$ for Crop II.

Figure 2-3. Potassium and ${ }^{137} \mathrm{Cs}$ concentrations in corn versus the amount of added $\mathrm{K}$ for Crop III.

Figure 2-4. ${ }^{137} \mathrm{Cs}$ concentration in corn versus the amount of added $\mathrm{K}$ for Crop V

Figure 2-5. Potassium and ${ }^{137} \mathrm{Cs}$ concentrations in corn versus the amount of added $\mathrm{K}$ for Crop IV.

Figure 2-6. Correlation between the ${ }^{137} \mathrm{Cs}$ and $\mathrm{K}$ concentrations in corn for Crops III, IV, and V.

Figure 2-7. Green weight and ${ }^{137} \mathrm{Cs}$ concentration in sweet potato versus added K. ....................22

Figure 2-8A. Green weight of Crops XII, XIII, and XIV versus added K. ......................................2

Figure 2-8B. ${ }^{137} \mathrm{Cs}$ concentration in Crops XII, XIII, and XIV versus added K...............................23

Figure 2-9A. Total green weight of corn and sorghum, Crops XV and XVI, versus previously added K.

Figure 2-9B. ${ }^{137} \mathrm{Cs}$ concentration in sorghum, Crops XV and XVI, versus previously added $\mathrm{K}$

Figure 3-1. Concentration of ${ }^{137} \mathrm{Cs}$ vs lon-on-ignition $\left(430^{\circ} \mathrm{C}\right)$ in soil from sample plots.............28

Figure 3-2. Total Kjeldahl nitrogen vs loss-on-ignition $\left(430^{\circ} \mathrm{C}\right)$ in soil from sample plots...........28

Figure 3-3. Cumulative rainfall and green weight ${ }^{137} \mathrm{Cs}$ concentrations for nine consecutive crops grown with or without large pre-sowing application of $\mathrm{K}$ or $\mathrm{Na}$.................29

Figure 4-1. Green mass of sorghum for five successive crops with and without added K............32

Figure 4-2. Association between ${ }^{137} \mathrm{Cs}$ and $\mathrm{K}$ concentrations in sorghum, Crops I and II............34

Figure 4-3. Correlation between ${ }^{137} \mathrm{Cs}$ and $\mathrm{K}$ concentrations in sorghum, Crops III and IV. ........34

Figure 4-4. Correlation between ${ }^{137} \mathrm{Cs}$ and $\mathrm{K}$ concentrations in sorghum, Crop V........................35

Figure 5-1. Correlation between ${ }^{137} \mathrm{Cs}$ in plants and $\mathrm{K}$ added to soil, Crops I and II......................37

Figure 5-2. Correlation between ${ }^{137} \mathrm{Cs}$ in plants and K added to soil, Crops III and IV................38

Figure 5-3. Correlation between ${ }^{137} \mathrm{Cs}$ and $\mathrm{K}$ concentrations in sorghum, Crops I and III. ...........38

Figure 5-4. Correlation between ${ }^{137} \mathrm{Cs}$ and $\mathrm{K}$ concentrations in sorghum, Crops III and IV. ........39

Figure 6-1. Diagrammatic sketch of treatments, arranged in numerical order.

Figure 6-2. ${ }^{137} \mathrm{Cs}$ concentration in Crops I, II, III, and IV versus the amount of K added to various ways to the rows of sorghum. 
Figure 6-3. Correlation between the ${ }^{137} \mathrm{Cs}$ and $\mathrm{K}$ concentrations in sorghum, Crop III. ................44

Figure 7-1. Relationship of ${ }^{137} \mathrm{Cs}$ to organic matter in $28 \mathrm{~cm}$ depth of well-mixed soil................47

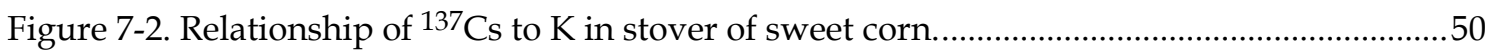

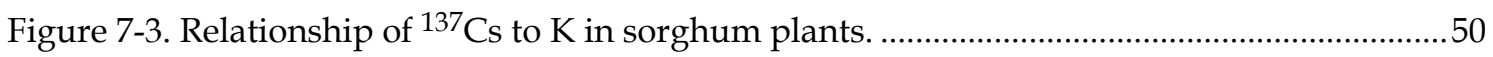

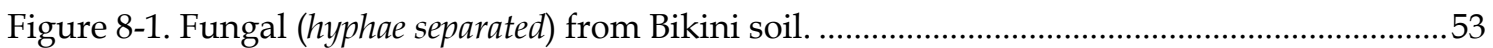

Figure 8-2. ${ }^{137} \mathrm{Cs}$ concentrations in sweet corn kernels and cobs versus those in 62

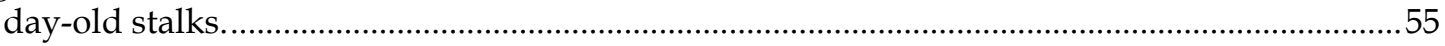




\section{INTRODUCTION}

In 1954 a radioactive plume from the thermonuclear device codenamed BRAVO contaminated the principal residential islands, Eneu and Bikini, of Bikini Atoll $\left(11^{\circ} 36^{\prime} \mathrm{N}\right.$; $165^{\circ}$ $22^{\prime}$ E), now part of the Republic of the Marshall Islands. The resulting soil radioactivity diminished greatly over the three decades before the studies discussed below began. By that time the shorter-lived isotopes had all but disappeared, but strontium-90 $\left({ }^{90} \mathrm{Sr}\right)$, and cesium-137, $\left({ }^{137} \mathrm{Cs}\right)$ were reduced by only one half-life. Minute amounts of the long-lived isotopes, plutonium $-239+240\left({ }^{239+240} \mathrm{Pu}\right)$ and americium-241 $\left({ }^{241} \mathrm{Am}\right)$, were present in soil, but were found to be inconsequential in the food chain of humans and land animals. Rather, extensive studies demonstrated that the major concern for human health was ${ }^{137} \mathrm{Cs}$ in the terrestrial food chain (Robison et al., 1983; Robison et al., 1997). The following papers document results from several studies between 1986 and 1997 aimed at minimizing the ${ }^{137}$ Cs content of annual food crops.

The existing literature on radiocesium in soils and plant uptake is largely a consequence of two events: the worldwide fallout of 1952-58, and the fallout from Chernobyl. The resulting studies have, for the most part, dealt either with soils containing some amount of silicate clays and often with appreciable $\mathrm{K}$, or with the shortterm development of plants in nutrient cultures.

\section{Soil}

The atoll soil system differs from almost all others involved in radiological studies, because of its carbonate chemistry and the absence of silicate clays that absorb cesium, its distribution through the soil, the long period of "aging," or equilibrium of ${ }^{137} \mathrm{Cs}$ with soil organic matter and organisms since deposition, and the repeated cycling of at least some fraction of the total cesium through vegetation. The only other relevant accounts known to us are those from the University of Washington (Walker et al., 1961; Gessel and Walker, 1992; Walker et al., 1997).

The soils of deep-water atolls consist almost entirely of calcium (Ca) carbonate and some magnesium $(\mathrm{Mg})$ carbonate, with some additions of organic carbon $(\mathrm{C})$, nitrogen $(\mathrm{N})$ and phosphorus $(\mathrm{P})$ incorporated into the surface, or one-time surfaces now buried by later deposition. Organic matter in the upper 10 to $20 \mathrm{~cm}$ depth ranges from negligible in new deposits to 50 to $150 \mathrm{~g} \mathrm{~kg}^{-1}$ in the old black surface soils of wide island interiors. The latter soils have narrow $\mathrm{C} / \mathrm{N}$ ratios, often 12 or 13:1. Total $\mathrm{P}$ contents in these black soils are sometimes extraordinarily high, 5 to $15 \mathrm{~g} \mathrm{~kg}^{-1}$, a legacy from guano deposits by nesting seabirds. Total potassium (K) is universally low, mostly 0.2 to $0.4 \mathrm{~g} \mathrm{~kg}^{-1}$ (Fosberg and Carroll, 1965). Presumably the major continuing source of $\mathrm{K}$ is oceanic salt spray (Etherington, 1967; Shinn et al., 1997). The contents of exchangeable potassium in the soils of a particular area are often well correlated with organic matter. Much of the K determined as "exchangeable" is in fact water-soluble $\left(\mathrm{r}^{2}=0.72\right.$ to 0.98 in various soils), with the water-soluble averaging 60 to $75 \%$ of the exchangeable. Thus, exchangeable $\mathrm{K}$ near zones of rapid flow in the soil profile may be easily lost during prolonged rains.

These black-surfaced soils are now classed as Typic Rendolls, developed primarily in water-deposited limesands. Such soils were once classed as Arno sandy loam (Stone, 1951;

Fosberg and Carroll, 1965) although they lack silt and clay-size minerals other than carbonate.

Most of the experiments reported here were conducted in the interior of Bikini Island, where residual ${ }^{137} \mathrm{Cs}$ is higher than elsewhere on the atoll. An aerial radiological survey in 1975 (Tipton and Meibaum, 1981) indicated that the average surface gamma radiation ranged from 20 to $60 \mu \mathrm{R} \mathrm{hr}-1$ on the island interior. These values extrapolate to a range of 1.3 to $3.7 \mathrm{~Bq} \mathrm{~g}^{-1}$ in the upper $10 \mathrm{~cm}$ layer of soil.

A survey of Bikini Island was also conducted in 1978 using hand-held gamma survey meters on a $30 \mathrm{~m}$ grid across Bikini Island (Gudiksen et al., 1976). The results of the ground survey and the aerial survey gave essentially the same results for ${ }^{137} \mathrm{Cs}$ in both magnitude and distribution. 


\section{Field Methods}

Before these experiments began, the island interior was a 14 to 15 year old coconut grove. Maintenance had ended eight years previously, resulting in a ground cover and understory of grasses, vines, seedling palms and shrubs. Although this understory was cleared from areas to allow experiments with bearing palms, only a few areas were also cleared of the palm overstory so small plants could be grown.

Excepting Experiment 1, the following studies were conducted on small plots (Figure 0-1) with hand preparation and tending. Experiments were established during periodic visits of LLNL and supporting personnel to the atoll. Subsequent maintenance, including prescribed application of pre-packaged fertilizers and watering during dry periods, usually were carried out by Marshallese workers, and a U.S. camp manager temporarily resident on the atoll. Often they also harvested and weighed crops that matured between LLNL missions, or that had to be cut for other reasons. This arrangement was often highly satisfactory, but did not allow response to unanticipated problems or events.

We commonly used sweet corn and sorghum as test crops. Their importance in atoll diets is slight, but they are hardy crops adapted to atoll conditions and, with respect to ${ }^{137} \mathrm{Cs}$, they are effective surrogates for other crops. We also grew pumpkin, sweet potato, Chinese cabbage, beans, etc., in other studies, but these are more difficult to manage without continuous attention to moisture and fertility.

Our earlier studies with bearing coconut palms (Robison and Stone, 1992; Robison and Stone, unpublished data) demonstrated that relatively large applications of K, i.e., 50 to $100 \mathrm{~g}$ $\mathrm{m}^{-2}$, were required for large reductions in ${ }^{137} \mathrm{Cs}$. At that time, the mechanism for such reduction commonly was assumed to be competition between the two ions in soil. Thus, we did not anticipate the suppressive effects of small amounts of $\mathrm{K}$, i.e., $1-5 \mathrm{~g} \mathrm{~m}^{-2}$, added as a "starter" or "maintenance" to avoid deficiency symptoms in annual crops. Subsequently, we reduced or eliminated such applications when results from early trials became available.

Potassium was applied as KCl. Phosphorus usually was supplied as treble superphosphate, designated simply as superphosphate. Nitrogen was variously supplied as $\left(\mathrm{NH}_{4}\right)_{2} \mathrm{SO}_{4}$, $\mathrm{NH}_{4} \mathrm{NO}_{3}$, urea, or occasionally as ammoniacal phosphate in a mixed fertilizer such as 16-16-16. Surface application of any of these led to rapid volatilization of $\mathrm{NH}_{3}$. Thus, these carriers ordinarily were placed beneath the soil surface or "watered in." In some instances, the latter probably did not prevent nitrogen losses.

Almost all crop species were susceptible to acute iron deficiency on these calcareous soils. Hence, all experiments were routinely treated with an iron chelate, Sequestrene ${ }^{137} \mathrm{Fe}$ (CIBAGEIGY Corp $\left.{ }^{\circledR}\right)^{\dagger}$, or a trace-mineral mixture containing this plus $\mathrm{ZnSO}_{4}$ and $\mathrm{MnSO}_{4} \bullet \mathrm{H}_{2} \mathrm{O}$. Such material was applied at sowing and at intervals as needed. In some studies $\mathrm{ZnSO}_{4}$ was added to later $\mathrm{N}$ applications. Such micronutrient applications were made uniformly to all treatments of a study, and are not further discussed in the descriptions.

With few exceptions, $\mathrm{P}$ was applied at the beginning of a study or re-sowing. The total application of $\mathrm{N}$ or $\mathrm{K}$ to any one crop usually was divided into several small additions. The purpose was to avoid excessive salt concentrations during periods of low rainfall, or to replace soil solution concentrations of $\mathrm{N}$ or $\mathrm{K}$ when rainfall was high.

In general, the timing of post-sowing applications was prescribed at the beginning of a crop, and the requisite amounts prepackaged; with few exceptions, both $\mathrm{N}$ and $\mathrm{K}$ were applied in solution to increase uniformity of distribution.

Rainfall was measured at two gauging stations, both within 50 to 100 meters of the field studies reported here. One was a conventional U.S. Weather Bureau large-diameter rain gauge that was read daily and recorded. The other was a tipping bucket gauge coupled to a satellite transmission system that delivered results to LLNL. Daily rainfall with a 20-minute resolution has been collected for a $20 \mathrm{y}$ period at Bikini Island. Annual rainfall has varied from 80 to $250 \mathrm{~cm}$, as shown in Figure 0-2. The monthly averages are shown in Figure 0-3.

Individual treatments were replicated only two or three times in most of these experiments. Sources of variation among small plots proved

† sodium ferricethylenediamine di-(ohydroxyphenylacetate) 


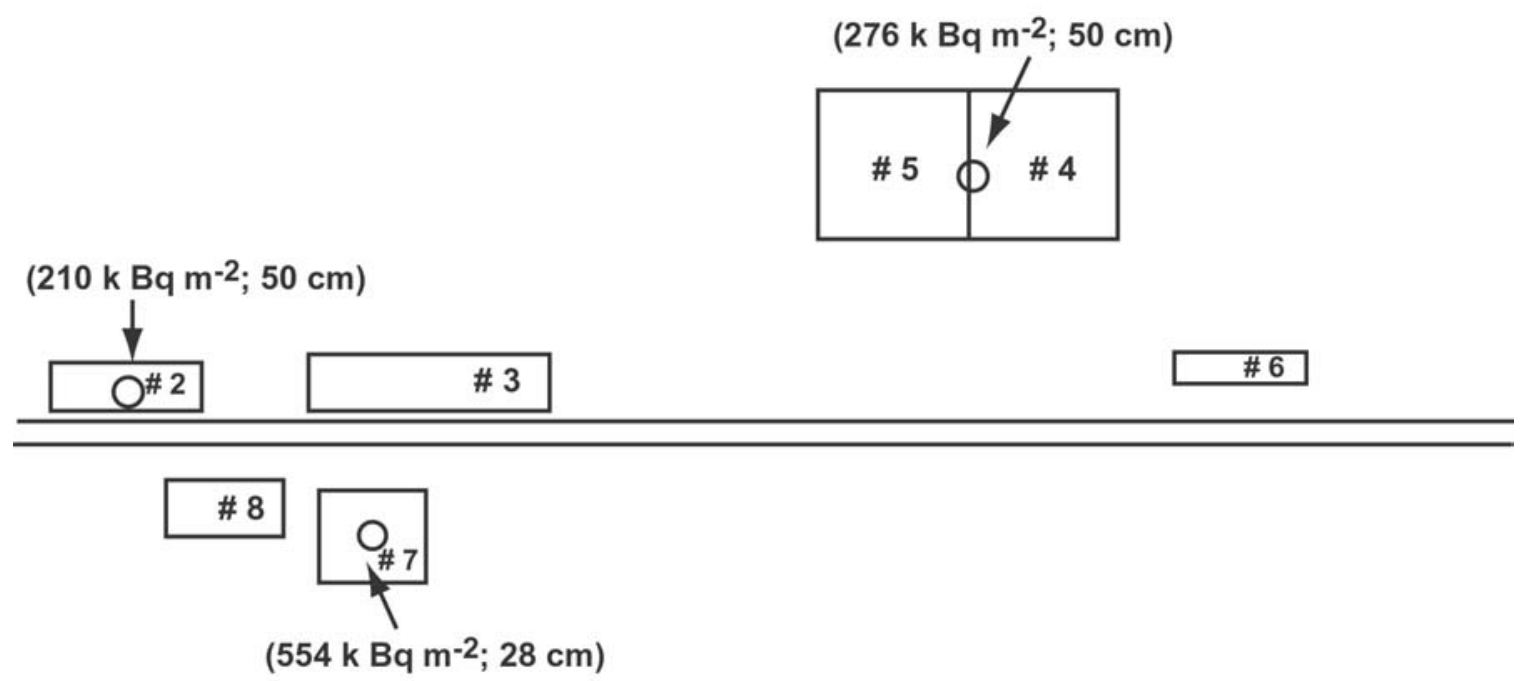

$\mathrm{O} \longleftarrow\left(462 \mathrm{k} \mathrm{Bq} \mathrm{m}{ }^{2} ; 20 \mathrm{~cm}\right)$

Figure 0-1. Schematic location of the seven field experiments described in this document (not to scale). Estimated mean contents of ${ }^{137} \mathrm{Cs}$ in upper soil shown in parentheses.

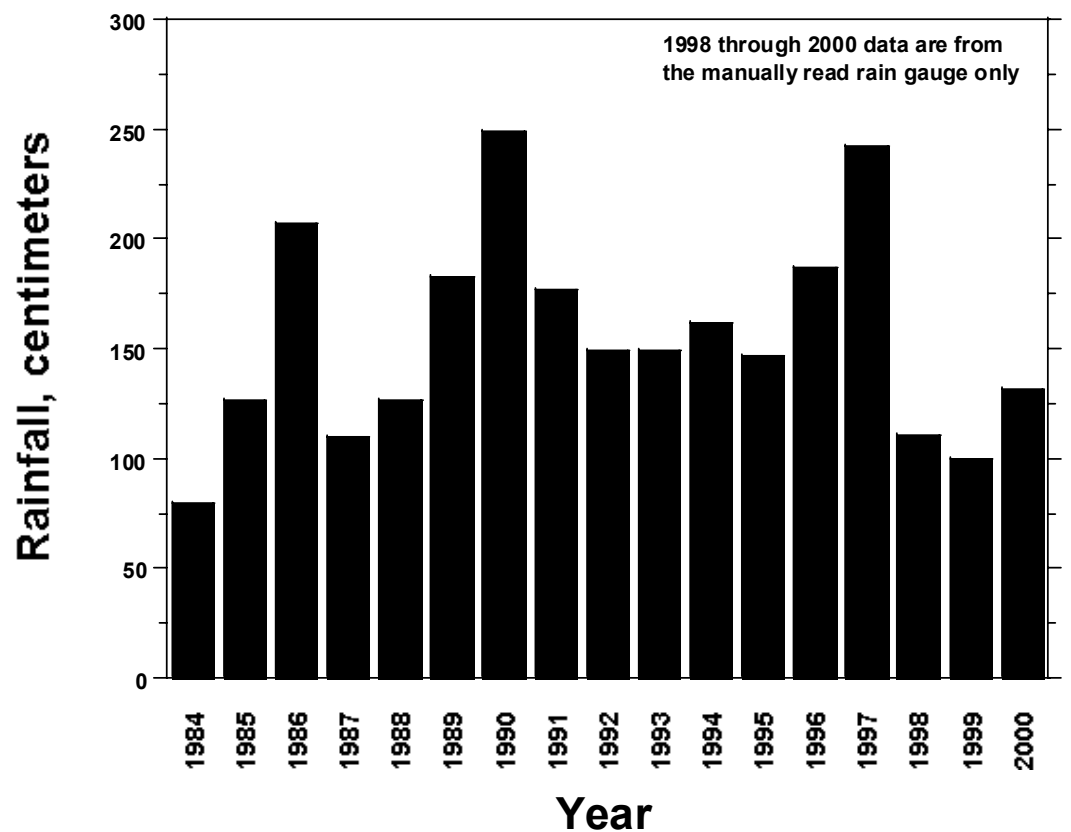

Figure 0-2. The annual rainfall at Bikini Island. 


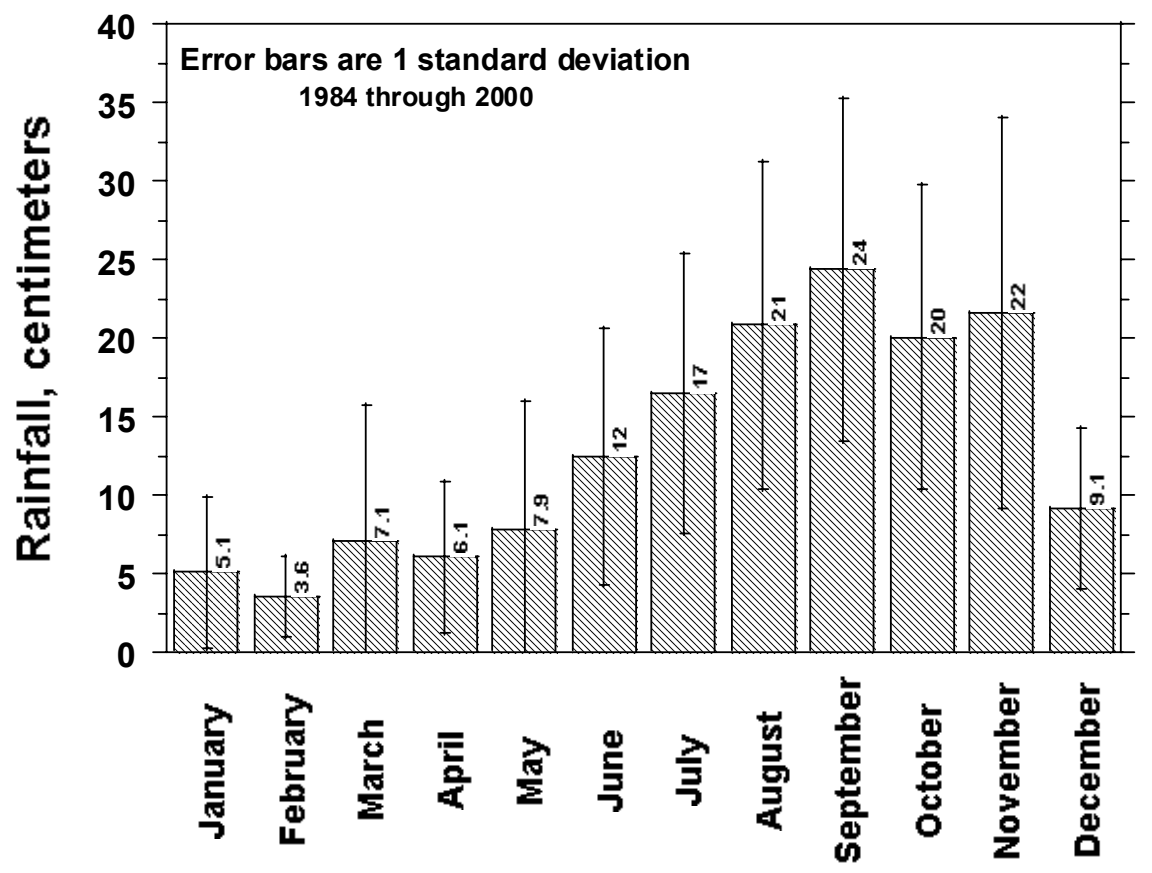

Figure $0-3$. The mean monthly rainfall ( \pm 1 standard deviation) at Bikini Island.

numerous and experiment coefficients were often high. Both yields and ${ }^{137} \mathrm{Cs}$ concentrations varied even among successive crops on the same plots according to seasonal differences in soil moisture, crop care and maturity at harvest. Thus, in a certain sense, the results reported are realistic, in having been obtained in experimental and cultural circumstances less than ideal.

At harvest, all crops or fruits were frozen and shipped to LLNL in that condition. Soil samples collected from some study sites likewise were shipped frozen.

\section{Analytical Methods}

Plant samples arriving at LLNL were freezedried and ground for analyses. Sweet corn ears, if sufficiently developed, were separated into kernels, cobs and husks before grinding. The remainder of the plant, referred to as stalks or stover, includes the leaves and any very immature ears. The skins were separated from both squash and sweet potato tubers. In any case, analysis for ${ }^{137} \mathrm{Cs}$ showed little evidence of soil contamination.

Frozen soil samples were dried at $100^{\circ} \mathrm{C}$ if only radionuclide analyses were to be done. If exchangeable $\mathrm{K}$ was to be determined, the soils were dried at $60^{\circ} \mathrm{C}$. Ordinarily, they were then sieved through disposable $1.4 \mathrm{~mm}$ screening; some, however, were sieved through a conventional $2 \mathrm{~mm}$ screen.

Cesium-137 in both soil and plant material was determined at LLNL as described elsewhere (Brunk 1995a; Brunk, 1995b; Kehl, 1995; Stuart, 1995; Wong et al., 1994).

Dietary intake for humans is generally expressed in terms of "fresh" or "green" weight. Hence, ${ }^{137} \mathrm{Cs}$ is expressed as $\mathrm{Bq} \mathrm{g}^{-1}$, green weight, in much of the following. A further argument for such use is Smolders and Shaw's (1995) observation that tissue water represents the "physiological pool" for ${ }^{137} \mathrm{Cs}$, with almost all of the nuclide being water soluble, at least in some plants (Cheshire and Shand, 1995). In studies of plant and soil nutrition, however, element composition is commonly stated in 
terms of dry material, and this convention also has been used where appropriate.

Potassium and, occasionally, other cations in plants were determined either by flame photometry or IPS at the University of Florida. Later, plant potassium was determined at LLNL, using an X-ray fluorescence (XRF) analyzer from ASOMA Instruments (Model 200T). The instrument was calibrated separately for analysis of coconut meat and coarse vegetation using a series of associated internal matrix standards. The standards were prepared from samples of the same matrix type previously analyzed by atomic absorption spectrometry. Quality assurance checks were performed on a regular basis. Data were accepted where replicate analyses were within $\pm 10 \%$ (or within 3 standard deviations of the measurement error) over the full analytical range. Nitrogen in some soil and plant materials was assessed by a micro-Kjeldahl procedure. Soil organic matter was initially estimated by a Walkly-Black Procedure, and later by loss on ignition at $430^{\circ} \mathrm{C}$ (Ball, 1964; Davies, 1974). Other analytical procedures are mentioned under individual experiments.

\section{Acknowledgements}

We are indebted to many people who, in one way or another, contributed to the conduct of these studies and analyses of plants and soils. Some studies begun prior to 1988 were supported through joint sponsorship with the congressionally funded Bikini Atoll Rehabilitation Committee (BARC), and benefited from discussions within the Committee.
Members of the changing Bikini field station staff were too numerous for mention here, but we are grateful to them for much of the site preparation, crop maintenance, and often harvest of experimental plots. Leo Migvar, onetime agriculturist with the U.S. Trust Territories Government, was from the beginning an invaluable colleague, agronomic guide, and field supervisor who also made several visits between LLNL missions in order to carry out particular treatments and harvests.

LLNL personnel visiting Bikini, notably Marshall Stuart, but at various times including Cynthia Conrado, Henry Jones, Steve Kehl, Bill Phillips, John Rehder, and Carol Stoker, were responsible for much of the harvesting, soil sampling, recording and preparation for shipment to LLNL. Subsequently, at LLNL they oversaw the many tasks of sample preparation and analysis for ${ }^{137} \mathrm{Cs}$ and sometimes other radionuclides.

At the University of Florida, Mary McLeod carried out numerous soil and plant analyses, especially for the earlier experiments. Dr. Terry Hamilton and Henry Jones of LLNL analyzed many hundreds of samples for K using XRF. They all did an outstanding job and we are grateful.

Finally, we also thank Drs. Lloyd Fox, Kent Gustafson, and Nathan Stone for some of the statistical analyses, and Dr. Henry Aldrich for the SEM photo, Figure 8-1.

This work was performed under the auspices of the U.S. Department of Energy by the University of California, Lawrence Livermore National Laboratory under contract No. W-7405-Eng-48.

\section{Experiment 1: Potassium and Stable Cesium Reduce Uptake of Radiocesium by Pearl Millet and Tomato in Pot Cultures}

Cesium-137, with a half-life of 30 years, is readily transmitted through the terrestrial food chain on atolls and remains a radiological dose problem when growing food crops on Bikini. As a basis for subsequent field experiments, we conducted a greenhouse study using pot cultures of three Bikini soils. At that time, very little was known about the chemistry and plant uptake of ${ }^{137} \mathrm{Cs}$ in atoll soils where the present mass concentrations are very low (often $10^{-12} \mathrm{~g} \mathrm{~g}^{-1}$ soil), and the sole source of cation exchange capacity is organic matter. Walker et al. (1961), however, had demonstrated that K applied to a comparable soil from Rongelap Atoll reduced uptake of ${ }^{137} \mathrm{Cs}$ by tomato and squash in pot cultures, as well as by a native grass, Lepturus repens, (Forst) R. Br. in the field. 
Hence, the objectives of the present study were (1) to determine the effects of potassium applied at increasing rates, and (2) explore the effects of stable cesium, ${ }^{133} \mathrm{Cs}$, applied alone and in combination with added $\mathrm{K}$.

\section{Materials and Methods}

Bulk samples of surface soils were collected from three Typic Rendoll profiles on Bikini Island. They were frozen, then air-dried and sieved. The weight of soil per greenhouse pot varied somewhat according to the quantities then available, as shown in Table 1-1. The initial ${ }^{137} \mathrm{Cs}$ concentrations, the experimental addition of ${ }^{133} \mathrm{Cs}$, and derived values used in this paper are also included in Table $1-1$. Native ${ }^{133} \mathrm{Cs}$ was not determined in un-amended soils. Plants grown on such soils, however, contained from 1.5 to $5.0 \mathrm{mg} \mathrm{kg}^{-1}$ of ${ }^{133} \mathrm{Cs}$, about $1 \%$ of the range in plants grown in soils treated with this isotope. Properties of nearby profiles are given in Table 2-1 and by Robison and Stone (1992).

The intended experimental design was an incomplete factorial: Three soils; ${ }^{133} \mathrm{Cs}$ at rates of zero and $10 \mathrm{mg} /$ pot; $\mathrm{K}$ at four rates, 0, 100, 200, and $300 \mathrm{mg} /$ pot; two species; and two replicates of each. The species were pearl millet, Pennisetum americanum (L.) K. Schum. Hybrid \#1, and tomato, Lycopersicon lycopersicum (L.) Karst, ex Farw. cv Margrove. The omitted treatment was ${ }^{133} \mathrm{Cs}, 10 \mathrm{mg} \times \mathrm{K}, 200 \mathrm{mg}$. Tomato plants on the B-7 soil, however, were destroyed before harvest. Thus, a factorial analysis was not employed.

The same absolute quantities of all elements were added to all plots regardless of the different amounts of soil. The total quantities indicated hereafter can be converted to $\mathrm{mg} \mathrm{kg}^{-1}$ soil by multiplying the amounts given for B- 1 by 0.77 ; those for B-7 by 1.00; and those for B-12 by 0.83 , respectively.

The amounts of ${ }^{133} \mathrm{Cs}$, and of $\mathrm{K}$ up to 200 $\mathrm{mg}$, both as chlorides, plus $100 \mathrm{mg} \mathrm{P}$ as superphosplate, were mixed with each pot when filling. The additional $\mathrm{K}$ required for the $300 \mathrm{mg}$ treatment was added in solution when the plants were half-grown. Nitrogen as $\mathrm{NH}_{4} \mathrm{NO}_{3}$, at the rate of $100 \mathrm{mg} \mathrm{N} /$ pot, and $\mathrm{Mg}$ as $\mathrm{MgSO}_{4}$ at a rate of 50 or $100 \mathrm{mg} \mathrm{Mg} /$ pot were added in solution in accordance with apparent plant need. Foliar sprays of Fe-Na EDTA were applied several times to overcome leaf chlorosis.
Soil moisture was maintained by watering to weight; thus no nutrients were leached from the cultures.

The plant tops were harvested at first flowering. They were dried at $70^{\circ} \mathrm{C}$, ground, and analyzed as described below.

\section{Results and Discussion}

Additions of $\mathrm{K}$ increased both plant mass and $K$ concentration of both species (Figures 1$1 \mathrm{~A}, 1-1 \mathrm{~B}, 1-2 \mathrm{~A}$, and 1-2B). The increased mass of tomato was only moderate and chiefly due to the first $100 \mathrm{mg}$ increment of K. Possibly an earlier and larger application of $\mathrm{N}$ would have increased the harvest mass of both species. Unpublished results indicate mean nitrogen contents of $138 \pm 8$ and $84 \pm 14 \mathrm{~g} \mathrm{~kg}^{-1}$ (dry weight; all treatments combined) for millet grown in soil B-1 and B-12, respectively.

Addition of $\mathrm{K}$ decreased concentration of ${ }^{137} \mathrm{Cs}$ in both species, but the interaction of added $\mathrm{K}$ and ${ }^{133} \mathrm{Cs}$ are better described in terms of internal concentration, as shown later.

The relative uptake of ${ }^{137} \mathrm{Cs}$ is frequently expressed as a plant/soil concentration ratio, sometimes referred to as a transfer factor. In this instance, both plant and soil are dry. The data in Table 1-2 demonstrate the large differences among soils and the reduction at the largest $\mathrm{K}$ application.

An alternative comparison is the association between the respective concentrations of $\mathrm{K}$ and ${ }^{137} \mathrm{Cs}$ in whole plant tops, with comparison of ${ }^{133} \mathrm{Cs}$ interactions also. Figures 1-3A and 1-3B demonstrate such association for pearl millet, as do Figures 1-4A and 1-4B for tomato.

In the absence of added ${ }^{133} \mathrm{Cs}$, ${ }^{137} \mathrm{Cs}$ falls abruptly as $\mathrm{K}$ increases from some minimum concentration needed for survival to 4 to $5 \mathrm{~g} \mathrm{~kg}^{-1} \mathrm{~K}$ (Figure 1-3A). Further increases in $\mathrm{K}$ produce a much more gradual decrease in ${ }^{137} \mathrm{Cs}$ concentration.

An addition of stable cesium apparently altered the uptake of ${ }^{137} \mathrm{Cs}$ with increasing K (Figure 1-3B), although the data are too variable to determine any precise relationship. Again, the initial increase in plant $\mathrm{K}$, to about $3 \mathrm{~g} \mathrm{~kg}^{-1}$, was associated with an abrupt decrease in ${ }^{137} \mathrm{Cs}$, followed by little response to greater $\mathrm{K}$ concentration even though growth continued to increase. 
Table 1-1. Soil mass, ${ }^{137} \mathrm{Cs}$ activity, and derived parameters used in this study.

\begin{tabular}{|c|c|c|c|c|c|c|c|}
\hline \multirow{3}{*}{$\begin{array}{c}\text { Soil } \\
\text { no. }\end{array}$} & \multirow{3}{*}{$\begin{array}{c}\text { Soil } \\
\text { mass } \\
\text { g pot }^{-1}\end{array}$} & \multicolumn{3}{|c|}{${ }^{137} \mathrm{Cs}$} & \multirow{3}{*}{$\begin{array}{l}{ }^{133} \mathrm{Cs} \\
\text { mass }^{\mathrm{a}} \\
\mathrm{g} \mathrm{pot}^{-1}\end{array}$} & \multicolumn{2}{|c|}{ Ratios, $\frac{{ }^{137} \mathrm{Cs}}{{ }^{133} \mathrm{Cs}}$} \\
\hline & & \multicolumn{2}{|c|}{ Activity } & \multirow{2}{*}{$\begin{array}{l}\text { Mass } \\
\mathrm{g} \mathrm{pot}^{-1}\end{array}$} & & \multirow{2}{*}{$\begin{array}{l}\text { Activity } \\
\text { Bq mg }^{-1}\end{array}$} & \multirow{2}{*}{$\begin{array}{l}\text { Mass } \\
\mathrm{g} \mathrm{g}^{-1}\end{array}$} \\
\hline & & $\overline{\mathrm{Bq} \mathrm{g}^{-1}}$ & Bq pot ${ }^{-1}$ & & & & \\
\hline B-1 & 1200 & 2.1 & 2560 & $790 \times 10^{-12}$ & $1 \times 10^{-2}$ & 260 & $7.9 \times 10^{-8}$ \\
\hline B-7 & 1000 & 2.4 & 2410 & $750 \times 10^{-12}$ & $1 \times 10^{-2}$ & 240 & $7.5 \times 10^{-8}$ \\
\hline B-12 & 1300 & 0.97 & 1260 & $390 \times 10^{-12}$ & $1 \times 10^{-2}$ & 130 & $3.9 \times 10^{-8}$ \\
\hline
\end{tabular}

a $10 \mathrm{mg} \mathrm{pot}^{-1}$ added to half of the experimental treatments.

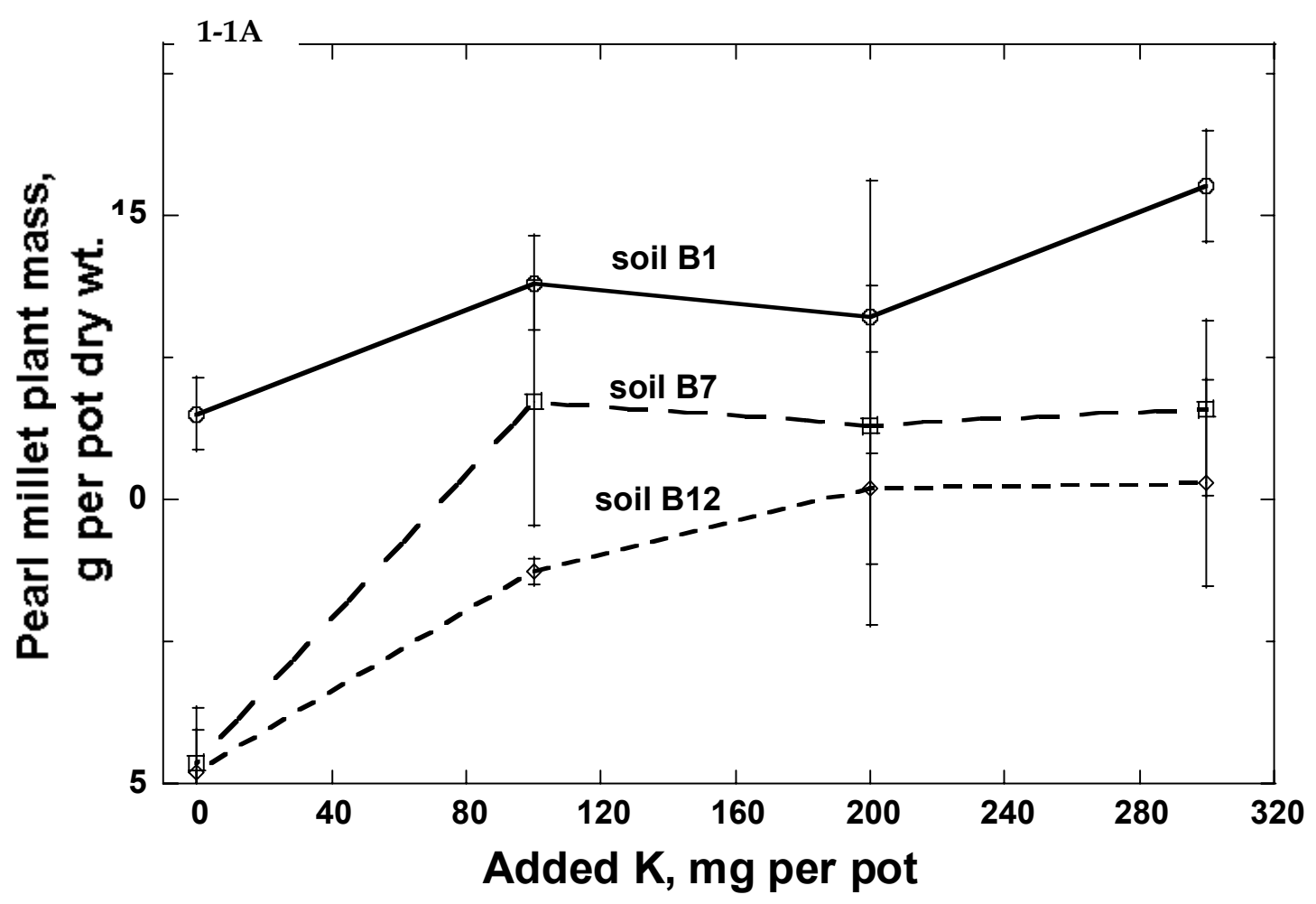

Figure 1-1A. The effect of added $\mathrm{K}$ on plant mass of pearl millet. 


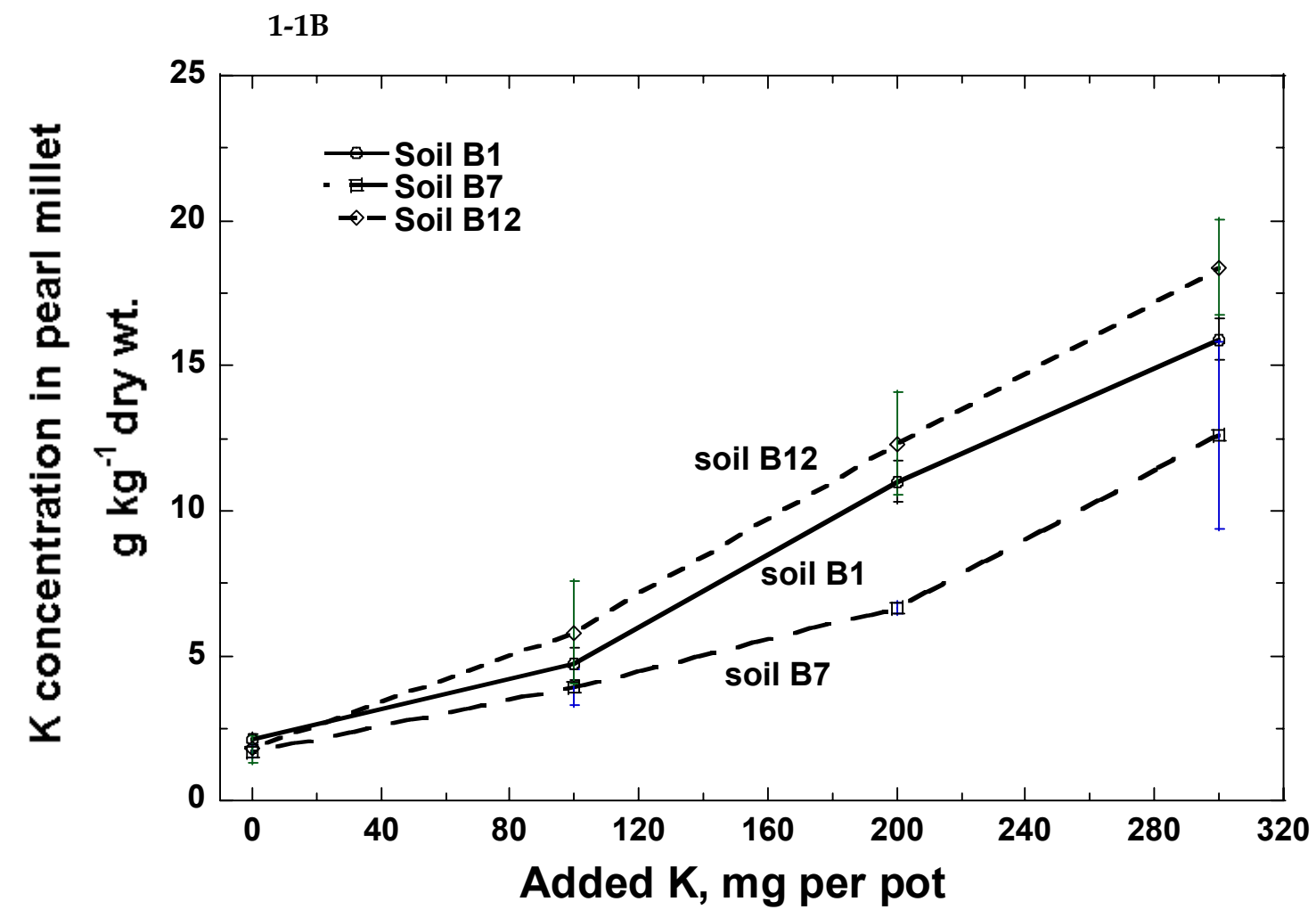

Figure 1-1B. The effect of added $\mathrm{K}$ on $\mathrm{K}$ concentration in pearl millet.

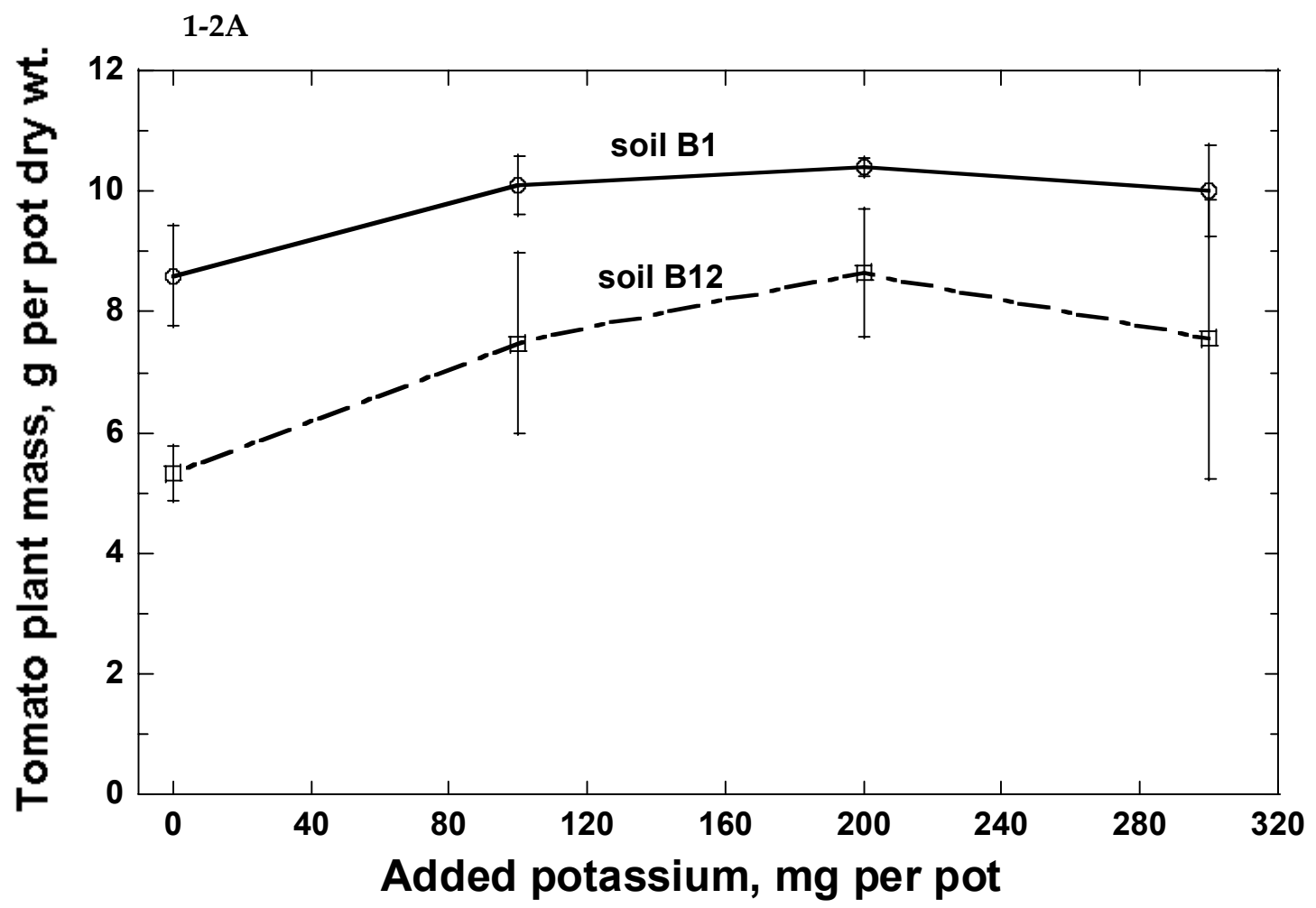

Figure 1-2A. The effect of added $\mathrm{K}$ on plant mass of tomato. 


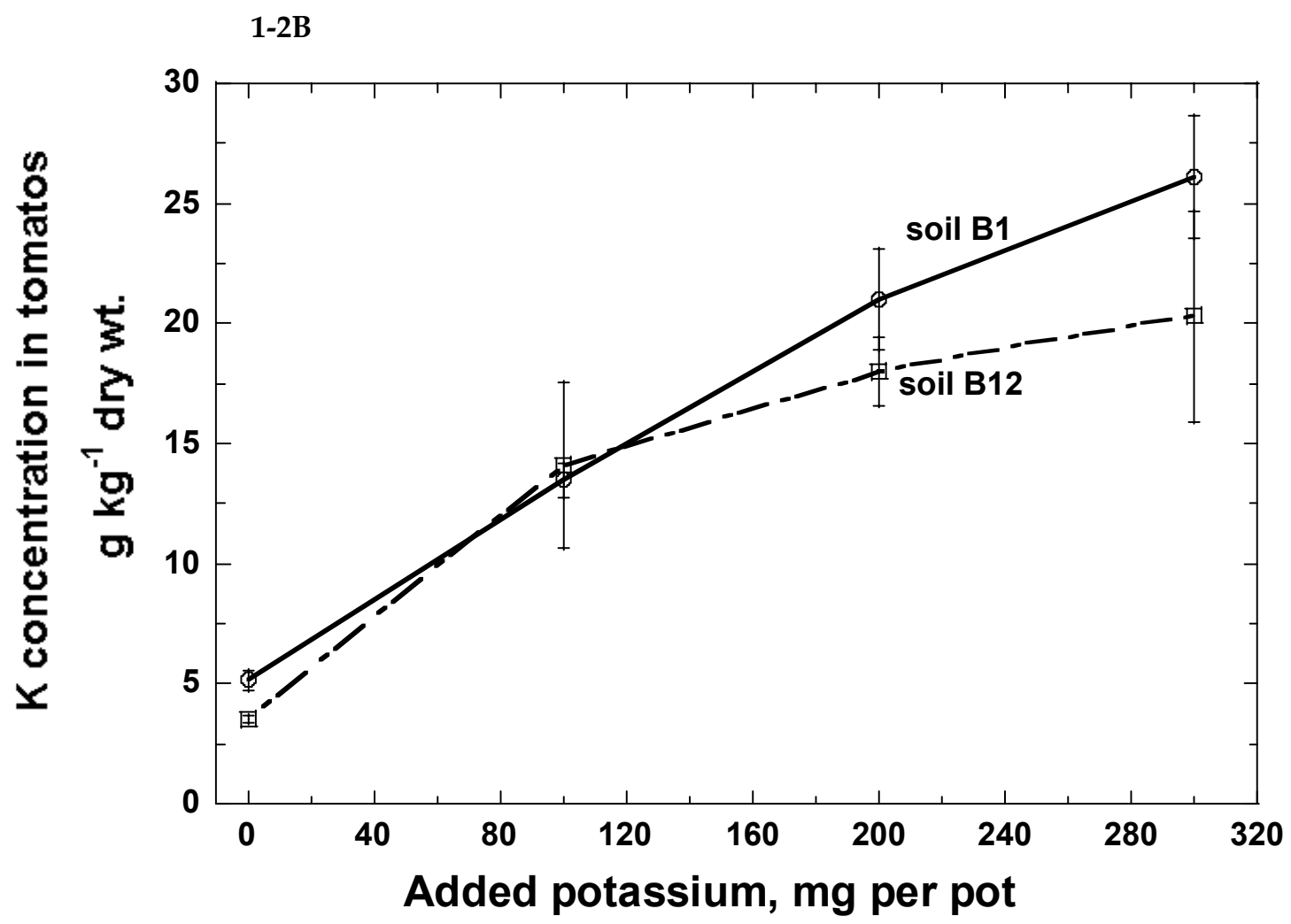

Figure 1-2B. The effect of added $\mathrm{K}$ on $\mathrm{K}$ concentration in tomato.

Table 1-2. Average plant/soil concentration ratios (dry weight) of ${ }^{137} \mathrm{Cs}$ in cultures.

\begin{tabular}{lccccc}
\hline & \multicolumn{2}{c}{ Pearl millet } & & \multicolumn{2}{c}{ Tomato } \\
\cline { 2 - 3 } \cline { 5 - 6 } Soil & K-0 & K-300 & & K-00 & K-300 \\
\hline B-1 & 5.1 & 2.3 & 8.1 & 0.6 \\
B-7 & 10 & 2.3 & & - & $-\overline{8}$ \\
B-12 & 28 & 4.9 & 24 & 3.8 \\
\hline
\end{tabular}



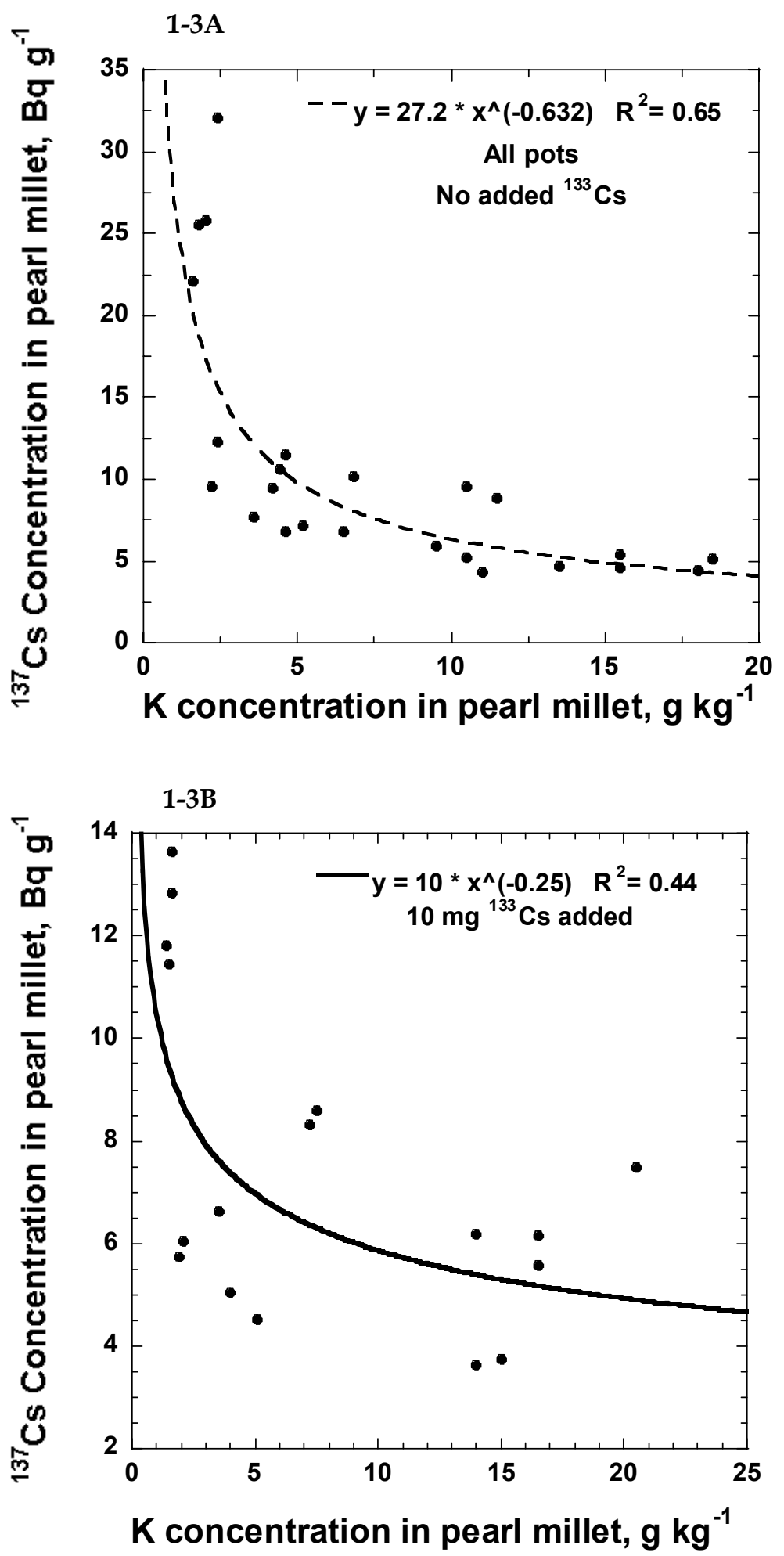

Figures 1-3A\&3B. The ${ }^{137} \mathrm{Cs}$ concentration as a function of $\mathrm{K}$ concentration in pearl millet (A) with no stable Cs added, and (B) with $10 \mathrm{mg}{ }^{133} \mathrm{Cs}$ per pot. 

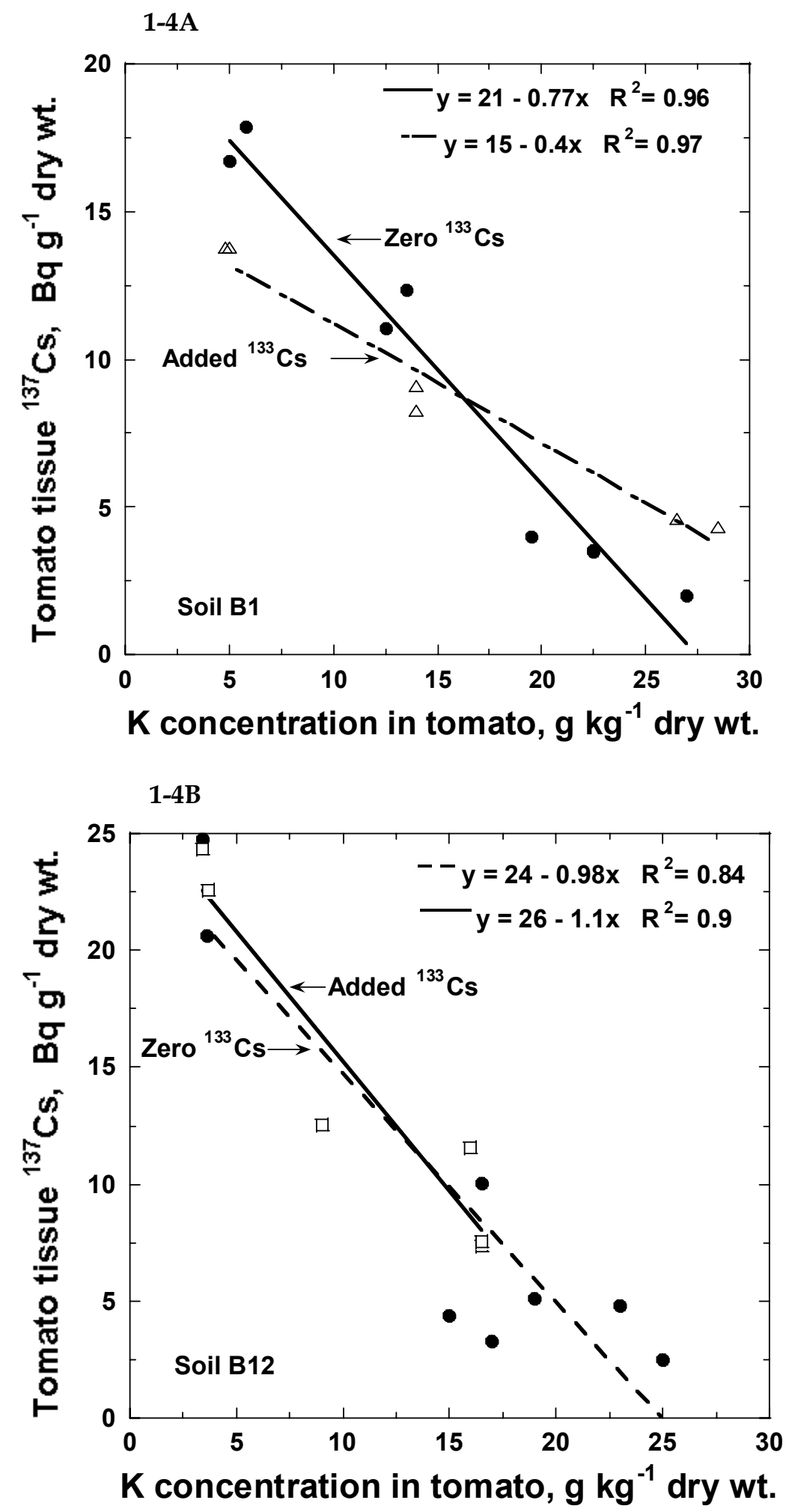

Figures 1-4A \&4B. The correlation between ${ }^{137} \mathrm{Cs}$ concentration and $\mathrm{K}$ concentration in tomato, with and without ${ }^{133}$ Cs for soils, (A) B1, and (B) B12. 
In contrast to these relationships in millet, ${ }^{137} \mathrm{Cs}$ in tomato decreased linearly as $\mathrm{K}$ increased (Figures 1-4A and 1-4B), whether or not ${ }^{133} \mathrm{Cs}$ was present. The lowest $\mathrm{K}$ concentrations in tomato, however, are greater than those in millet; still lower concentrations might change the linear relationship. The two species also differ in other respects (Figures 1-1 and 1-2), with pearl millet stems being determinate in growth rather than indeterminate as the Marglobe tomato is.

As would be expected, the plant concentrations of ${ }^{137} \mathrm{Cs}$ and ${ }^{133} \mathrm{Cs}$ are closely associated, independent of soil or $\mathrm{K}$ treatment (Figure 1-5A, 1-5B). The scatter of points along the regressions of Figures 1-5A and B presumably represents sampling and analytical errors or variation in culture, rather than variable ratios of the two isotopes.

The ratios of the two isotopes represented by the regression coefficients of Figure 1-5 can be compared with equivalent ratios in soil (Table 1-2), assuming ${ }^{133} \mathrm{Cs}$ in untreated soil to be small relative to the $10 \mathrm{mg} /$ pot addition. The large differences between the soil and plant ratios (Table 1-3) imply that about $10 \%$ of ${ }^{137} \mathrm{Cs}$ in soils B-1 and B-7, and perhaps $20 \%$ of that in B-12 became available for plant uptake in this study. The radiocesium in soil had "aged" (Wallace et al., 1982), or equilibrated with soil components for some 30 years at the beginning of this study, whereas the ${ }^{133}$ Cs was freshly added. Further, the total mass of the stable isotope exceeded that of ${ }^{137} \mathrm{Cs}$ by a factor of $10^{7}$ to $10^{8}$ (Table 1-1). Substances or organisms capable of sequestering much more than the present amount of ${ }^{137} \mathrm{Cs}$ might have had no detectable effect on uptake of a much larger amount of freshly added ${ }^{133}$ Cs.

Inasmuch as $\mathrm{K}$ applications increased both dry weight and $\mathrm{K}$ concentration in both species (Figures 1-1 and 1-2), total removal in the harvested crop rose rapidly as $\mathrm{K}$ additions were increased from 0 to $300 \mathrm{mg} /$ pot (Figure 1-6A). Contrarily, radiocesium concentrations decreased, although variable mass and concentration sometimes led to greater variability in their product, as appears in Figure 1-6B.

Although soil B-12 contained only half as much ${ }^{137}$ Cs as B-1 and B-7, all three soils allowed similar total uptake by both species in the $\mathrm{K}-0$ cultures (Figure 1-6B). Progressive additions of $K$, however, decreased total ${ }^{137} \mathrm{Cs}$ uptake from soil B-12 more rapidly than from the other soils.

Adding stable cesium to the cultures changed the ${ }^{137} \mathrm{Cs}$ uptake pattern by pearl millet. Total uptake by millet was independent of both soil and $\mathrm{K}$ treatment, and averaged $65.9 \pm 1.0 \mathrm{~Bq} /$ pot (SEM) (Figure 1-6C). This amount is about $2.6 \%$ of the total ${ }^{137} \mathrm{Cs}$ in pots of the B-1 and B-7 soils, and 5.0\% of that in B-12. In contrast, total removal by tomato decreased with added K (Figure 1-6C).

As expected in cultures to which ${ }^{133} \mathrm{Cs}$ was added, total uptake of the stable isotope paralleled that of ${ }^{137} \mathrm{Cs}$ (Figure 1-6D). The harvest removal in pearl millet averaged $2.26 \pm 0.05$ (SEM) mg ${ }^{133}$ Cs per pot, about $22.5 \%$ of the total added at the beginning of the study. In contrast, total uptake by tomato in the zero K cultures is about twice as great as pearl millet.

\section{Summary}

Results from pot culture studies such as these often differ from those of the same treatments applied in the field. Nevertheless, the present studies appear to demonstrate the following:

1. Potassium applied to previously uncultivated atoll soil increases both plant mass and its K concentration, and decreases ${ }^{137} \mathrm{Cs}$ uptake, in both pearl millet and Marglobe tomato (Figure 1-2).

2. In pearl millet, ${ }^{137} \mathrm{Cs}$ concentration decreases precipitously as $\mathrm{K}$ concentration increases from some minimum to around $4 \mathrm{~g} \mathrm{~kg}^{-1}$. Further increases in $\mathrm{K}$ continue to decrease ${ }^{137} \mathrm{Cs}$, but at a much lower rate (Figure 1-3A).

3. Comparable data for tomato include few $\mathrm{K}$ concentrations less than $4 \mathrm{mg} \mathrm{kg}^{-1}$, and the decreases in ${ }^{137} \mathrm{Cs}$ relative to increasing $\mathrm{K}$ appear linear (Figures 1-4A, 1-4B).

4. Addition of stable cesium at rates around $10 \mathrm{mg} \mathrm{kg}^{-1}$ alters the above responses to K. With pearl millet, addition of stable cesium reduces uptake of ${ }^{137} \mathrm{Cs}$ when plant 

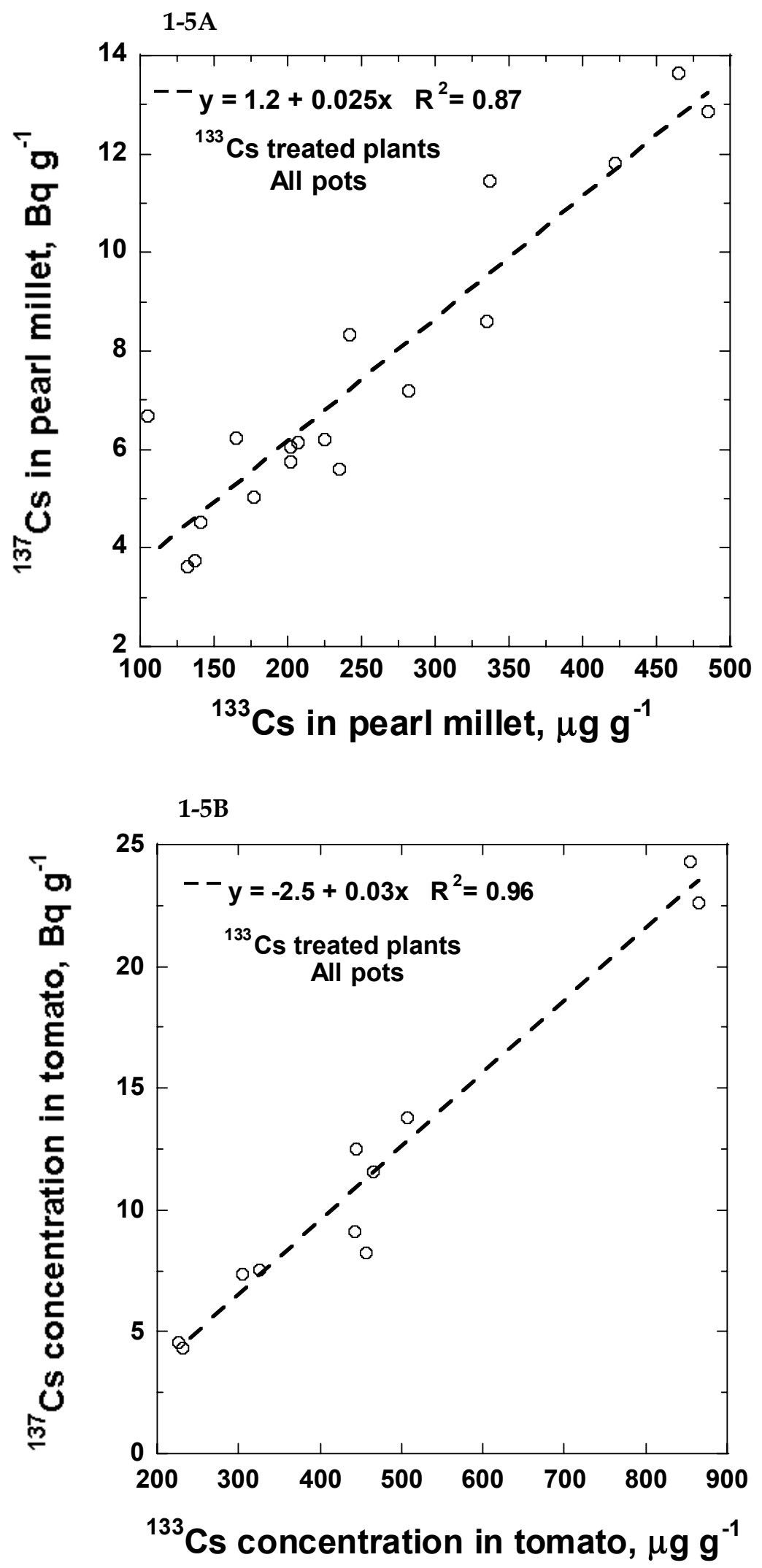

Figures 1-5A \& 5B. The correlation between ${ }^{137} \mathrm{Cs}$ and ${ }^{133} \mathrm{Cs}$ concentrations in (A) pearl millet, and (B) tomato. 
Table 1-3. Comparison of radiocesium/stable cesium ratios, $\frac{{ }^{137} \mathrm{Cs}, \mathrm{Bq} \mathrm{g}^{-1}}{{ }^{133} \mathrm{Cs} \mathrm{ug} \mathrm{g}^{-1}}$, in soil and plants. ${ }^{137} \mathrm{Cs}$ is expressed as $\mathrm{Bq} \mathrm{g}^{-1}$ and ${ }^{133} \mathrm{Cs}$ as, $\mu \mathrm{g} \mathrm{g}^{-1}$.

\begin{tabular}{lccc} 
& & \multicolumn{2}{c}{ Ratio, plant } \\
\cline { 3 - 4 } Soil & Ratio soil & Pearl millet & Tomato \\
\hline B-1 & 260 & 27 & 25 \\
B-7 & 240 & 27 & - \\
B-12 & 130 & 27 & 25 \\
\hline
\end{tabular}

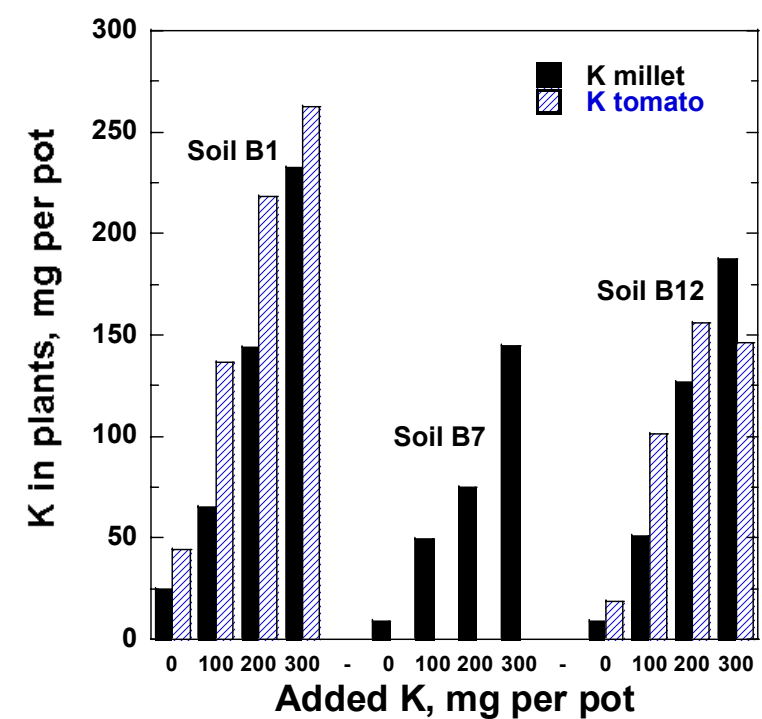

Figure 1-6A. Potassium in plants (tops only) versus added $\mathrm{K}$ per pot with no added ${ }^{133} \mathrm{Cs}$.

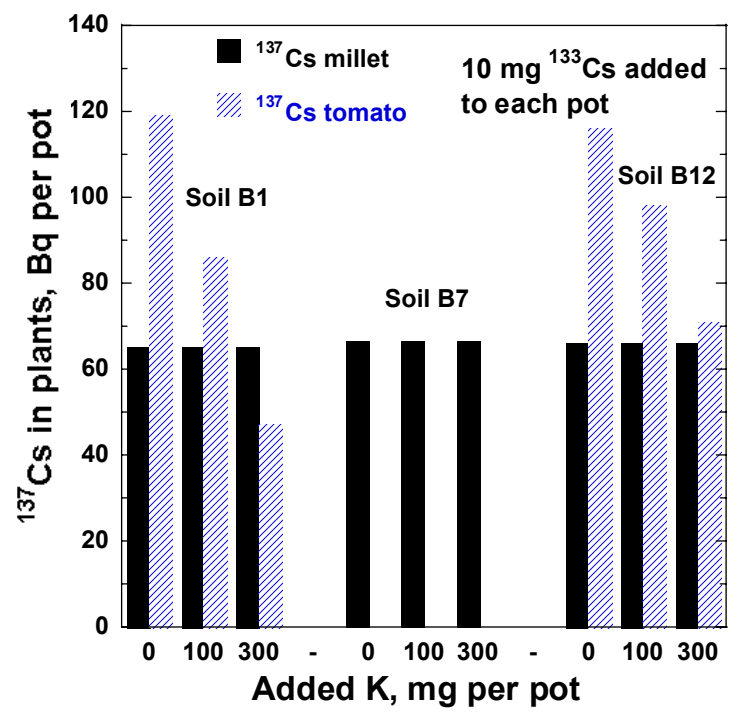

Figure 1-6C. ${ }^{133} \mathrm{Cs}$ in plants (tops only) versus added $\mathrm{K}$ per pot when $10 \mathrm{mg}$ of ${ }^{133} \mathrm{Cs}$ was added to each pot.

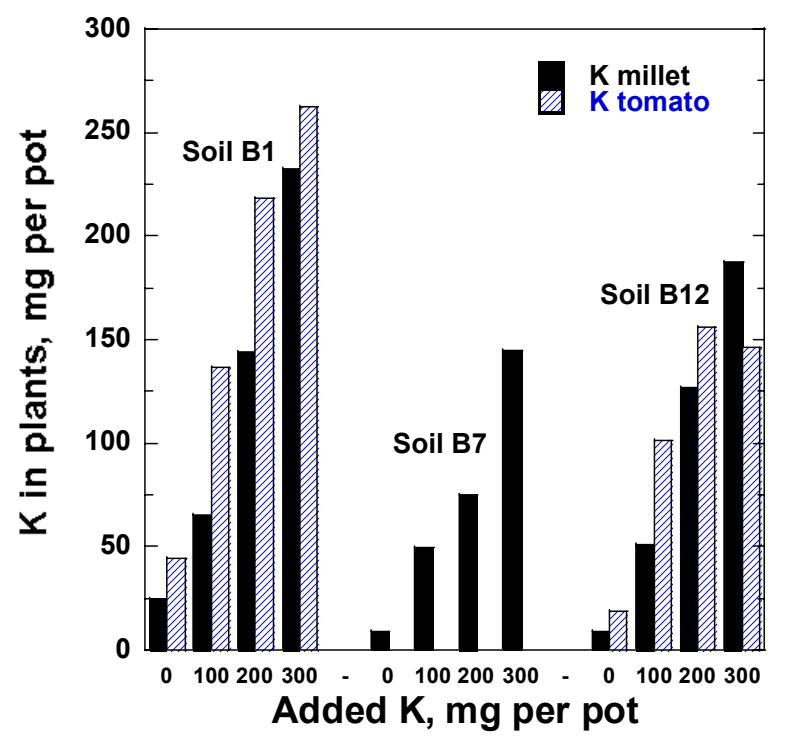

Figure 1-6B. ${ }^{137} \mathrm{Cs}$ in plants (tops only) versus added $\mathrm{K}$ per pot with no added ${ }^{133} \mathrm{Cs}$.

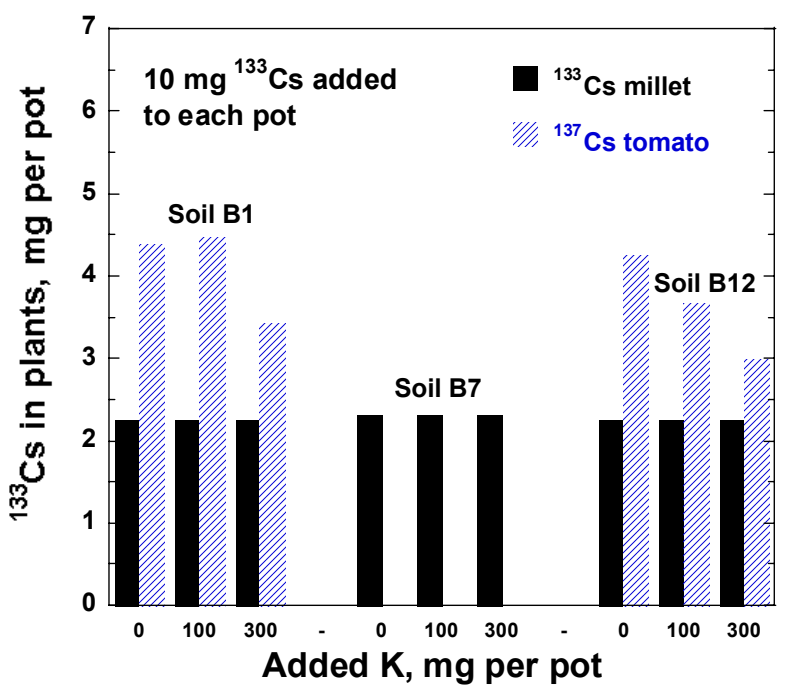

Figure 1-6D. ${ }^{137} \mathrm{Cs}$ in plants (tops only) versus added $\mathrm{K}$ per pot when $10 \mathrm{mg}$ of ${ }^{133} \mathrm{Cs}$ was added to each pot. 
concentrations of $\mathrm{K}$ are very low, less than 2 or $3 \mathrm{mg} \mathrm{K} \mathrm{g}^{-1}$. Further increases in $\mathrm{K}$ have negligible effects (Figure 13B). With tomato, however, the data do not allow any certain generalization (Figures 1-4A and 1-4B).

5. The uptake of stable and radiocesium are closely correlated (Figure 1-5). The ratio, $\frac{{ }^{137} C s, \mathrm{~Bq}}{{ }^{133} C s, \mathrm{mg}}$, in plants, however, is only 5 to $10 \%$ of that in soil, indicating low availability of the soil ${ }^{137} \mathrm{Cs}$ inventory. This is attributed to incorporation of ${ }^{137} \mathrm{Cs}$ in soil organic matter and soil organisms over the three decades since deposition.

\section{Experiment 2: Potassium Reduces ${ }^{137}$ Cs in Annual Crops Grown on an Atoll Soil}

\section{Introduction}

This study began as an unreplicated exploration of how different amounts of soil potassium might affect ${ }^{137} \mathrm{Cs}$ in food crops. At this time, suitable space for a larger study was not available.

Phase I of the study consisted of five successive crops of a single sweet corn variety, followed by one crop of sweet potato. Phase II, not reported here, included four successive crops of sorghum on each of the four plots. Nitrogen and $\mathrm{P}$ were added as before, but not $\mathrm{K}$, to deplete any $\mathrm{K}$ remaining from previous additions. Invasion of roots from supposedly distant palms further reduced yields and increased variability. This was followed by Phase III, in which the magnitude of potassium applications to individual plots was reversed. Three successive crops of the same sweet corn cultivar were grown as in Phase I, followed by two crops of sorghum without added $\mathrm{K}$.

Reversing K treatments and using of the same sweet corn genotype offsets the lack of plot replication when interpreting major effects. Results from the same genotype grown with the same or similar fertilizer treatments on the same plot can vary, but the variation has not obscured the large effects of potassium rates.

\section{Methods and Materials}

The soil on which this study was conducted is a Typic Rendoll. Maximum coarse fragment (>2 $\mathrm{mm}$ ) content at this site was $4 \%$. Some other characteristics are given in Table 2-1.

The plots were prepared by removing a heavy cover of grass, chiefly Eustachys petraea, which had developed in the 10 months since clearing a 14 to 15 year old coconut grove. The upper $25 \mathrm{~cm}$ of soil was loosened without mixing. The small area available was divided into four $5.0 \times 6.6$ meter plots, contiguous except for 1-meter separation strips. Each plot was randomly assigned to one of four $\mathrm{K}$ treatments termed Zero, Low, Medium and High, which remained the same throughout Phases I and II.

For Phase III, however, the treatments were reversed. The previous Zero, Low, Medium and High treatment plots were changed to, respectively, High, Medium, Low, and Zero plots.

Potassium as $\mathrm{KCl}$ was applied in solution by sprinkling an entire plot in attempts to achieve uniform distribution. In Phase I, small applications were made at sowing (excluding the Zero plot) followed by multiple applications intended to counter leaching from the sandy soil. In Phase III, however, one-third or one-half of the total was applied in solution after sowing each crop, followed by one or two later applications.

The relative rate of potassium applied to any one crop in total was scaled, with a low rate of 1.8 to $2.8 \mathrm{~g} \mathrm{~m}^{-2} \mathrm{~K}$ and multiples of four thereafter. For a variety of reasons the absolute amounts varied, as is shown on the graphs that follow. In six instances extreme K deficiency in the previous crop prompted a small application of $\mathrm{K}$ to the Zero plot, 0.3 or $0.5 \mathrm{~g} \mathrm{~m}^{-2}$, as a "starter solution" directly over the seeded row.

Crop IV was an exception to the Zero to High K gradation applied to other crops. By mischance, 0-20-20 fertilizer was applied in 


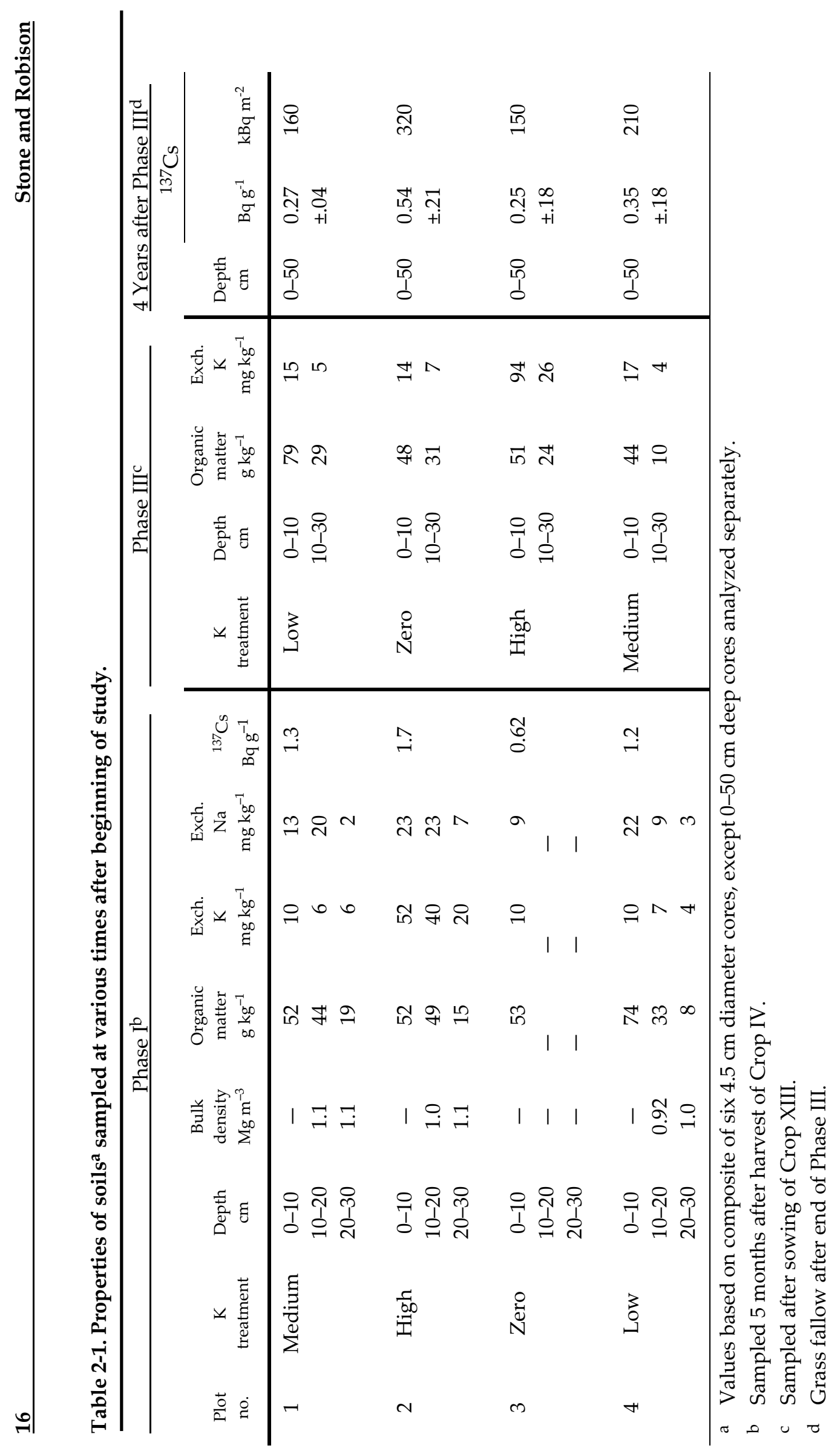


place of $0-45-0$, thus adding $6.3 \mathrm{~g} \mathrm{~m}^{-2} \mathrm{~K}$ to all plots at sowing.

Phosphorus, as treble superphosphate, was applied before sowing in a hand-dug trench about 10 to $15 \mathrm{~cm}$ from the seed row.

Nitrogen $(\mathrm{N})$ was applied as $\left(\mathrm{NH}_{4}\right)_{2} \mathrm{SO}_{4}$. An initial application was placed in a band with superphosphate; the remainder was applied in solution as side-dressings in shallow trenches, 3 to $5 \mathrm{~cm}$ deep, covered immediately to prevent volatilization of $\mathrm{NH}_{3}$. In Phase I a total of 7.5 to $10 \mathrm{~g} \mathrm{~m}^{-2} \mathrm{~N}$ per crop was applied, mostly in multiple side-dressings. In Phase III, however, the application rate totaled $20 \mathrm{~g} / \mathrm{m}^{2}$ per crop, with one-third to one-half in the superphosphate band, and the remainder in one or two sidedressings.

In the intervals between LLNL missions, fertilizer applications were carried on by mostly unskilled workers using pre-packaged materials, and scheduled methods and dates. Thus, there was little opportunity to modify applications in accord with weather or observation of crops.

The four crops grown here were sweet corn, (Zea mays), cv Silver Queen; sorghum, (Sorghum bicolor) Cargill co \#40; sweet potato (Ipomea batatas) cv unknown; and squash, (Curcurbita sp.) a landrace, "Wetak."

Crops grown in the dry season or low rainfall months were watered for all or part of their growth periods. The only freshwater supply, however, was from rainfall catchment stored in cisterns. The amounts available were frequently less than required for optimum growth. The maturity of harvested crops often varied inasmuch as the sowings and most harvests depended on periodic visits of LLNL personnel. Corn ears, whether filled or not, were separated from stover in the field. Corn stover and stems of sorghum - generally with immature grain - were cut at a height of 8 to 10 $\mathrm{cm}$ and the lowermost dead leaves discarded in order to reduce contaminating soil. Squash fruits were few and the collection times varied. In Phase I, crop weight was not generally recorded inasmuch as the original interest was ${ }^{137} \mathrm{Cs}$ concentration rather than total quantity.

All harvested plant materials and soil were frozen upon collection and transmitted to LLNL.

\section{Results and Discussion}

Dry matter content of the green crops often varied greatly according to stage of maturity, and the consequences of a wide range in $\mathrm{K}$ adequacy. The dry matter content of corn kernels in Crop I, for example, was about $75 \%$ in each of the four $\mathrm{K}$ treatments, whereas the dry matter in stover decreased from 46 to $33 \%$ as potassium supply increased. In contrast, stover of the very immature Crop V was only 15\% dry matter, approximately constant across the range of $\mathrm{K}$ addition.

\section{Phase I. Sweet Corn}

Crops I to V. Addition of only 1.8 to $2.8 \mathrm{~g}$ $\mathrm{m}^{-2} \mathrm{~K}$ to the Low treatment markedly reduced ${ }^{137} \mathrm{Cs}$ in both stover and kernels of Crops I, II, and III (Figure 2-1, 2-2, 2-3) and in the stover and immature ears of Crop V (Figure2-4). The Medium treatment, 6.1 to $11.1 \mathrm{~g} \mathrm{~m}^{-2} \mathrm{~K}$, completed the rapid reduction of ${ }^{137} \mathrm{Cs}$ if it had not occurred before. Cesium-137 concentrations were still lower at the High treatment, variously 21 to $44 \mathrm{~g} \mathrm{~m}^{-2} \mathrm{~K}$, although the reduction per unit of $\mathrm{K}$ was far less.

Crop IV (Figure 2-5) is comparable only in part with the others. As mentioned, all plots mistakenly received an application of $6.3 \mathrm{~g} \mathrm{~m}^{-2}$ $\mathrm{K}$ at sowing, which rendered the Zero and Low treatments similar to the Medium treatment of other crops. Nevertheless, ${ }^{137}$ Cs in kernels and stover decreased further with additional $\mathrm{K}$. This may imply little or no long-term retention of unabsorbed $\mathrm{K}$ by soil organic matter, inasmuch as cumulative rainfall during the growth of Crop IV was high, $\sim 75 \mathrm{~cm}$ in 64 days.

The seemingly low concentration of ${ }^{137} \mathrm{Cs}$ in plants from the Zero and Low plots of Crop V is due to the low proportion of dry matter, already mentioned as $\sim 15 \%$. When expressed on a dry basis, ${ }^{137} \mathrm{Cs}$ from the Zero plot is $6.8 \mathrm{~Bq} \mathrm{~g}^{-1}$ (Figure 2-6), comparable with $8.1 \mathrm{~Bq} \mathrm{~g}^{-1}$ from the Zero plot of Crop II (Figure 2-2).

Measured yield responses are available only for Crop II. The effect of $\mathrm{K}$ in increasing growth of stover appears linear here (Figure 2-2). It suggests that the reduction in ${ }^{137} \mathrm{Cs}$ concentration is not due to dilution by greater mass. The data in Figures 2-1 and 2-2 also demonstrate that the response curves of stover and kernels are often similar. 


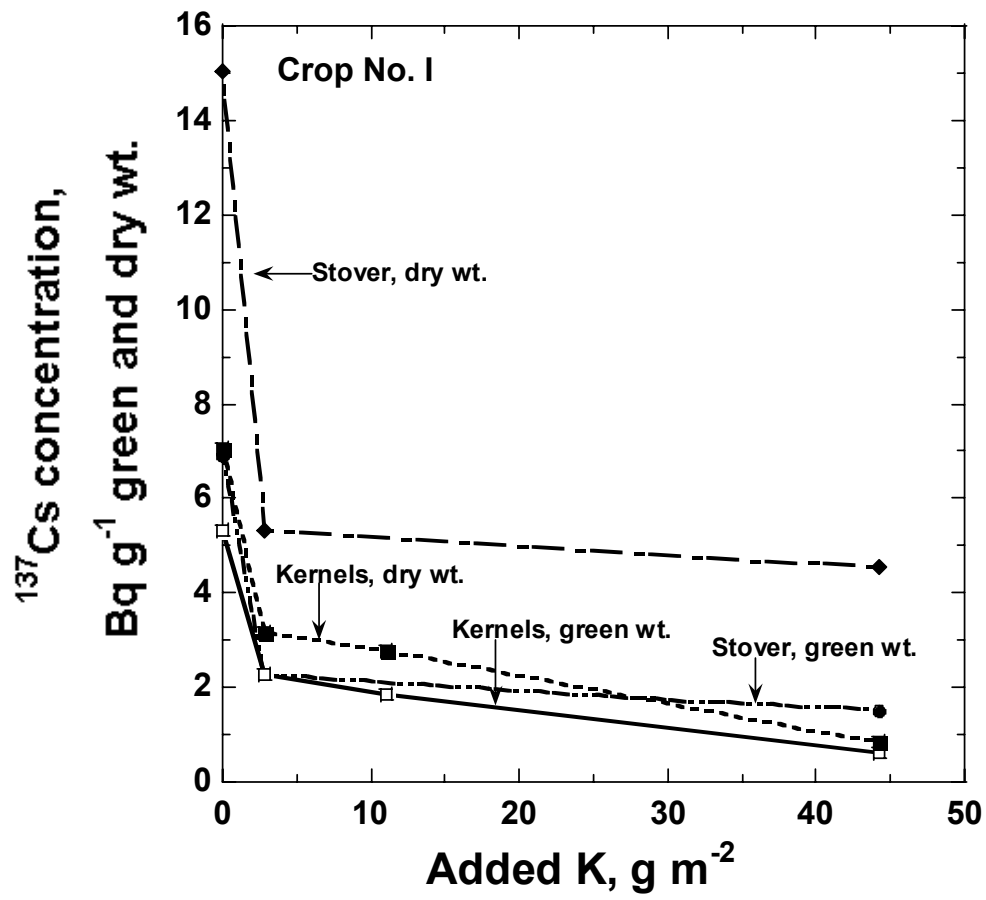

Figure 2-1. ${ }^{137} \mathrm{Cs}$ concentration in corn versus the amount of added $\mathrm{K}$ for Crop I.

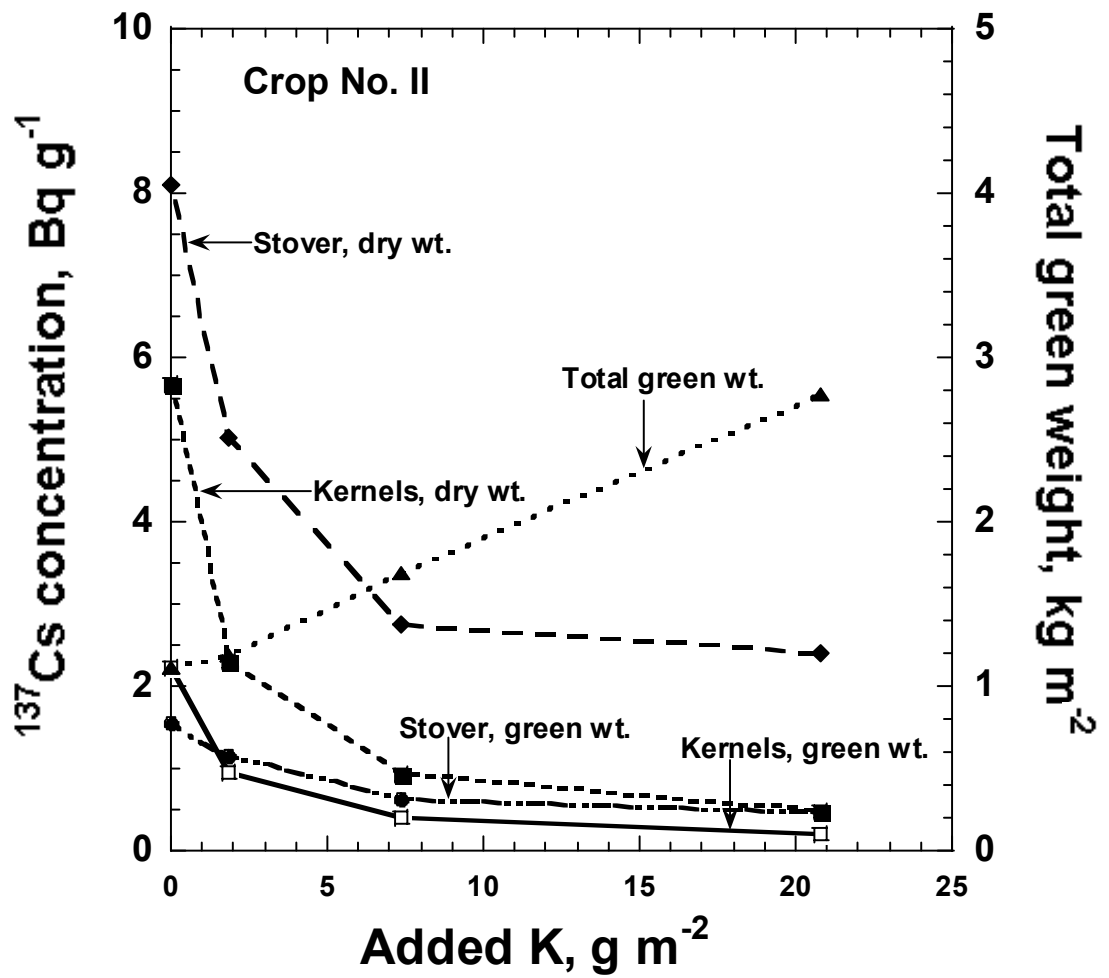

Figure 2-2. Green weight and ${ }^{137} \mathrm{Cs}$ concentration in corn versus the amount of added K for Crop II. 


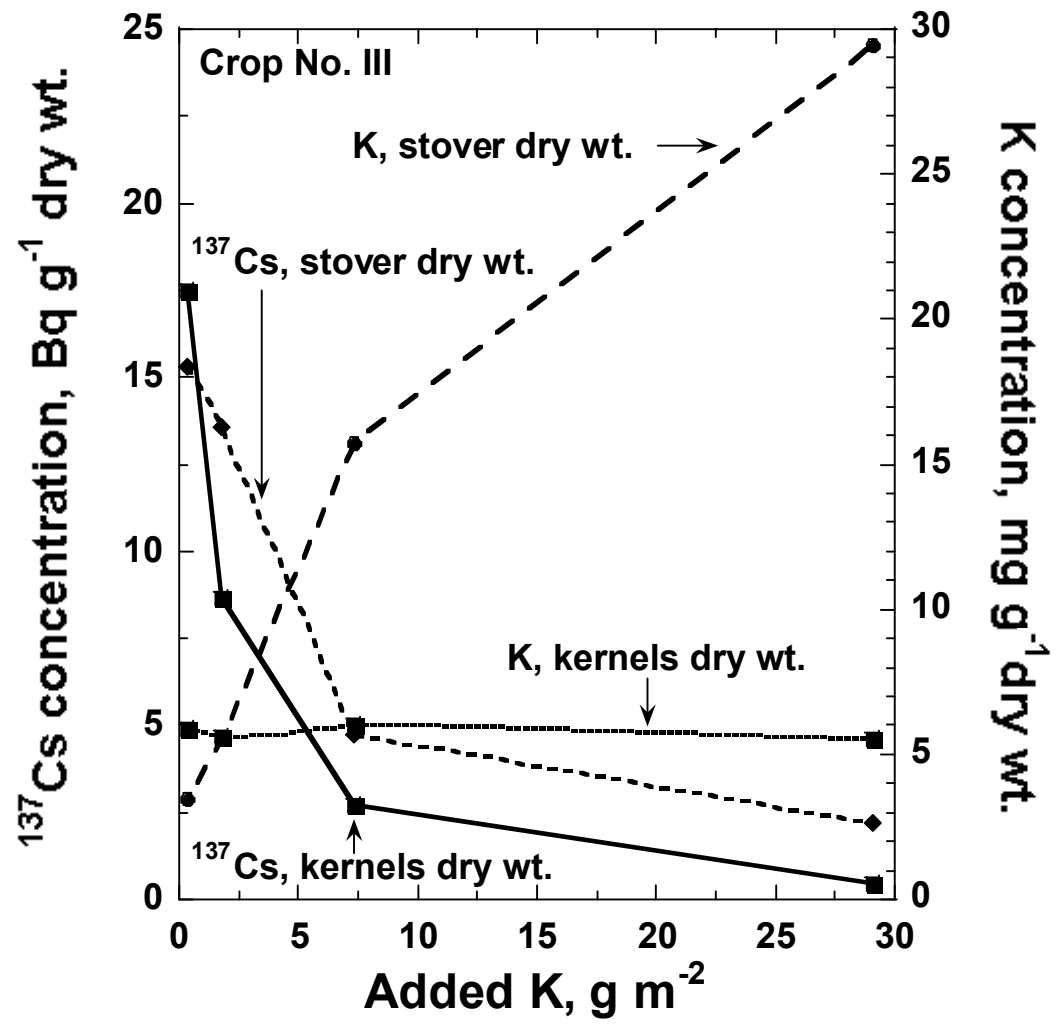

Figure 2-3. Potassium and ${ }^{137} \mathrm{Cs}$ concentrations in corn versus the amount of added $\mathrm{K}$ for Crop III.

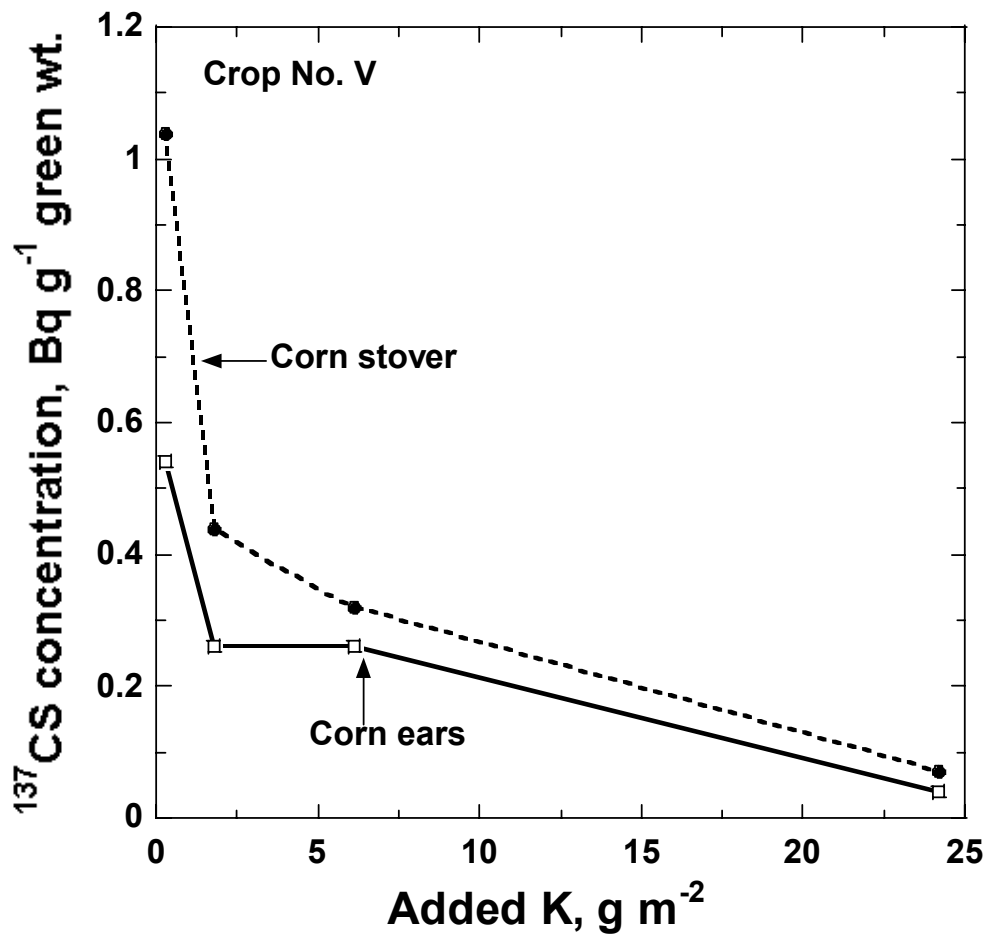

Figure 2-4. ${ }^{137} \mathrm{Cs}$ concentration in corn versus the amount of added $\mathrm{K}$ for Crop V. 


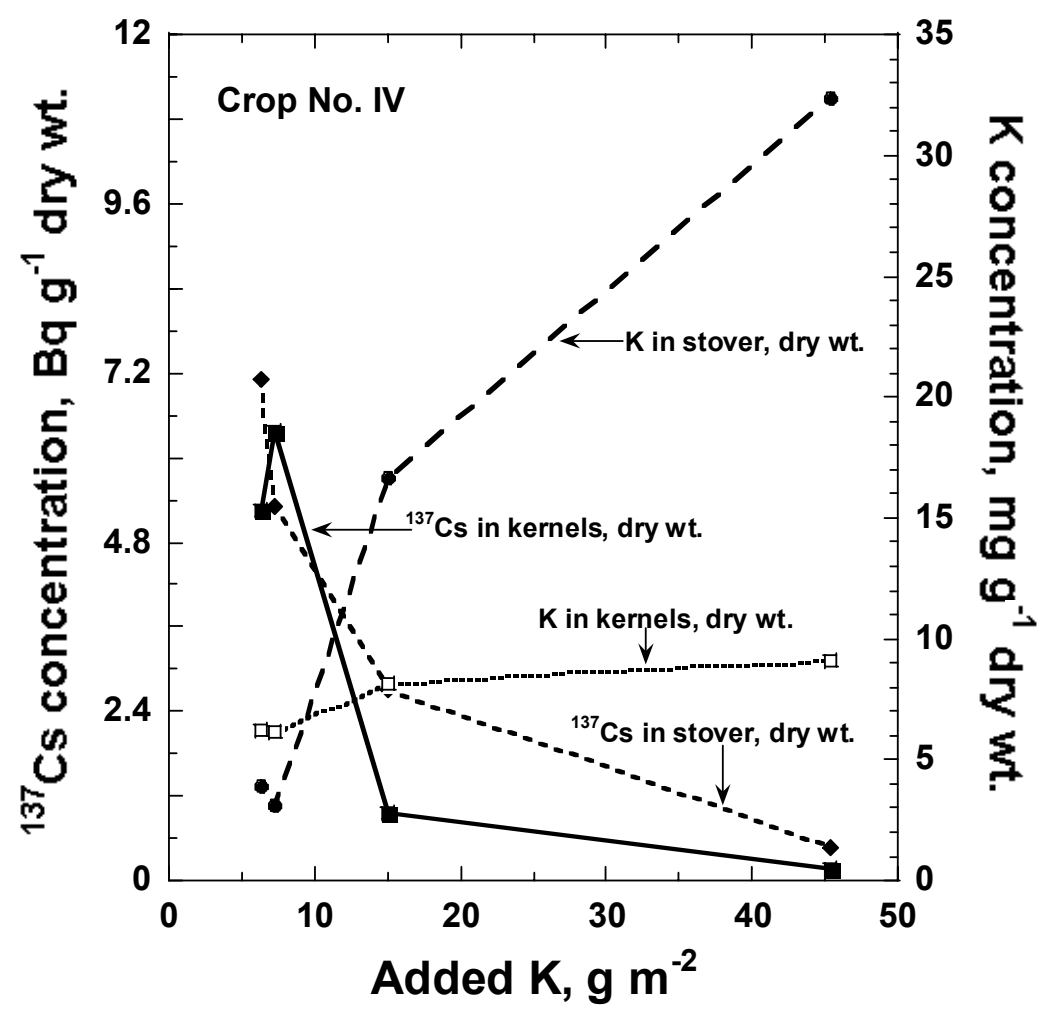

Figure 2-5. Potassium and ${ }^{137} \mathrm{Cs}$ concentrations in corn versus the amount of added K for Crop IV.

When ${ }^{137} \mathrm{Cs}$ is expressed on a green weight basis, kernels and stover respond somewhat alike with respect to ${ }^{137} \mathrm{Cs}$ as soil $\mathrm{K}$ increases, but this similarity is not true of $\mathrm{K}$ concentration (Figures 2-3, 2-4). As soil $\mathrm{K}$ increases from the Zero to High level, $\mathrm{K}$ in stover increases from $\sim 5$ to $\sim 30 \mathrm{mg} \mathrm{g}^{-1}$, dry weight. In contrast, $\mathrm{K}$ in kernels increases by no more than one third or not at all. Thus, concentration in kernels is a poor measure of $\mathrm{K}$ in the whole plant; this is also true for coconut endosperm (Robison and Stone, unpublished data).

Association of plant ${ }^{137} \mathrm{Cs}$ concentration with plant $\mathrm{K}$ concentration, rather than soil additions in three crops for which data are available, is compared in Figure 2-6. Differences among successive crops are unexplained except that Crops IV and V were less mature, with dry matter contents $\sim 15 \%$, as well as subject to higher rainfall. Clearly, the Cs/K relationships are not linear. Power curves show a high degree of correlation in all cases.

\section{Phase I. Sweet Potato-Crop VI.}

Crop VI (Figure 2-7) was sustained largely by artificial watering during its 5-month growth inasmuch as rainfall totaled only $17 \mathrm{~cm}$. Drought and salt injury symptoms appeared before the third month, and further applications of $\mathrm{N}$ and $\mathrm{K}$ were postponed until late in the growing season. Neither vine nor tuber yields responded to added K. Nevertheless, ${ }^{137}$ Cs concentrations in tubers decreased from 2.12 to $0.17 \mathrm{~Bq} \mathrm{~g}^{-1}$, green weight, as $\mathrm{K}$ addition increased.

\section{Phase I. Squash-Crops II to V}

Wetak squash was grown in separate rows along with sweet corn Crops II to V. Fruit production was severely curtailed by pruning to keep rooting vines within the plots, as well as by $\mathrm{K}$ deficiency and the need for hand pollination. No fruits matured in the Zero K plot. No weights were recorded, but the data in Table 2-2 indicate ${ }^{137} \mathrm{Cs}$ in fruits accumulated over two successive periods. High moisture content of the edible flesh resulted in relatively low green 


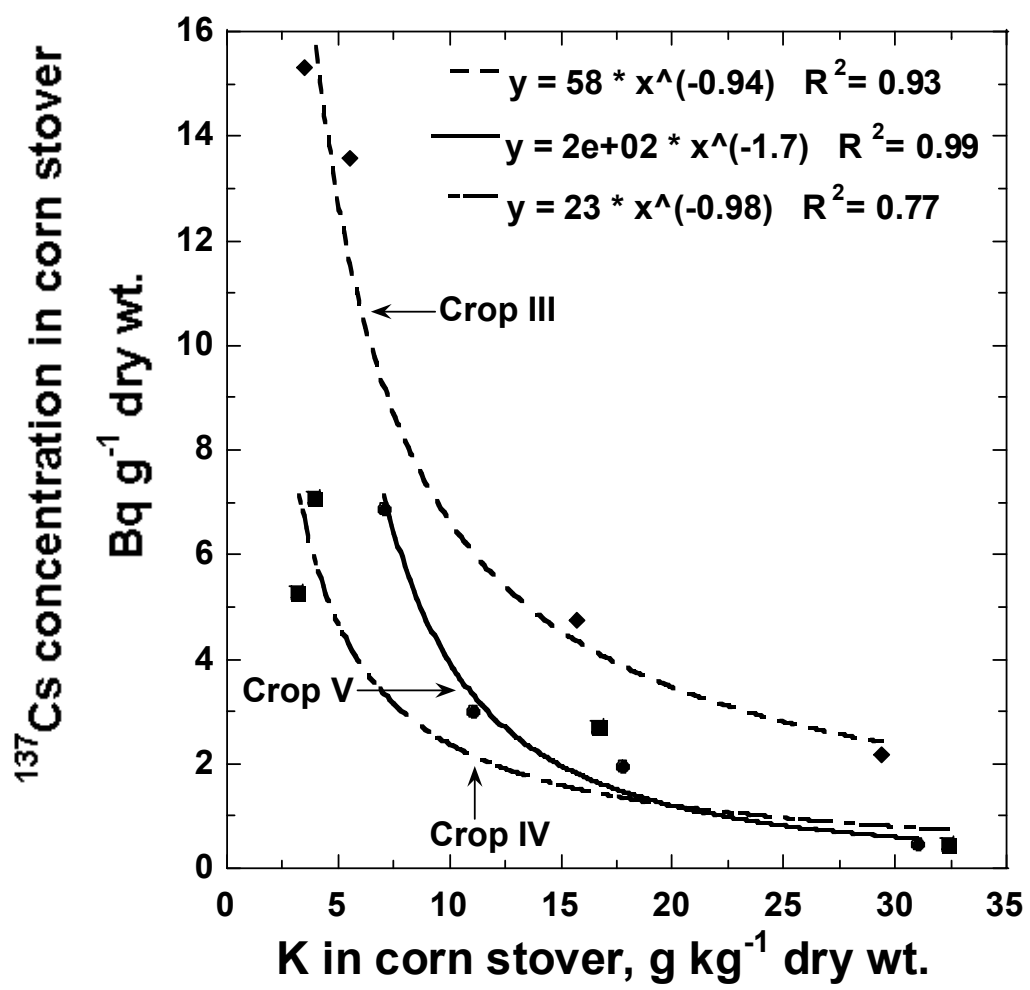

Figure 2-6. Correlation between the ${ }^{137} \mathrm{Cs}$ and $\mathrm{K}$ concentrations in corn for Crops III, IV, and V.

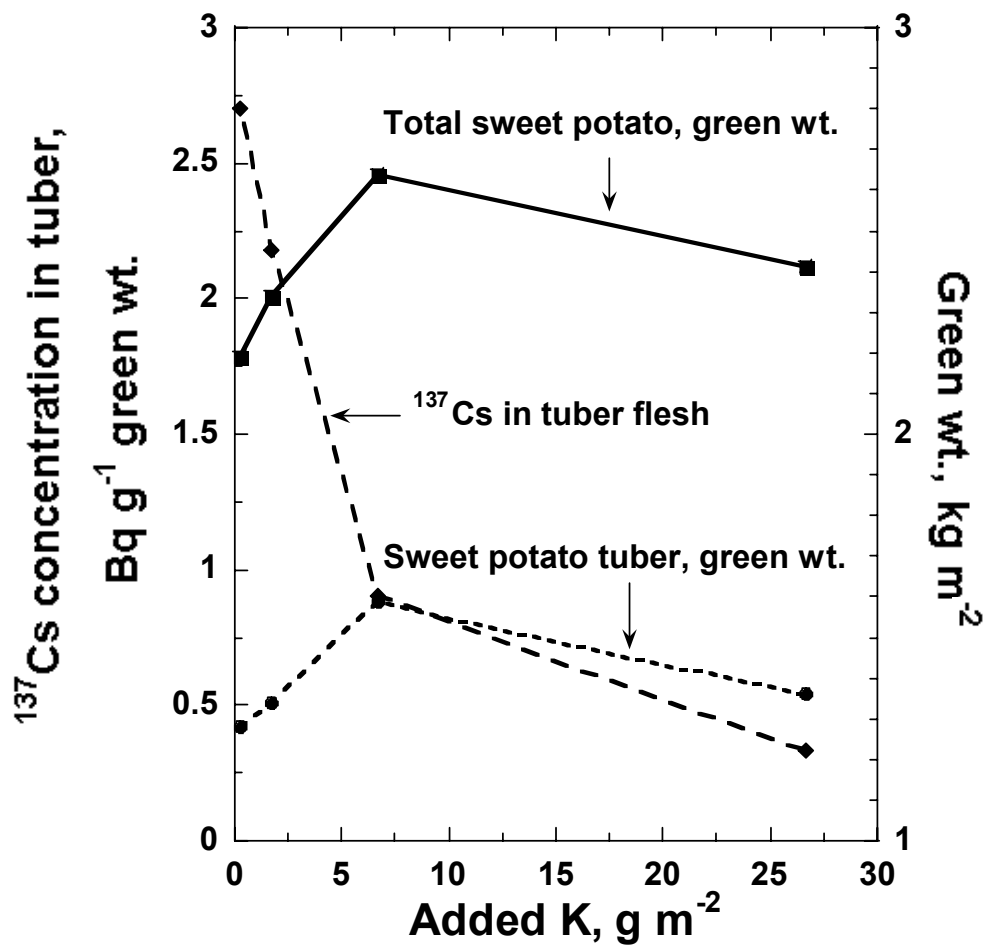

Figure 2-7. Green weight and ${ }^{137} \mathrm{Cs}$ concentration in sweet potato versus added $\mathrm{K}$. 
Table 2-2. Crops II to V. Effect of potassium rate on two successive collections of Wetak squash. (See text.)

\begin{tabular}{|c|c|c|c|c|c|}
\hline \multirow[b]{2}{*}{$\begin{array}{l}\text { Collection } \\
\text { period }\end{array}$} & \multirow[b]{2}{*}{ Tissue } & & \multicolumn{2}{|r|}{$\mathrm{K}$ treatment } & \multirow[b]{2}{*}{ High } \\
\hline & & Zero & Low & $\begin{array}{c}\text { Med } \\
{ }^{137} \mathrm{Cs}, \mathrm{Bq} \mathrm{g}^{-1}, \text { green wt. }\end{array}$ & \\
\hline \multirow[t]{2}{*}{ A } & Flesh $^{\mathrm{a}}$ & $-\mathrm{b}$ & 1.6 & 0.33 & 0.09 \\
\hline & Seed & - & 4.4 & 0.78 & 0.15 \\
\hline \multirow[t]{2}{*}{ B } & Flesh & $-\mathrm{b}$ & 1.1 & 0.52 & 0.21 \\
\hline & Seed & - & 2.5 & 1.1 & 0.72 \\
\hline
\end{tabular}

a Skin removed.

b No fruit.

weight concentrations but the reduction in ${ }^{137} \mathrm{Cs}$ as $\mathrm{K}$ increased is apparent.

\section{Phase III. Sweet Corn-Crops XII to XIV}

As noted under Methods, the amounts of $\mathrm{K}$ applied to the four plots in Phase I were reversed in Phase III. The former Zero, Low, Medium, and High plots became, respectively, the High, Medium, Low, and Zero plots of Phase III.

We then grew three successive crops of sweet corn much as in Phase I except that the initial applications of $\mathrm{N}$ and $\mathrm{K}$ were larger, and the remainder applied in only one or two later dressings. The corn was followed by two crops of sorghum grown without added $\mathrm{K}$ to assess the contribution of any native $\mathrm{K}$ sources plus that residual from previous additions.

Yields of the three sweet corn crops with comparable additions of $\mathrm{K}$ were generally similar (Figure 2-8A). Depletion of native soil supplies of $\mathrm{K}$ and the large responses to additions of $8 \mathrm{~g} \mathrm{~m}^{-2} \mathrm{~K}$ are evident (Figure 2-8B). Cesium-137 is somewhat higher in the first crop, but comparison is lessened by loss of the Zero samples from Crop XIV before analysis.

Comparison of stover yields can be extended to include those from Crop II. Green weight from the Zero treatment of Crop II is higher than those for Crops XII and XIV, suggesting greater availability of native $\mathrm{K}$ at that early stage of cropping.

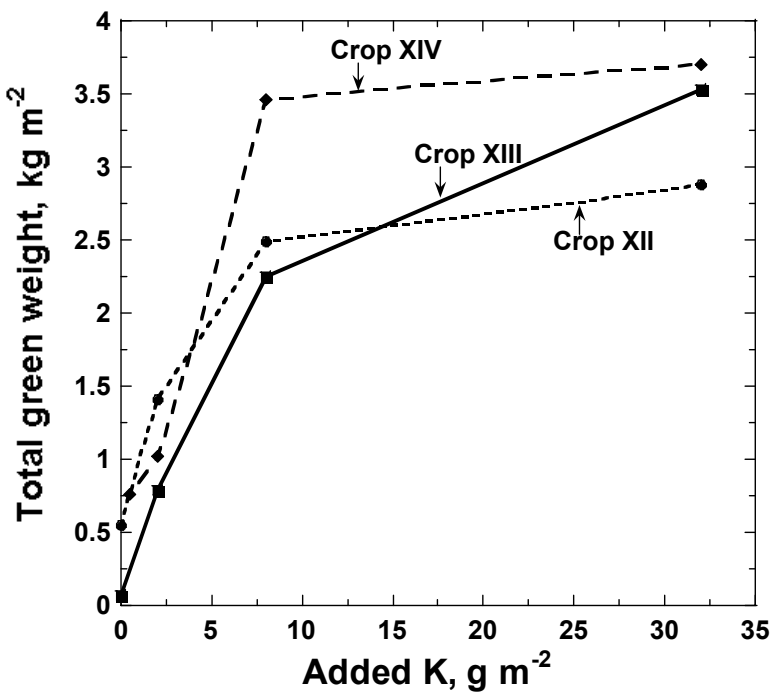

Figure 2-8A. Green weight of Crops XII, XIII, and XIV versus added K. 


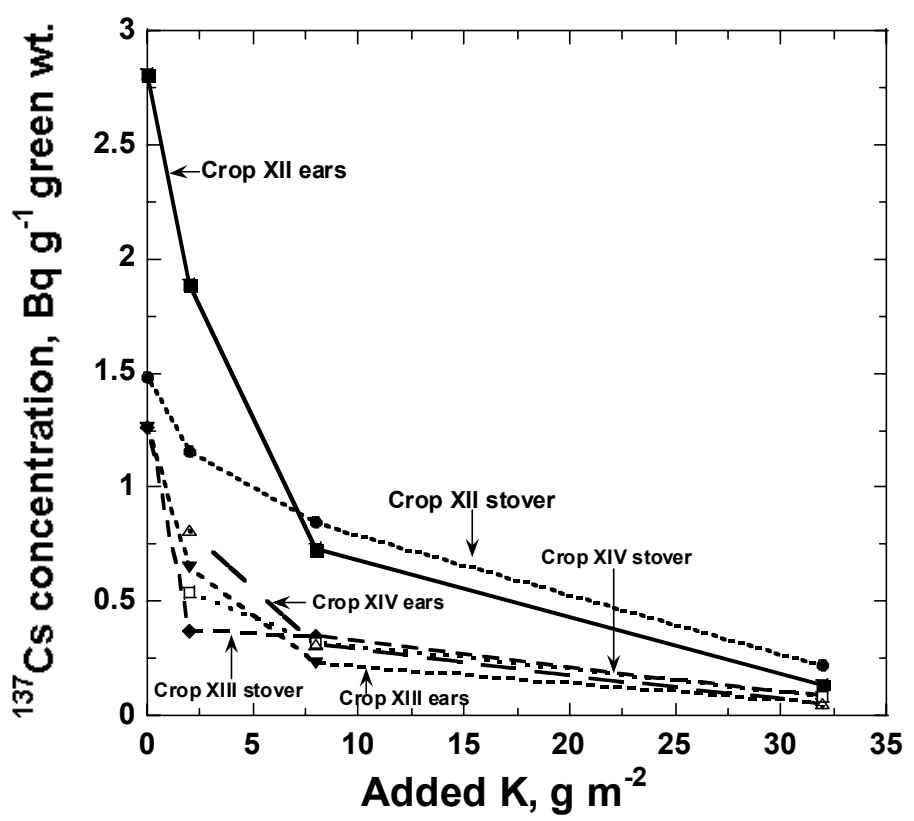

Figure 2-8B. ${ }^{137} \mathrm{Cs}$ concentration in Crops XII, XIII, and XIV versus added K.

\section{Phase III. Sorghum - Crops XV to XVI}

As might be expected, yields from the first sorghum Crop (XV) (Figure 2-9A), grown without added $\mathrm{K}$, are less than those of previous crops. Yields from the previous Medium and High treatments are surprisingly high, however, and together with the sustained decrease in ${ }^{137} \mathrm{Cs}$, (Figure 2-9B) indicate carryover of potassium from previous crops.

The difference between yields from the Medium and High plots is small relative to the amounts of K previously added, however, whereas the difference in ${ }^{137} \mathrm{Cs}$ concentration is relatively large. In contrast to Crop XV, yields of the following sorghum Crop (XVI) are uniformly low, with no differences attributable to residual K (Figure 2-9A). Yet the pattern of ${ }^{137} \mathrm{Cs}$ decrease is similar to that of Crop XV, except for a lesser decrease from the Medium' to High plot in Crop XVI (Figure 2-9B).

The conflicting evidence of yield (mass) ${ }^{137} \mathrm{Cs}$ concentration, relative to residual $\mathrm{K}$ in these two crops, is likely a consequence of high rainfall. Cumulative rainfall in four overlapping intervals following harvest of Crop XIV - the last crop grown with added $\mathrm{K}-$ is listed below:
Interval

Between Crop XIV harvest and Crop XV sowing:

During growth of sorghum Crop XV:

Between Crop XIV harvest and Crop XVI sowing: During growth of sorghum Crop XVI:
Rainfall $-\mathrm{cm}$

Total 117

192

$\underline{77}$ 


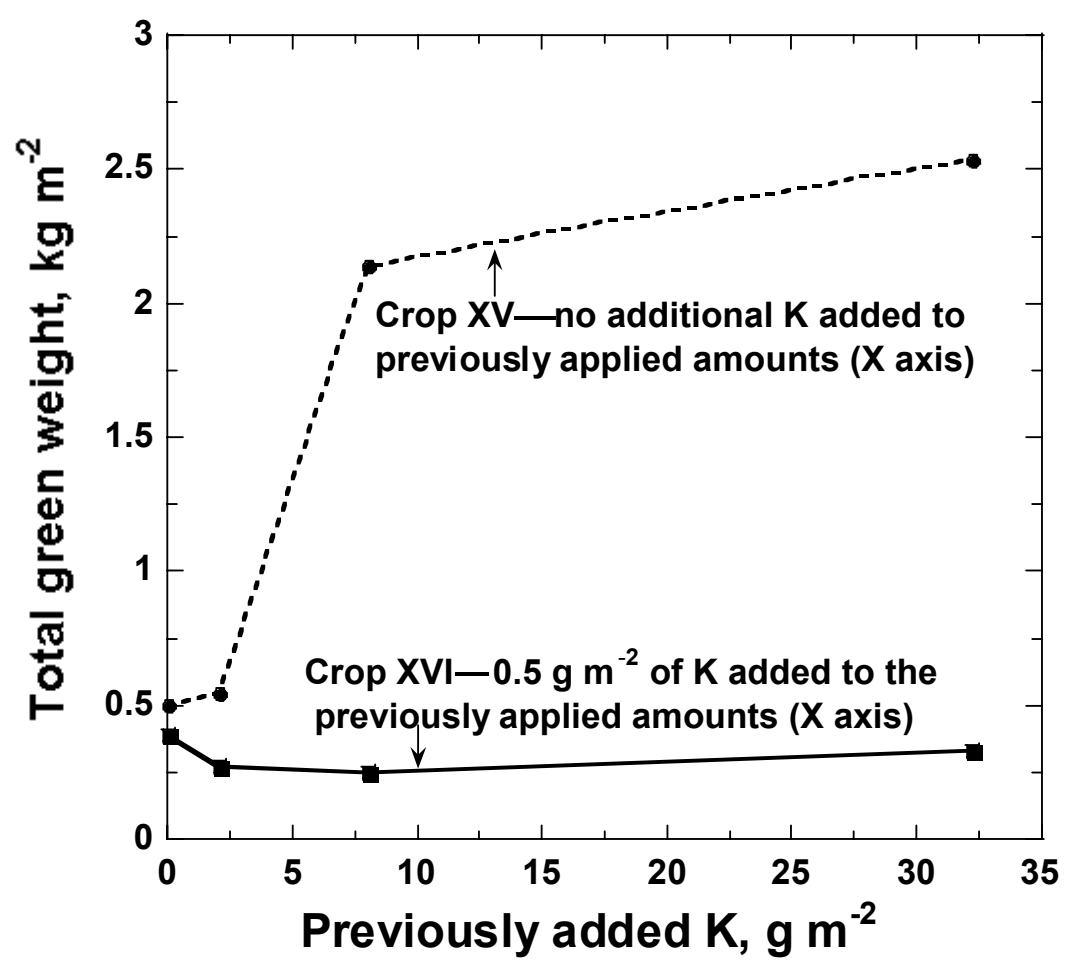

Figure 2-9A. Total green weight of corn and sorghum, Crops XV and XVI, versus previously added K.

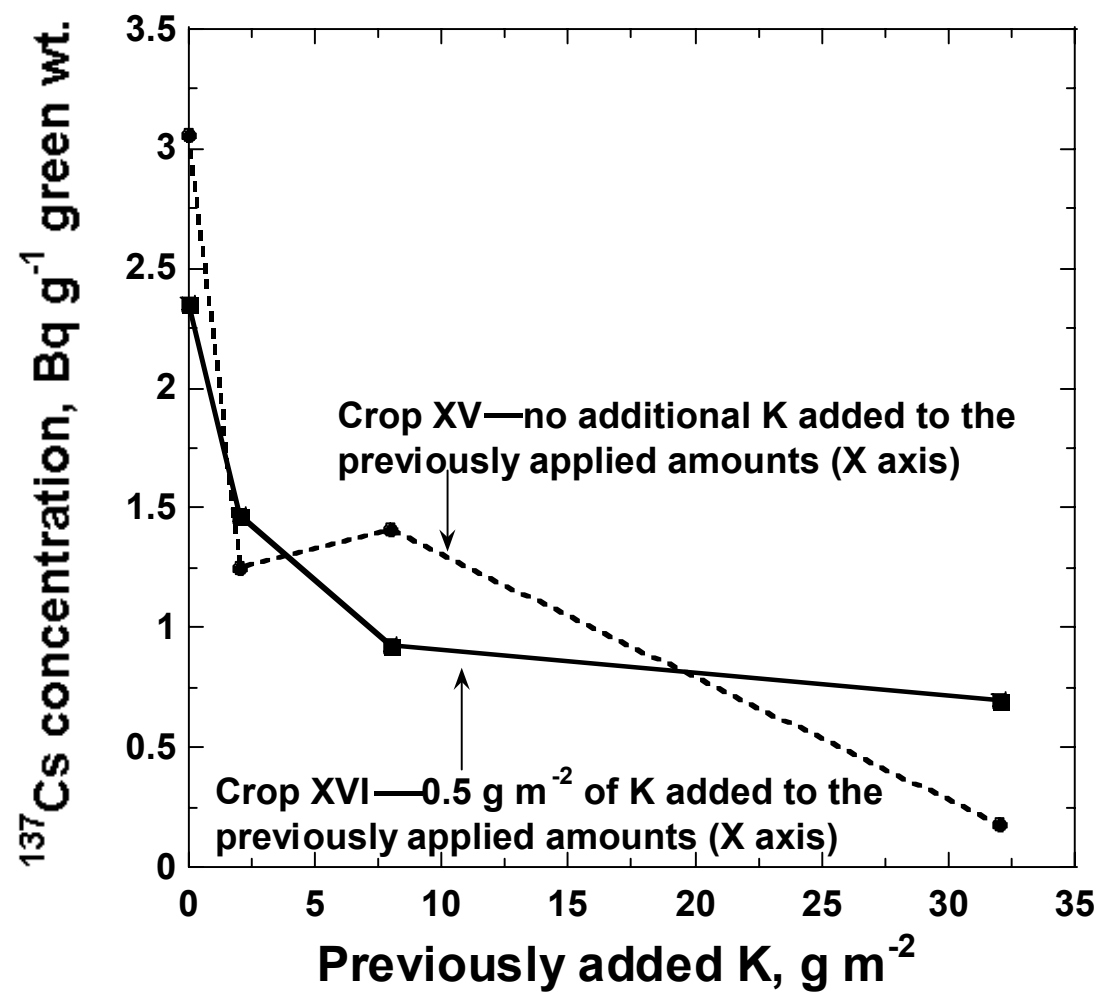

Figure 2-9B. ${ }^{137} \mathrm{Cs}$ concentration in sorghum, Crops XV and XVI, versus previously added K. 
Two possible explanations are (1) ${ }^{137} \mathrm{Cs}$ uptake is somehow restricted by amounts of residual $\mathrm{K}$, or its secondary effects, that are too small to influence growth, or (2) high rainfall has leached some other nutrient needed for growth. Nitrogen is an obvious candidate. Thus in Figure 2-9A, the small yield differences between the Medium and High plots of Crop XV may be due to leaching of added $\mathrm{N}$, rather than lack of sufficient residual $\mathrm{K}$ in the High plot. Likewise, the uniformly low yield from Crop XVI, despite addition of $0.5 \mathrm{~g} \mathrm{~m}^{-2} \mathrm{~K}$ over the seed row, could be due to nearly complete loss of $\mathrm{N}$, both initially applied and added. Ammonium sulfate placed beneath the surface of calcareous soil is rapidly transformed to $\mathrm{NO}_{3}$, but $\mathrm{NH}_{4}+$ itself could have been thoroughly leached by the average daily rainfall of $1.2 \mathrm{~cm}$ during the first 56 days of the 86-day cropping period.

\section{Concluding Discussion}

Progressively larger additions of $\mathrm{K}$ to soil progressively reduced ${ }^{137} \mathrm{Cs}$ in the four crop species tested. Application of $\mathrm{K}$ at the rate of only 1.8 to $8 \mathrm{~g} \mathrm{~m}^{-2}$ of soil reduced ${ }^{137} \mathrm{Cs}$ greatly in all sampled parts of the plants. The reduction of ${ }^{137} \mathrm{Cs}$ is decidedly curvilinear, becoming small per unit of $\mathrm{K}$ at the highest levels applied. In contrast, growth increased with added $K$. The exception is Crop VI where lack of water limited yields.

The total inventory of ${ }^{137} \mathrm{Cs}$ is contained in soil organic matter (Koranda et al., 1978). It appears that the small fractions(s) subject to leaching and plant uptake can be depleted and replaced (Robison \& Stone, 1998). Possibly the rate of replacement limits plant uptake during periods of high rainfall or rapid growth.
The molecular concentrations of ${ }^{137} \mathrm{Cs}$ in corn stover, however, are 9 to 10 orders of magnitude lower than those of $\mathrm{K}\left(1 \mathrm{~Bq}{ }^{137} \mathrm{Cs}=\right.$ $2.2686 \times 10^{-15}$ mole; $1 \mathrm{mg} \mathrm{K}=2.5574 \times 10^{-5}$ mole). Such large differences are not readily reconciled with hypotheses either of greater ${ }^{137}$ Cs competition at the root surface, or of substitution of ${ }^{137} \mathrm{Cs}$ in plant processes, as the soil content of $\mathrm{K}$ diminishes over one or two orders of magnitude.

Removal of ${ }^{137}$ Cs from soil by repeated cropping can be estimated whenever both crop weights and ${ }^{137} \mathrm{Cs}$ concentrations are known. Summing contents in Crops II, XII to XV, and VI (tubers only) indicates the following totals for the four treatments:

$\begin{array}{lrl}\text { Zero } & 10.4 & \mathrm{k} \mathrm{Bq} \mathrm{m}^{-2} \\ \text { Low } & 8.2 & \mathrm{k} \mathrm{Bq} \mathrm{m}^{-2} \\ \text { Medium } & 8.4 & \mathrm{k} \mathrm{Bq} \mathrm{m}^{-2} \\ \text { High } & 3.2 & \mathrm{k} \mathrm{Bq} \mathrm{m}^{-2}\end{array}$

Clearly, greater plant production resulting from applied $\mathrm{K}$ has offset much of the striking reduction in ${ }^{137} \mathrm{Cs}$ concentration.

The above totals do not include the unmeasured removal in Crops I, III, V, sweet potato vines, and squash fruit and vines. Addition of these would no more than double the totals indicated above. Thus, the larger removal would be less than $10 \%$ of the mean soil inventory at the beginning of the study (Table 2-1).

The comparison bears on the frequently advanced proposal to remove ${ }^{137} \mathrm{Cs}$ from soil by repeated cropping. The lack of fresh water to irrigate more than small experimental plots is an obvious prohibition against extending the results given here to whole islands and atolls.

\section{Experiment 3: Effect of Large K and Na Applications on ${ }^{137} \mathrm{Cs}$ Uptake by Annual Crops as Related to Rainfall}

This study began at a time when little was known about the suppression of ${ }^{137} \mathrm{Cs}$ uptake by added K. The suppressive effect of salt water leaching (Robison and Stone, 1999) suggested that Na might have similar though lesser effects. The present study results revealed some soil relationships, and the loss of large $\mathrm{K}$ additions during periods of high rainfall. 


\section{Methods and Materials}

The study area was located between Experiments 2 and 6, and hence is similar in soil properties. It had been cleared of a $\sim 15$-year coconut palm plantation about 14 months previously. A cover of dry grass was burned, and the soil loosened, but not overturned, using a small airborne bulldozer to break up old coconut and grass roots.

Thirty-three one-meter-square open plywood frames were then emplaced 12 to 15 $\mathrm{cm}$ deep in the smoothed soil surface. The three rows of these frame-enclosed "micro plots" that were spaced one meter between each row, onehalf or one meter apart within rows, or further apart when needed to avoid old stumps. The plots were grouped as three contiguous blocks, and the initial treatments randomized within blocks. The three types of treatments were an untreated Control (two replications per block), $\mathrm{K}$ added at three rates (one of each per block), and $\mathrm{Na}$ added in molecularly equivalent amounts. The cations, added as chlorides, corresponded to 33,67 , and $100 \%$ of the assumed cation exchange capacity in the upper $30 \mathrm{~cm}$ of soil, i.e., 28 centi-equivalents $\mathrm{kg}^{-1}$ to a depth of $30 \mathrm{~cm}$.

Hence, the amounts were massive: 311, 612, and $934 \mathrm{gm}^{-2} \mathrm{~K}$, or 183,361 , and $551 \mathrm{~g} \mathrm{~m}^{-2} \mathrm{Na}$. The commercial $\mathrm{NaCl}$ used may have contained a small amount of $\mathrm{K}$. A fourth treatment with salt water proved of little interest and is not reported here.

Both control and cation-treated plots were irrigated periodically during and after application, with a total of $25 \mathrm{~cm}$ water over a 10-day period.

A succession of nine annual crops were grown on these plots: six of sweet corn, (Zea mays, cv. Silver Queen), one of sweet potato, (Ipomea batatas, cv. unknown), and two of sorghum (Sorghum bicolor, cv Cargill \#40) (Table 3-1). All plots were variously fertilized with broadcast applications of a 16-16-16 mixed fertilizer, triple superphosphate, $\left(\mathrm{NH}_{4}\right)_{2} \mathrm{SO}_{4}$, and $\mathrm{KCl}$ where indicated. The total amounts per crop were divided into a minimum of four applications, with seven applications on corn Crops II and III when rainfall was high. We attempted to reduce loss of $\mathrm{NH}_{3}$ from surface application by watering immediately after application unless rain was imminent.
Crops grown during the dry seasons were watered irregularly as supply permitted.

At the beginning of this study, we did not know that moderate amounts of $\mathrm{K}$, (i.e., 3 to $10 \mathrm{~g} \mathrm{~m}^{-2}$ ) would materially reduce ${ }^{137}$ Cs uptake by annual crops. Accordingly we applied presumed "maintenance dressing," totaling 7.7, 10, and $12 \mathrm{~g} \mathrm{~m}^{-2} \mathrm{~K}$, respectively, to all plots, including controls, of Crops I, II, and III. These amounts were reduced to 3.0 to $0.75 \mathrm{~g} \mathrm{~m}^{-2} \mathrm{~K}$ per subsequent crop. Table 3-1 indicates these additions together with the cropping sequence and rainfall.

Plots were harvested and re-sown at times when LLNL personnel visited the atoll. Consequently, the sampled material varied in maturity and dry matter content. The plants, especially sweet potato, often occupied more than the allocated meter-square air space but were not allowed to root. Hence no plant weights per $\mathrm{m}^{2}$ are given.

We took soil samples prior to addition of any element, compositing four 2-cm-diameter cores from the $0-10$ and $10-20 \mathrm{~cm}$ depths for each meter-square micro plot. The depths sampled were often more or less than would have been taken from the original surface because of soil movement during plot installation. Plant and soil samples were frozen and shipped to LLNL where the ${ }^{137} \mathrm{Cs}$ concentration was determined on entire sorghum stems including immature seed, on sweet potato vines, on cornstalks (including leaves) and ear components, and on soil. Losson-ignition (LOI) and total Kjeldahl $\mathrm{N}$ of soil samples were determined in the Department of Soil Science, University of Florida.

The standard temperature for loss-onignition in calcareous soils, $430^{\circ} \mathrm{C}$, was taken from Ball (1964) and Davies (1974). Other samples heated overnight to $375^{\circ} \mathrm{C}$ or $550^{\circ} \mathrm{C}$, although respectively lower or higher in loss, were both closely correlated with the $430^{\circ} \mathrm{C}$ results $\left(\mathrm{r}^{2}=0.97\right)$.

\section{Statistical Analysis}

Both crop growth and ${ }^{137} \mathrm{Cs}$ concentration varied appreciably among replicates due in part to soil variability (Figure 3-1), and, possibly, to irregularities in application of fertilizer and water. 
Table 3-1. Cropping sequence, rainfall, and $\mathrm{K}$ addition to all plots ${ }^{\mathrm{a}, \mathrm{b}}$.

\begin{tabular}{|c|c|c|c|c|c|}
\hline \multirow[b]{2}{*}{$\begin{array}{l}\text { Crop } \\
\text { no. }\end{array}$} & \multirow[b]{2}{*}{ Species } & \multicolumn{2}{|c|}{ Potassium added } & \multirow{2}{*}{$\begin{array}{l}\text { Periodic } \\
\text { rainfall } \\
\mathrm{cm}\end{array}$} & \multirow[b]{2}{*}{$\begin{array}{c}\text { Duration } \\
\text { days }\end{array}$} \\
\hline & & $\begin{array}{l}\text { Total } \\
\mathrm{g} \mathrm{m}^{-2}\end{array}$ & $\begin{array}{c}\text { Applications } \\
\text { no. }\end{array}$ & & \\
\hline $\mathrm{I}$ & Sweet corn & 7.7 & 5 & 26 & 91 \\
\hline \multirow[t]{2}{*}{ II } & Sweet corn & 10 & 7 & 45 & 76 \\
\hline & (Fallow) & - & - & (24) & (16) \\
\hline \multirow[t]{2}{*}{ III } & Sweet corn & 12 & 7 & 72 & 65 \\
\hline & (fallow) & - & - & (6) & (12) \\
\hline IV & Sweet corn & 2.0 & 5 & 30 & 72 \\
\hline $\mathrm{V}$ & Sweet potato & 3.0 & 4 & 18 & 166 \\
\hline VI & Sweet corn & 0.75 & 4 & 46 & 86 \\
\hline \multirow[t]{2}{*}{ VII } & Sweet corn & 2.3 & 5 & 46 & 69 \\
\hline & (Fallow) & - & - & (33) & (185) \\
\hline VIII & Sorghum & 1.5 & 4 & 33 & 59 \\
\hline \multirow[t]{2}{*}{ IX } & Sorghum, ratoon & 1.5 & 4 & 55 & 88 \\
\hline & Totals & 40 & & 434 & 985 \\
\hline
\end{tabular}

a Does not include pre-sowing addition of $\mathrm{K}$ or $\mathrm{Na}$.

b Rainfall in the two months proceeding the study totaled $\sim 10 \mathrm{~cm}$. Additions of water during treatment and leaching before sowing approximated $25 \mathrm{~cm}$. Subsequently, small additions were made during crop germination and after fertilizer applications. Irrigation of Crop V during dry weather probably totaled less than $12 \mathrm{~cm}$.

Preliminary ANOVAs of ${ }^{137} \mathrm{Cs}$ concentrations showed no significant differences among the three rates of $\mathrm{K}$, or of $\mathrm{Na}$, respectively, in any of the nine crops. This could be attributed to rapid leaching of added $\mathrm{K}$ and $\mathrm{Na}$ in some proportion to their excess over some low level of retention, beginning in the presowing period. The lack of differences allowed combining the three rates of each cation into single $\mathrm{K}$ or $\mathrm{Na}$ treatments for re-analysis. The probability of the difference between the treatments was examined using Scheffe's test.

\section{Results and Discussion}

\section{Soil}

Cesium-137 concentration in the $0-10$ and $10-20 \mathrm{~cm}$ depths of this somewhat disturbed soil was related to organic matter content as determined by LOI (Figure 3-1). The regression is near linear, except that the slope becomes much less below about $6.5 \%$ LOI. The range displayed in Figure 3-1 reveals an unexpectedly high variability in ${ }^{137} \mathrm{Cs}$ among such small, closely grouped plots although it includes any sampling and analytical errors. Not surprisingly,
LOI and total $\mathrm{N}$ are also closely related $\left(\mathrm{r}^{2}=.90\right)$ (Figure 3-2). Assuming that LOI closely estimates actual organic matter content and that the conventional $\mathrm{OM} / \mathrm{C}$ ratio of 1.72 is applicable here, the mean $\mathrm{C} / \mathrm{N}$ ratio is $11.7 \pm$ 0.17 (S.E.M.). Such a narrow ratio is consistent with the well-decomposed nature of organic matter in Typic Rendolls, as well as with the several sources of $\mathrm{N}$ in atolls.

Plant

Figure 3-3 describes the uptake of ${ }^{137} \mathrm{Cs}$ in successive crops as affected by the $\mathrm{K}$ and $\mathrm{Na}$ pre-sowing treatments, by the much smaller applications of $\mathrm{K}$ to each crop, and by unusually high annual rainfall during the experimental period. Data in Table 3-2 demonstrate that, with two exceptions, the reductions in ${ }^{137} \mathrm{Cs}$ for the K-treated plots of Crops I to V are significant at probabilities of $5 \%$ or less. For the two exceptions the probabilities are only slightly greater than 5\%. In Crops VI to IX, however, the effects of initial treatment are no longer significant.

For a variety of reasons, the crop components sampled and their maturity differed between crops. Cesium-137 


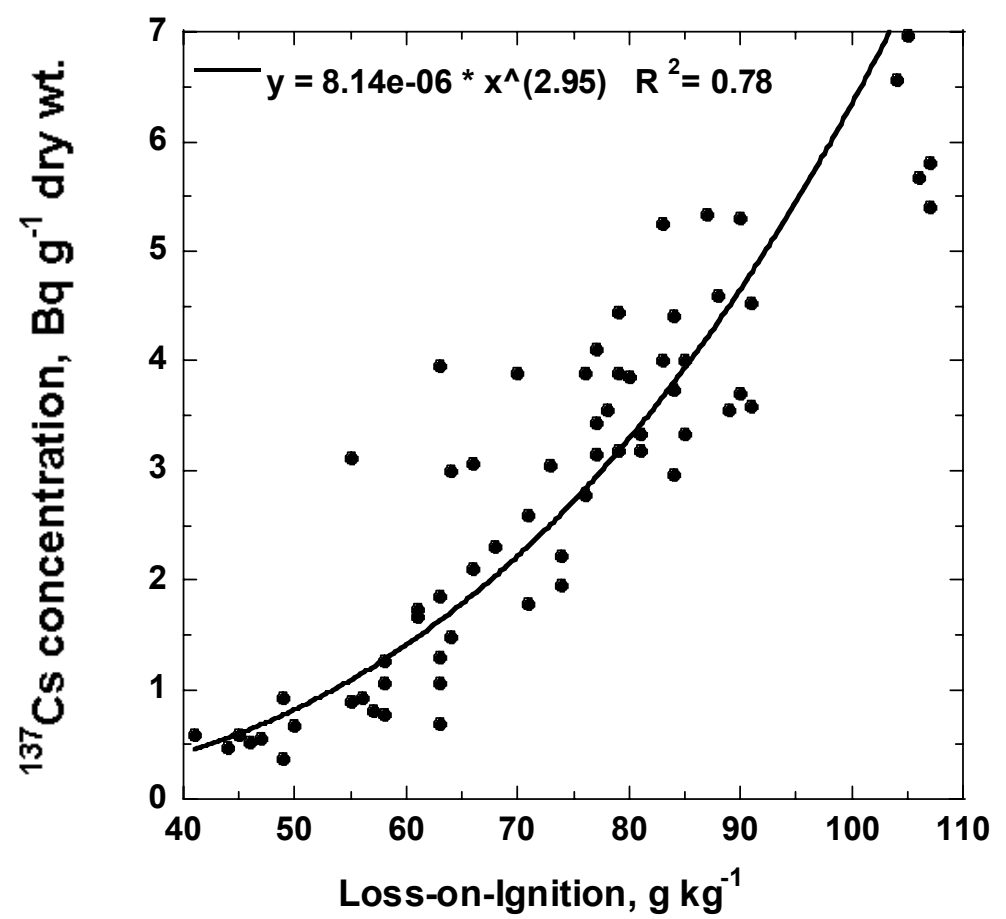

Figure 3-1. Concentration of ${ }^{137} \mathrm{Cs}$ vs lon-on-ignition $\left(430^{\circ} \mathrm{C}\right)$ in soil from sample plots.

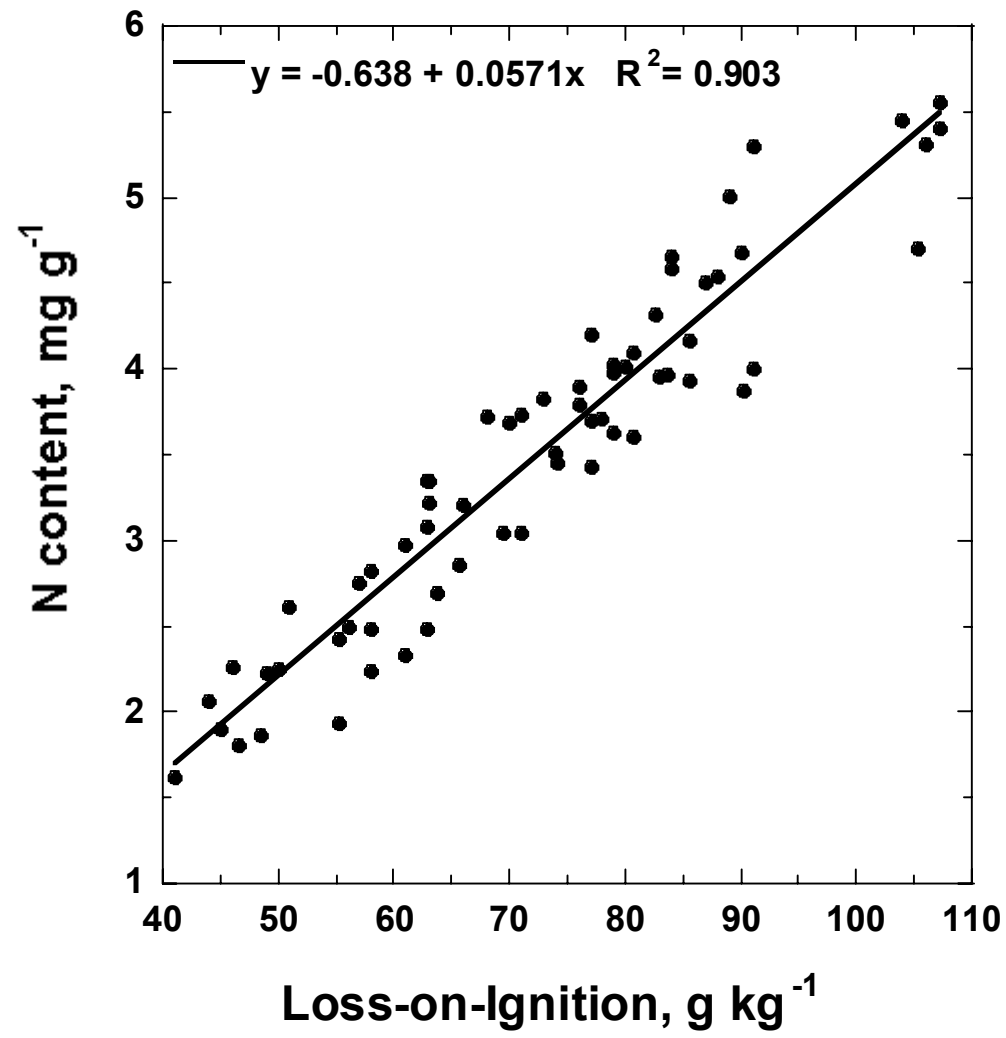

Figure 3-2. Total Kjeldahl nitrogen vs loss-on-ignition $\left(430^{\circ} \mathrm{C}\right)$ in soil from sample plots. 


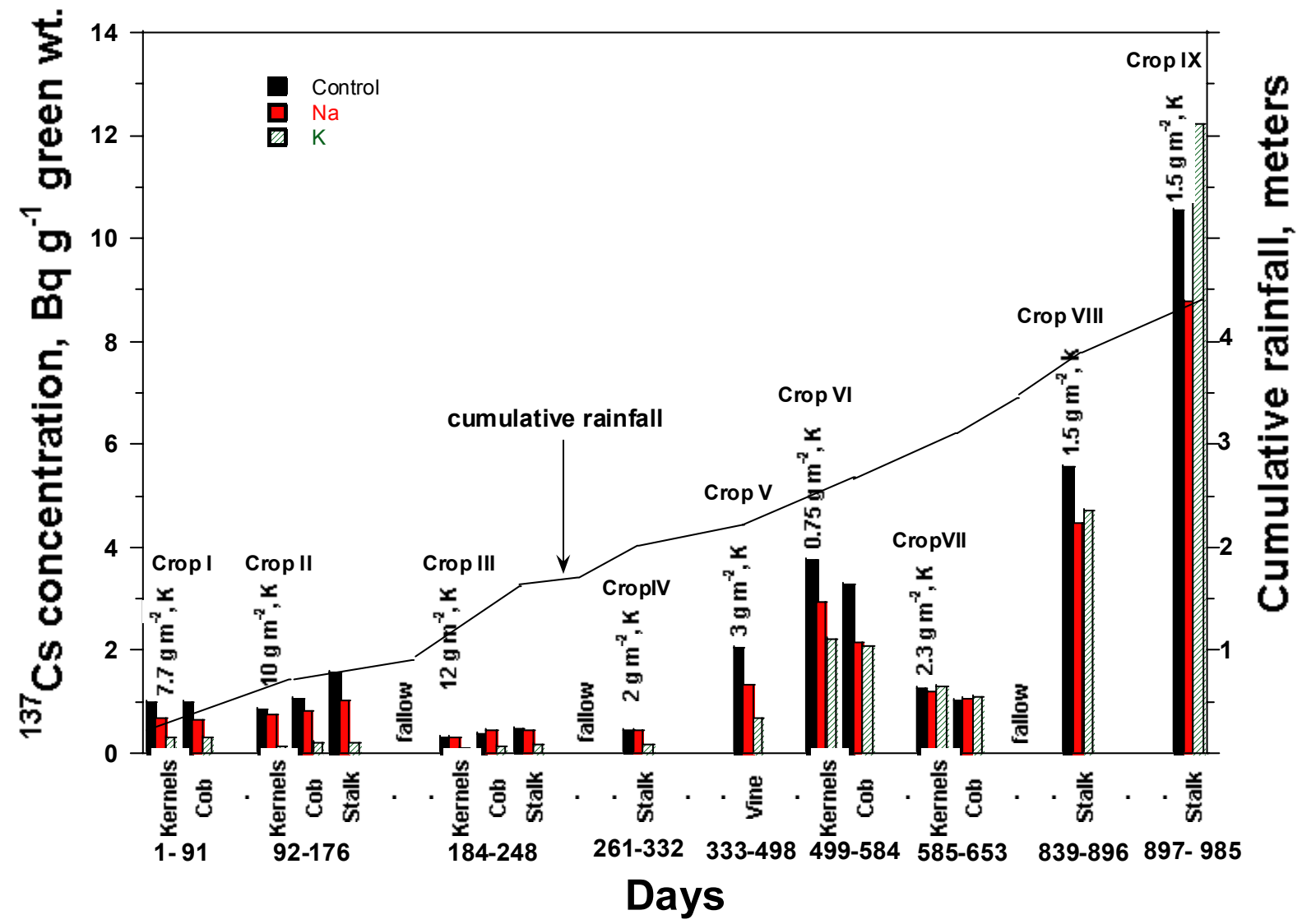

Figure 3-3. Cumulative rainfall and green weight ${ }^{137} \mathrm{Cs}$ concentrations for nine consecutive crops grown with or without large pre-sowing application of $\mathrm{K}$ or $\mathrm{Na}$. Values indicate further addition of to all treatments.

Table 3-2. Significance of treatment differences by Scheffe's test, Crops I-V ${ }^{\text {a }}$ (values are probabilities; mean ${ }^{137}$ Cs concentrations shown in Figure 3-3).

\begin{tabular}{|c|c|c|c|c|c|c|c|c|c|c|}
\hline \multirow[b]{2}{*}{ Comparison } & \multicolumn{2}{|c|}{ I } & \multicolumn{2}{|c|}{ II } & \multicolumn{2}{|c|}{ III } & \multicolumn{2}{|c|}{ IV } & \multicolumn{2}{|c|}{$\mathrm{V}$} \\
\hline & Kernels & Cobs & Kernels & $\overline{\text { Cobs }}$ & Stalks & $\overline{\text { Kernels }}$ & Cobs & $\overline{\text { Stalks }}$ & Stalks & Vines \\
\hline Control vs K & .0016 & .0041 & .0005 & .0002 & $<.0001$ & 0.048 & .053 & .0026 & 0.075 & .0027 \\
\hline Control vs $\mathrm{Na}$ & ns & ns & ns & ns & .015 & ns & ns & ns & ns & ns \\
\hline $\mathrm{K}$ vs $\mathrm{Na}$ & .0530 & ns & .0009 & .0009 & .0002 & .0090 & .0049 & .0024 & 0.023 & ns \\
\hline
\end{tabular}

a No significant differences within Crops VI-IX. 
concentrations in the stalks (stem and leaves) of sweet corn are well correlated with those of other components, however, so any one may serve as an appropriate index. Thus, the linear correlations between kernels or cobs, and the stalks, yield $\mathrm{r}^{2} \mathrm{~s}$ of .87 and .82 for Crop III, and .87 and .71 for Crop IV, respectively. Although only 6 of the 24 plots of sweet potatoes bore harvestable tubers, ${ }^{137} \mathrm{Cs}$ in these vines and tubers were highly correlated: $\mathrm{r}^{2}=.98$.

Maturity usually reduces plant moisture content, and hence increases green weight concentrations in otherwise similar materials. Thus in the over-mature Crop VI, the median green weight moisture contents of kernels and cobs, respectively, were 53 and $65 \%$, as compared with 76 and 78\% in Crop VII (Figure 3-3). Similarly, the median moisture contents of successive sorghum Crops VIII and IX were 81 and $67 \%$, respectively. If expressed on a dry weight basis, however, these values indicate a two-fold difference in water content. Accordingly, the striking difference between the two final crops of sorghum, VIII and IX in Figure 3-3, disappears when expressed on a dry weight basis $\left(\mathrm{Bq} \mathrm{g}^{-1} \pm \sigma\right)$, as indicated below:

\begin{tabular}{lll} 
& VIII & IX \\
\hline Control & $39 \pm 12$ & $43 \pm 15$ \\
$\mathrm{Na}$ & $31 \pm 5$ & $34 \pm 11$ \\
$\mathrm{~K}$ & $32 \pm 10$ & $43 \pm 14$ \\
\hline
\end{tabular}

Nevertheless, Figure 3-3 and Table 3-2 reveal several features of interest. Although this initial application of $\mathrm{Na}$ appears to decrease ${ }^{137}$ Cs in Crops I, II and V, the reduction was significant only for the stalks of Crop II. Thus,
$\mathrm{Na}$ in soil has little, if any, effect on ${ }^{137} \mathrm{Cs}$ uptake.

Uptake of ${ }^{137} \mathrm{Cs}$ by plants that had received no $\mathrm{K}$ is unknown, although it may be inferred from Crops VIII and IX. As subsequently recognized, however, the "maintenance dressings" of K applied to all plots during Crops I, II, and III were so high-7.7.996, and $11.7 \mathrm{~g} \mathrm{~m}^{-2} \mathrm{~K}$ - as to greatly reduce ${ }^{137} \mathrm{Cs}$ concentrations even in the designated controls. Further reductions due to the massive applications of $\mathrm{K}$ before first sowing are evident in Figure 3-3, but are surprisingly small in absolute terms. The strongly curvilinear effects of added $\mathrm{K}$ on ${ }^{137} \mathrm{Cs}$ uptake apparent in Fig 2-3 to 2-6 are again demonstrated here.

Reducing the amount of $\mathrm{K}$ added for "maintenance" resulted in greater ${ }^{137}$ Cs uptakes by crops after Crop IV. Uptake of ${ }^{137} \mathrm{Cs}$ by Crop IV remained low, presumably reflecting residual $\mathrm{K}$ from previous applications, as shown in Figure 2-9A.

From Crop VI onward, however, ${ }^{137} \mathrm{Cs}$ in plants from plots initially treated with $\mathrm{K}$ do not differ from those of the control or $\mathrm{Na}$ treatments. The evident conclusion is that the initial applications of $\sim 300$ to $900 \mathrm{~g} \mathrm{~m}^{-2} \mathrm{~K}$ have been entirely lost from the rooting zone of these plants. Some fraction of this may have been removed by high concentrations in harvested crops. Most of the loss, however, is attributed to the initial leaching followed by high cumulative rainfall-about $2 \mathrm{~m}$ in the first nine or ten months of the study. Hence, additions of $\mathrm{K}$ that exceed root uptake or the limited retention of these calcareous sands are readily lost. Perhaps the only surprising feature is that the residual effects of the pre-sowing application of $K$ have persisted so long, given the high rainfall and competition from $\mathrm{Ca}^{++}$.

\section{Experiment 4: Effects of Stable ${ }^{133} \mathrm{Cs}$ and K Additions on ${ }^{137} \mathrm{Cs}$ in Sorghum}

In a previous pot culture study (Experiment 1) ${ }^{133} \mathrm{Cs}$ applied at rates of around $10 \mathrm{mg} \mathrm{kg}^{-1}$ reduced ${ }^{137} \mathrm{Cs}$ in pearl millet and tomato when no $\mathrm{K}$ was added. As in most pot cultures, the volume of soil was limited and soil moisture contents never approached the wilting point.
The study reported here undertook to determine whether small applications of ${ }^{133} \mathrm{Cs}$ might prove equally effective in plants grown in the normal field environment of atolls. Small applications were indicated because an early exploratory study with 15 -year old coconut palms demonstrated that ${ }^{133} \mathrm{Cs}$ applied at the 
rate between 2.0 and $2.8 \mathrm{~g} \mathrm{~m}^{-2}$ severely damaged the foliage and effectively ended nut production for a decade or more (Robison, unpublished data).

\section{Materials and Methods}

The soil was a Typic Rendoll, similar to that described in Experiment 2. The site had been cleared from an 18-20 year old coconut grove about four years previously. Two annual crops designated (LOM) had been grown; the first of mixed vegetable species with a total addition of $12.4 \mathrm{~g} \mathrm{~m}^{-2} \mathrm{~K}$; the second of sorghum without added $\mathrm{K}$. This was followed by $31 / 2$ years in grass and weed fallow before the present study. The original $450 \mathrm{~m}^{2}$ area had been divided into 60 plots, each $3.5 \times 2.1$ meters. The soil of each was sampled before the present study, but ${ }^{137} \mathrm{Cs}$ data are available for only two transects across 10 or 11 contiguous plots of the original study. One transect, consisting of six separate cores, 4.5 $\mathrm{cm}$ diameter $\times 50 \mathrm{~cm}$ deep on each plot, provided an estimate of $0.46 \pm 0.9 \mathrm{~Bq} \mathrm{~g}^{-1}{ }^{137} \mathrm{Cs}$ or $276 \mathrm{kBq} \mathrm{m}^{-2}$. This is taken as an approximate inventory of the total present. The other transect, based on composites of four cores, $0-5 \mathrm{~cm}$ deep per plot, revealed a mean content of $3.9 \pm 1.8 \mathrm{~Bq} \mathrm{~g}^{-1}$ in the uppermost surface. Calculation based on this mean indicates 176 $\mathrm{kBq} \mathrm{m}^{-2}$, or $64 \%$ of the total inventory; the coefficient of variation, however, was $45 \%$. (Bulk densities assumed were $1.2 \mathrm{Mg} \mathrm{m}^{3}$ for the $0-50$ cm depth and 0.9 for $0-5 \mathrm{~cm}$.)

The center block of the original experiment, consisting of four tiers each of five plots, was used for the present study. One of the 20 plots was partly occupied by an old coconut stump and was deleted. The vegetation was burned and root clumps removed by shallow grubbing.

The study design was factorial with two levels of $\mathrm{K}, 0$ and $20 \mathrm{~g} \mathrm{~m}^{-2}$, and five levels of ${ }^{133} \mathrm{Cs}, 0,0.001,0.01,0.10$, and $1.0 \mathrm{~g} \mathrm{~m}^{-2}$. Both elements were applied as chlorides in dilute solution. Potassium treatments were randomized over the four tiers of plots, and Cs over the plots within each tier. The $20 \mathrm{~g} \mathrm{~m}^{-2} \mathrm{~K}$ was equivalent to $510 \mathrm{~m} \mathrm{~mol} \mathrm{~m}^{-2}$, and $1.0 \mathrm{~g}$ ${ }^{133} \mathrm{Cs}$ to $7.5 \mathrm{mmol} \mathrm{m}^{-2}$. The mean content of ${ }^{137} \mathrm{Cs}$ in the upper $5 \mathrm{~cm}$ can be estimated as about $4.4 \times 10^{-10} \mathrm{mmol} \mathrm{m}^{-2}$.

Five successive crops of sorghum (Sorghum bicolor) cv Cargill \#40, were grown on each plot.
Phosphorus, as treble superphosphate, was applied in a band to Crops I, III, and V at the rate of $2 \mathrm{~g} \mathrm{~m}^{-2}$ inasmuch as the area had been heavily treated with $\mathrm{P}$ in the earlier LOM experiment. Nitrogen was added to all plots at total rates from 6 to $14 \mathrm{~g} \mathrm{~m}^{-2}$ per crop, usually in 1 or 2 applications.

Potassium was applied at the sowing of Crops I, III, and V, and ${ }^{133} \mathrm{Cs}$ at the sowing of Crops I, and V (Table 4-1). Multiple applications of dilute solutions of $\mathrm{K}$ or ${ }^{133} \mathrm{Cs}$ were made to increase uniformity of distribution.

The plots were sown with soaked seed in rows $60 \mathrm{~cm}$ apart, and later thinned to an average spacing of 15 to $20 \mathrm{~cm}$ in the row. At harvest the entire plant, including any seed, was cut 7 to $8 \mathrm{~cm}$ above the soil, and any lower leaves in contract with the soil were discarded. Harvested samples were weighed, frozen and shipped to LLNL for analysis. Potassium in Crops III and IV was determined by XRF fluorescence.

\section{Results and Discussion}

The five crops varied in duration of the growth period and in periodic rainfall (Table 4-1), in green mass production (Figure 4-1), and in relative maturity as indicated by dry matter content (Table 4-1). Thus, the effects of potassium on growth are best compared within individual crops (Figure 4-1). The increases due to potassium are evident despite the variability between tiers.

The small applications of ${ }^{133} \mathrm{Cs}$ were not expected to influence growth and evidently did not.

ANOVAs detected neither consistent nor significant effects of ${ }^{133} \mathrm{Cs}$ on ${ }^{137} \mathrm{Cs}$ content or ${ }^{133} \mathrm{Cs} \times \mathrm{K}$ interactions even in Crops I and V. This is contrary to findings in a pot culture study (Experiment 1) where the application rate approximated the highest rate of the present study. Plants growing in the field exploit a much greater volume of soil and far greater soil heterogeneity than do plants in pot cultures, which may account for the differences in findings.

The three additions of K, with carryover to the following ratoon crops, markedly reduced ${ }^{137} \mathrm{Cs}$ in all crops. An ANOVA demonstrated that in Crop I, however, the difference in ${ }^{137} \mathrm{Cs}$ 
Table 4-1. Treatments, growth features, and dry matter content of tops at harvest for five successive crops of sorghum.

\begin{tabular}{|c|c|c|c|c|c|}
\hline \multirow[b]{2}{*}{$\begin{array}{c}\text { Crop } \\
\text { no. }\end{array}$} & \multicolumn{2}{|c|}{ Treatments } & \multicolumn{2}{|c|}{ Growth period } & \multirow{2}{*}{$\begin{array}{c}\text { Dry matter } \\
\text { at harvest } \\
\% \mathrm{~b}\end{array}$} \\
\hline & $\begin{array}{c}\mathrm{K} \\
\mathrm{g} \mathrm{m}^{-2}\end{array}$ & $\begin{array}{l}{ }^{133} \mathrm{Cs} \\
\mathrm{g} \mathrm{m}^{-2}\end{array}$ & $\begin{array}{c}\begin{array}{c}\text { Length } \\
\text { days }\end{array}\end{array}$ & $\begin{array}{l}\text { Periodic rainfall } \\
\mathrm{cm}\end{array}$ & \\
\hline I-seeded & 0 or 20 & .001 to 1.0 & 84 & 38 & $19 \pm 0.7$ \\
\hline II-ratoon & 0 & 0 & 88 & 61 & $20 \pm 1.4$ \\
\hline III-seeded & 0 or 20 & 0 & 100 & $21^{\mathrm{a}}$ & $33 \pm 4.9$ \\
\hline IV-ratoon & 0 & 0 & 46 & 17 & $16 \pm 1.3$ \\
\hline V-seeded & 0 or 20 & 001 to1.0 & 90 & 56 & $20 \pm 1.3$ \\
\hline
\end{tabular}

a Seedlings watered, days 1 to 11.

b Mean $\pm \sigma, \mathrm{n}=9$

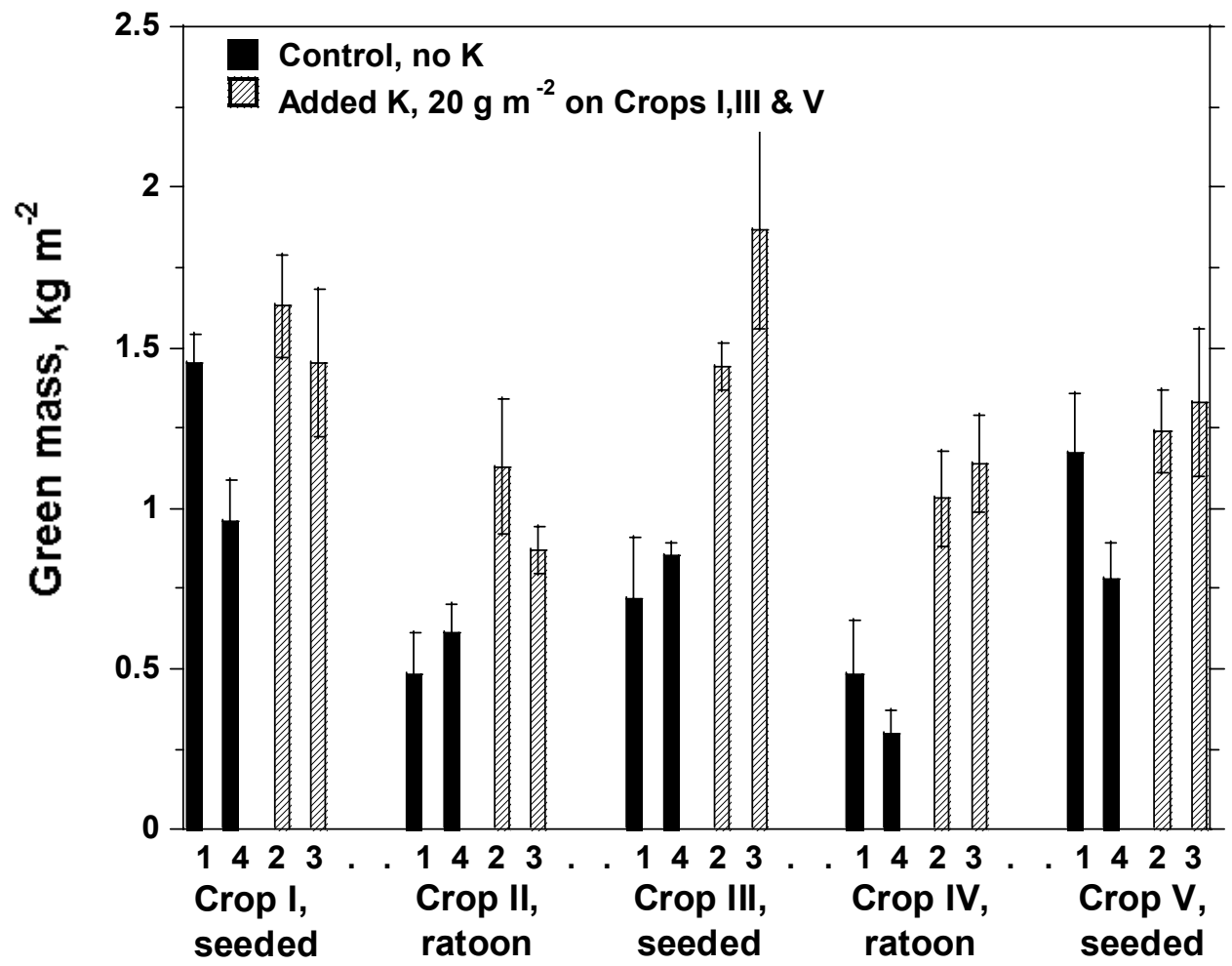

Figure 4-1. Green mass of sorghum for five successive crops with and without added K.

associated with added $\mathrm{K}$ did not reach even the 0.10 level of probability (Table $4-2)$. The differences were highly significant in the four subsequent crops. The lack of a significant difference for Crop I reflects the wide range in ${ }^{137}$ Cs concentrations of the plants on individual plots. Plants from the untreated controls ranged from 23 to $70 \mathrm{~Bq} \mathrm{~g}^{-1}$, dry weight (mean, $41 \pm 19$ ), whereas those from the K-treated plots ranged from 16 to $42 \mathrm{~Bq} \mathrm{~g}^{-1}$ (mean, $27 \pm 8$ ). Such variation is not wholly random, but appears associated with soil and/or crop root systems in these small plots (harvested area $2.65 \mathrm{~m}^{2}$ ). Thus, both ${ }^{137} \mathrm{Cs}$ and $\mathrm{K}$ concentrations in plants from individual Control plots of Crop II are linearly correlated with those from Crop I, with $\mathrm{r}^{2}=.89$ 
Table 4-2. ANOVA: Effect of potassium application on least squares ${ }^{137} \mathrm{Cs}$ mean concentrations, with probabilities.

\begin{tabular}{cccc}
\hline \multirow{2}{*}{$\begin{array}{c}\text { Crop } \\
\text { no. }\end{array}$} & \multicolumn{3}{c}{$\begin{array}{c}\text { K treatment } \\
137 \mathrm{Cs} \mathrm{Bq} \mathrm{g}^{-1}, \mathrm{dry} \text { wt }\end{array}$} \\
\cline { 2 - 3 } Control & $+\mathrm{K}$ & $\mathrm{Pr}>[\mathrm{t}]$ \\
\hline I & 41 & 27 & $\mathrm{~ns}$ \\
II & 38 & 12 & .0072 \\
III & 34 & 3.7 & .0002 \\
IV & 34 & 5.8 & .0003 \\
V & 22 & 3.8 & .0017 \\
\hline
\end{tabular}

and .61, respectively. Correlations between Cs and $\mathrm{K}$ within crops varies; thus $\mathrm{r}^{2}=.19$ for Crop I, and .55 for Crop II.

The wide range of ${ }^{137} \mathrm{Cs}$ displayed in the Crop I Control was not suppressed by addition of $20 \mathrm{~g} \mathrm{~m}^{2} \mathrm{~K}$ to the treated plots (Figure 4-2). Nevertheless, the amount of $\mathrm{K}$ remaining was sufficient to reduce ${ }^{137} \mathrm{Cs}$ in the following Crop II although no more $\mathrm{K}$ was added, suggesting that only a small fraction of the $20 \mathrm{~g} \mathrm{~m}^{2} \mathrm{~K}$ actually reached the roots of Crop I. This is born out by comparison of the amounts of $\mathrm{K}$ recovered at harvest of the Control, $1.8 \pm 0.6 \mathrm{~g}$ $\mathrm{m}^{2} \mathrm{I}$, vs $4.1 \pm 1.0$ for the K-treated plants. Rainfall during the cropping period (Table 4-1) was too slight for deep leaching, suggesting that at least $16 \mathrm{~g} \mathrm{~m}^{2} \mathrm{~K}$ remained at the beginning of Crop II.

Failure of plants on the K-treated plots to absorb more K likely is due to prolonged dryness of the surface layer containing most of the added K. Potassium, together with added ${ }^{133} \mathrm{Cs}$, was added in solution by multiple applications over the treated areas to maximize distribution. This also maximized contact with the highly organic surface soil. Rainfall in the 17 days after application totaled $13 \mathrm{~cm}$, sufficient to move unattached $\mathrm{K}$ below the extreme surface. Total rainfall in the next month, however, was only $4.3 \mathrm{~cm}$, so that much of the new sorghum root system would have developed below the uppermost surface. Presumably, this accounts for the small uptake of added $\mathrm{K}$ and limited reduction in ${ }^{137} \mathrm{Cs}$ absorption.

Subsequent rains may have moved $\mathrm{K}$ deeper. Its retention in the soil and root systems of sorghum throughout the growing period, however, is demonstrated by the greater $\mathrm{K}$ concentration and marked reduction of ${ }^{137} \mathrm{Cs}$ in the following ratoon crop (Figure 4-2).

Figures 4-2, 4-3, and 4-4 repeat the response pattern seen in earlier studies: a rapid decrease in ${ }^{137} \mathrm{Cs}$ concentration as $\mathrm{K}$ concentration increases above some minimum, whatever the source, followed by progressively smaller decreases as $\mathrm{K}$ increases further.

Figures 4-2 and 4-3 reveal the relatively large carryovers of $\mathrm{K}$ from seeded Crops I and III, which received $K$, to their respective ratoon Crops II and IV, which did not. This accounts for continued low ${ }^{137} \mathrm{Cs}$ values in the ratoon crops. The amount of this carryover can be estimated thus: $20 \mathrm{~g} \mathrm{~m}^{-2} \mathrm{~K}$ was applied to the treated plots of Crop III. Rainfall during its growth was only $21 \mathrm{~cm}$ so leaching losses were negligible. Total $\mathrm{K}$ removed in the Crop III harvest from treated plots averaged $13.3 \mathrm{~g} \mathrm{~m}^{-2}$, versus only 1.9 from the untreated plots. Hence, nearly half of the total available $\mathrm{K}$ remained in the soil and sprouting root stocks to sustain ratoon Crop IV on these plots.

Crop IV was harvested prematurely after only 46 days and $17 \mathrm{~cm}$ of rainfall. The harvest from its treated plots contained $4.5 \mathrm{~g} \mathrm{~m}^{-2} \mathrm{~K}$, indicating that some of the initial $20 \mathrm{~g} \mathrm{~m}^{-2}$ still remained onsite. As already noted, an appreciable carryover was manifested by reduced ${ }^{137} \mathrm{Cs}$ in Crop II.

The probability or amount of carryover obviously depends on the quantity of K added to the previous crop and the extent of rainfall leaching. In the present instances, the $20 \mathrm{~g} \mathrm{~m}^{-2} \mathrm{~K}$ additions to Crops I and III were large relative 


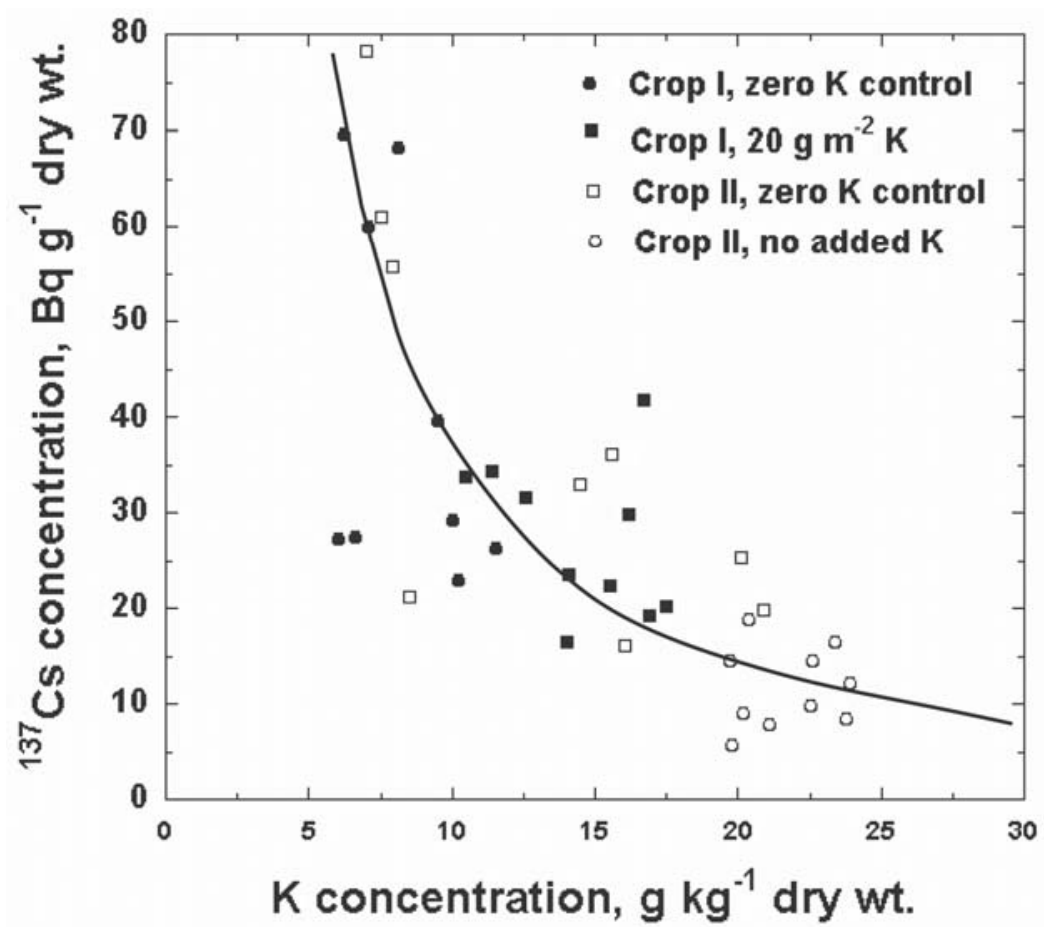

Figure 4-2. Association between ${ }^{137} \mathrm{Cs}$ and $\mathrm{K}$ concentrations in sorghum, Crops I and II.

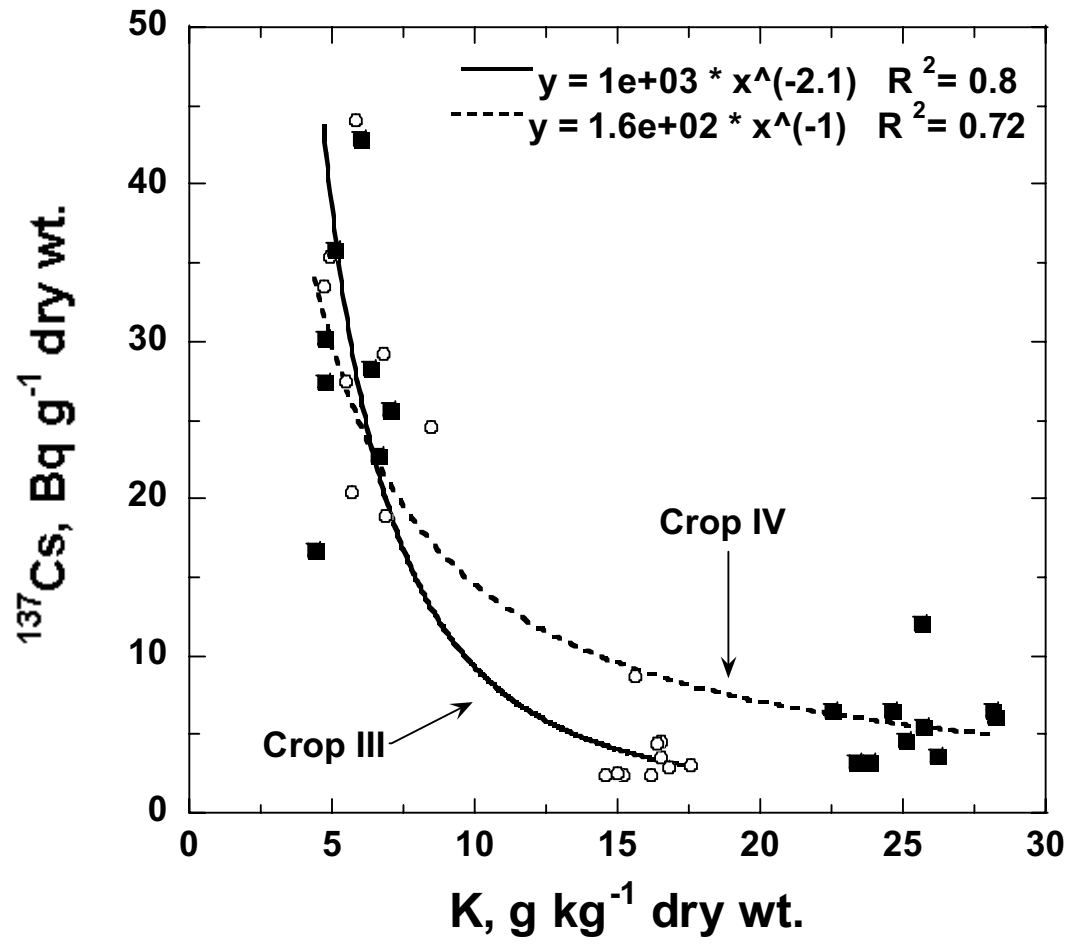

Figure 4-3. Correlation between ${ }^{137} \mathrm{Cs}$ and $\mathrm{K}$ concentrations in sorghum, Crops III and IV. 


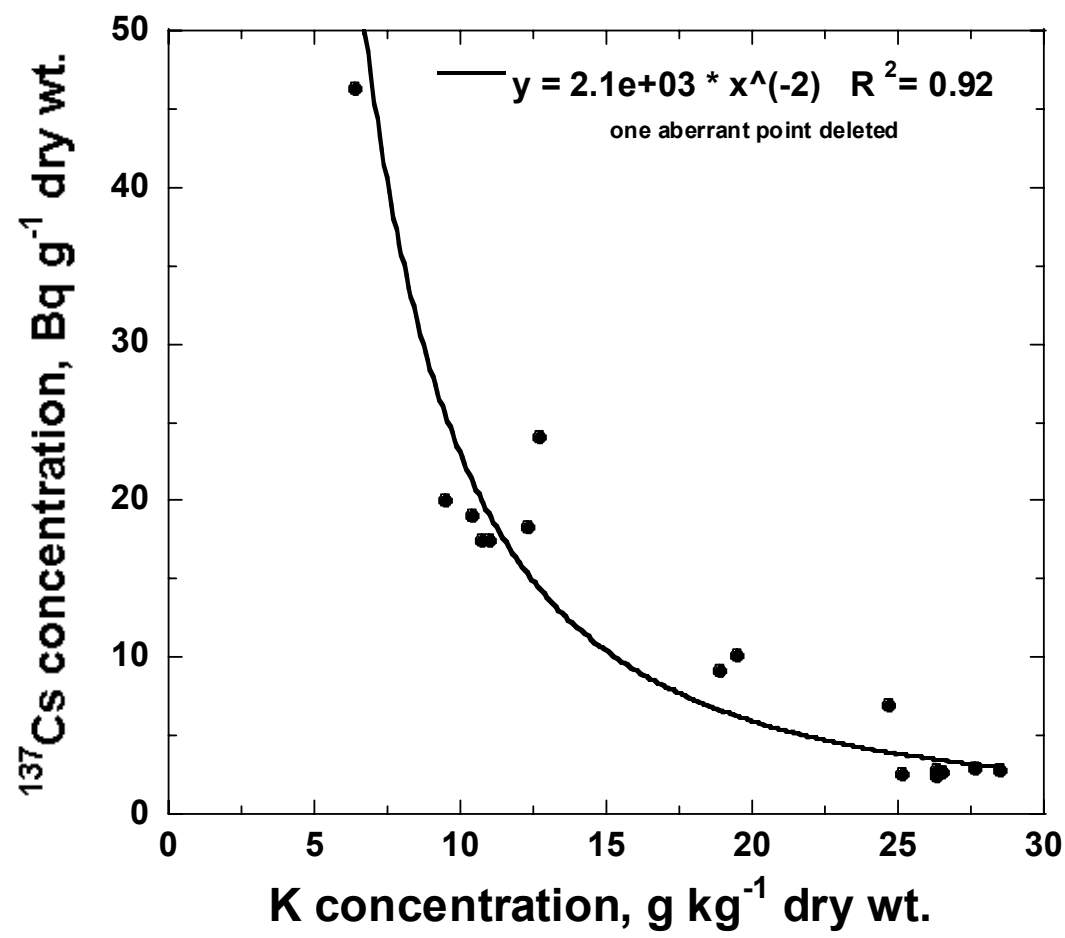

Figure 4.4. Correlation between ${ }^{137} \mathrm{Cs}$ and $\mathrm{K}$ concentrations in sorghum, Crop V.

to plant uptake, and the periodic rainfalls were moderate or low relative to potential evapotranspiration in this climate. As indicated by Bikini weather records and in Experiment III, much greater rainfalls sometimes occur.

Cesium-137 concentrations from the untreated plots were similar in the first three crops and thereafter decreased from a mean of $10.6 \pm 4.3$ in Crop III to $4.8 \pm 2.1 \mathrm{~Bq} \mathrm{~g}^{-1}$, green weight, in Crop IV (dry weight values are in Table 4-2). This suggests that repeated harvests may lower the fraction of soil ${ }^{137} \mathrm{Cs}$ available for short-term uptake. Cesium-137 removed in the five harvests from the plots not treated with $\mathrm{K}$ totaled $29 \mathrm{k} \mathrm{Bq} \mathrm{m}^{-2}$, about $10 \%$ of the previously estimated soil inventory, $276 \mathrm{kBq} \mathrm{m}^{-2}$, preharvest. These amounts compare with those from a nearby study (Experiment 2) where the post-harvest inventory was $211 \pm 78 \mathrm{kBq} \mathrm{m}^{-2}$, and removal in five grain crops plus one of sweet potato tubers had totaled $10.4 \mathrm{kBq} \mathrm{m}^{-2}$. The latter value, however, was influenced by very low yields of some untreated crops, as well as unmeasured removals in earlier crops.

\section{Experiment 5: Effect of Applied K on ${ }^{137} \mathrm{Cs}$ and K Concentrations in Sorghum}

The purpose of this study at its beginning was a better estimate of ${ }^{137} \mathrm{Cs}$ removal from soil by successive crops of a single species. Four successive crops of sorghum were grown, but plant yields were highly variable, both within and between treatments. Thus, the original purpose could not be achieved and the study was abandoned. The effects of added $\mathrm{K}$ on ${ }^{137} \mathrm{Cs}$ concentration in plants, however, were both well marked and consistent despite yield variations. These results amplify those obtained from other experiments in which reduced ${ }^{137} \mathrm{Cs}$ concentration after $\mathrm{K}$ treatment was commonly associated with increased plant yield. 


\section{Methods and Materials}

The study site is directly adjacent to that of Experiment 4 . The soil is similar except that irregular portions of Experiment 5 have a lesser depth of dark surface soil, presumably due to scraping two decades or earlier. Sites of the two experiments had been replicate blocks of an experiment (LOM) six years previously, and preparation for the two present studies was identical. A total of $10.4 \mathrm{~g} \mathrm{~m}^{-2} \mathrm{~K}$ had been applied to all plots of the previous study. This was followed by a harvested crop of sorghum that received no fertilizer, and then by nearly three years of grass and weed fallow. Annual rainfall during that period ranged between 147 and $174 \mathrm{~cm}$. Hence, no more than a fraction of the earlier K application would have remained in the soil when the present study began.

The description of Experiment 4 noted that two transects of soil samples extended over the site of Experiment 4 and much of 5 . The mean value of ${ }^{137} \mathrm{Cs}$ in the $0-50 \mathrm{~cm}$ deep samples was $0.46 \pm .09$ (SD) Bq g-1 or approximately $276 \mathrm{kBq}$ $\mathrm{m}^{-2}$. A second transect of the $0-5 \mathrm{~cm}$ depth, not wholly comparable with the first transect, averaged $3.92 \pm 1.79$ (SD) Bq g ${ }^{-1}{ }^{137} \mathrm{Cs}$ in that shallow depth.

The design of Experiment 5 consisted of three levels of $\mathrm{K}$, with three replications on $3.25 \times 4.20 \mathrm{~m}$ plots. Only a center $6.6 \mathrm{~m}^{2}$ subplot of each was harvested. All crops were sorghum (Sorghum bicolor, Cargill cv 40) in rows $50 \mathrm{~cm}$ apart. Germinated seedlings were thinned to a 15 to $20 \mathrm{~cm}$ spacing within the row. Each of the two seeded crops was followed by a ratoon crop.

Superphosphate had been added to $75 \%$ of the plots of the earlier LOM study at the rate of $20 \mathrm{~g} \mathrm{~m}^{-2}$. Untreated plots were later brought to that level. Accordingly, additions to the present study were relatively low, $4 \mathrm{~g} \mathrm{~m}^{-2} \mathrm{P}$, placed in trenches below the seeded rows. For Crops I and II, nitrogen was added as urea in solution at a total rate of $20 \mathrm{~g} \mathrm{~m}^{-2} \mathrm{~N}$, either in trenches or watered in. Some volatilization loss was expected. Applications were divided, and applied at the same time as K (Table 5-1). For Crop III, $\mathrm{N}$ was applied as a single broadcast application of $\mathrm{NaNO}_{3}$ at the rate of $9 \mathrm{~g} \mathrm{~m}^{-2} \mathrm{~N}$.

Potassium in solution was broadcast, with split applications as shown in Table 5-1. As noted, the total amounts of both $\mathrm{K}$ and $\mathrm{N}$ for
Crop III were applied at sowing, inasmuch as rainfall during the oncoming dry season was expected to be much less than potential evapotranspiration (ET). The following ratoon, Crop IV, received no fertilizer to allow estimating the residual effect of previous $\mathrm{K}$ applications.

The entire above-ground plants were harvested at various stags of maturity (Table 5-1) and sent frozen to LLNL for analyses. Cesium-137 was determined on all. Potassium was analyzed by XRF.

\section{Results and Discussion}

Figures 5-1 to 5-4 display the respective responses of the four successive crops, either to addition of $\mathrm{K}$ to the soil, or to the resulting $\mathrm{K}$ concentration in plants. To some extent, the two independent variables are surrogates for each other. Use of either demonstrates an abrupt decline in ${ }^{137} \mathrm{Cs}$ in plants as availability of $\mathrm{K}$ increases above near-minimal levels, provided allowance is made for possible carryover of $\mathrm{K}$ from one crop to the next.

Thus, although ratoon Crop IV received no $\mathrm{K}$ addition, the reduction in ${ }^{137} \mathrm{Cs}$ follows the same hyperbolic pattern as in Crop III (Figures 5-2 and 5-4). The two crops are dissimilar in age and maturity (Table 5-1). Rainfall during the 98day growth period of Crop III averaged only 2.1 $\mathrm{mm}$ per day, with a maximum 7-day total of 62 $\mathrm{mm}$. Hence there could have been little or no leaching of unabsorbed $\mathrm{K}$ from the surface layer. Graphs of ${ }^{137} \mathrm{Cs}$ variation in these two crops are similar, however, whether the independent variable is the amount of $\mathrm{K}$ added to soil or $\mathrm{K}$ concentration in the plant (Figures 5-2 vs 5-3). The relatively high concentrations of $\mathrm{K}$ in plants from the Medium and High treatments of Crop IV confirm the carryover of $\mathrm{K}$ from Crop III. The similarity of the ${ }^{137} \mathrm{Cs} / \mathrm{K}$ concentration graphs in Figure 5-4, however, implies greater carryover than existed. Calculated removal of $\mathrm{K}$ in the harvest of Crop III from the Medium treatment was $5.1 \mathrm{~g} \mathrm{~m}^{-2}$, whereas harvests of the younger, smaller, more succulent ratoon Crop IV from the same plots removed only $1.4 \mathrm{~g} \mathrm{~m}^{-2}$. The sum slightly exceeds the $6.0 \mathrm{~g} \mathrm{~m}^{-2}$ added to Crop III (Table 5-1). This, together with the high $\mathrm{K}$ concentration still present in Crop IV, suggests that some $\mathrm{K}$ still remained from 
Table 5-1. Potassium treatment, growth conditions, and dry matter content of tops at harvest for four successive crops of sorghum.

\begin{tabular}{|c|c|c|c|c|c|c|c|}
\hline Crop & $\begin{array}{l}\frac{\mathrm{Tc}}{\text { Zero }} \\
\mathrm{g} \mathrm{m}^{-2}\end{array}$ & 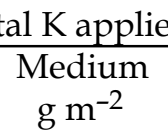 & $\begin{array}{l}\text { High } \\
\mathrm{g} \mathrm{m}^{-2}\end{array}$ & $\begin{array}{l}\text { aNumber } \\
\text { of } \\
\text { applications }\end{array}$ & $\begin{array}{l}\text { Cropping } \\
\text { period } \\
\text { days }\end{array}$ & $\begin{array}{l}\text { Periodic } \\
\text { rainfall } \\
\mathrm{cm}\end{array}$ & $\begin{array}{c}\text { Dry matter at } \\
\text { harvest } \\
\% \mathrm{~b}\end{array}$ \\
\hline I & 0 & 12 & 36 & 4 & 81 & 45 & $17 \pm 2.7$ \\
\hline $\begin{array}{l}\text { II, ratoon } \\
\text { (Fallow) }\end{array}$ & 0 & 8 & 24 & 3 & $\begin{array}{c}87 \\
(23)\end{array}$ & $\begin{array}{c}64 \\
(12)\end{array}$ & $\begin{array}{l}18 \pm 0.9 \\
-\end{array}$ \\
\hline III & 0 & 6 & 18 & 1 & 98 & 21 & $36 \pm 3.4$ \\
\hline $\mathrm{IV}$, ratoon & 0 & 0 & 0 & 0 & 46 & 18 & $16 \pm 1.4$ \\
\hline
\end{tabular}

a Number of K applications made to High treatment plots. Nitrogen applied equally to all plots at same intervals.

b Mean $\pm \sigma ; \mathrm{n}=9$.

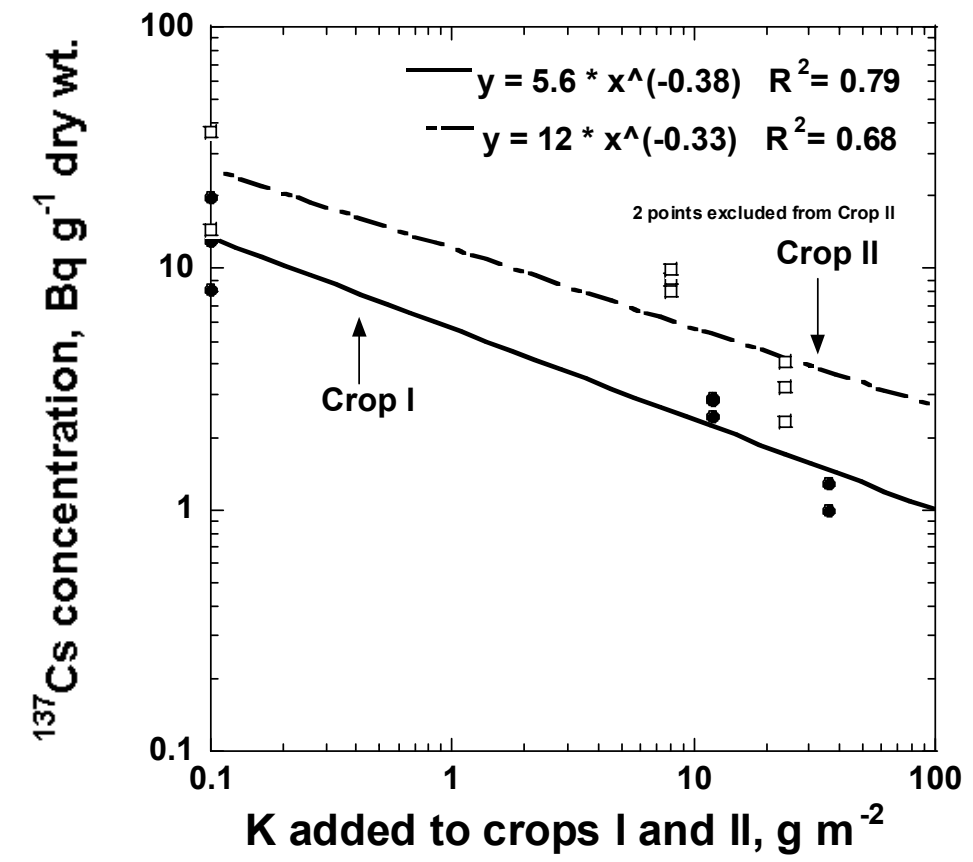

Figure 5-1. Correlation between ${ }^{137} \mathrm{Cs}$ in plants and $\mathrm{K}$ added to soil, Crops I and II.

previous additions to Crops I and II on the same plots.

The results confirm those of Experiments 2 and 4 in demonstrating how effectively residual $\mathrm{K}$ from previous crops in soil or rootstocks can reduce ${ }^{137} \mathrm{Cs}$ in a following crop that received no K. 


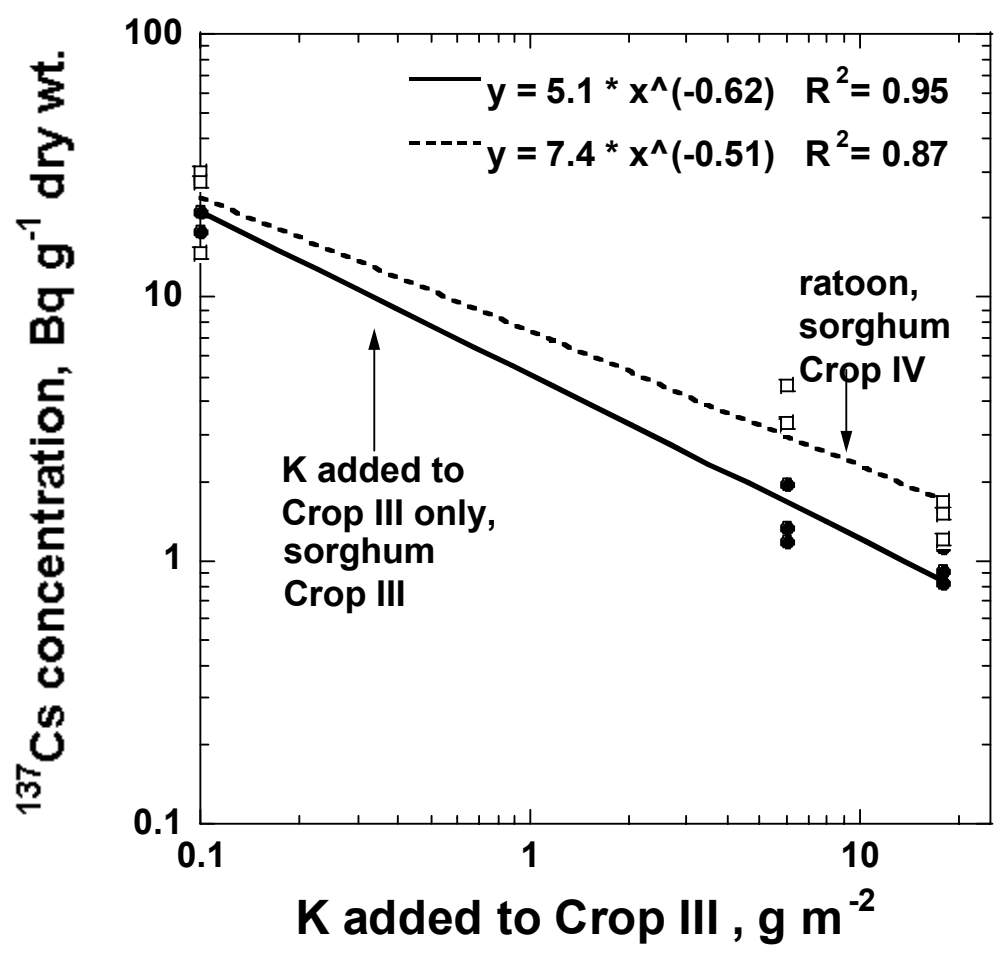

Figure 5-2. Correlation between ${ }^{137} \mathrm{Cs}$ in plants and $\mathrm{K}$ added to soil, Crops III and IV.

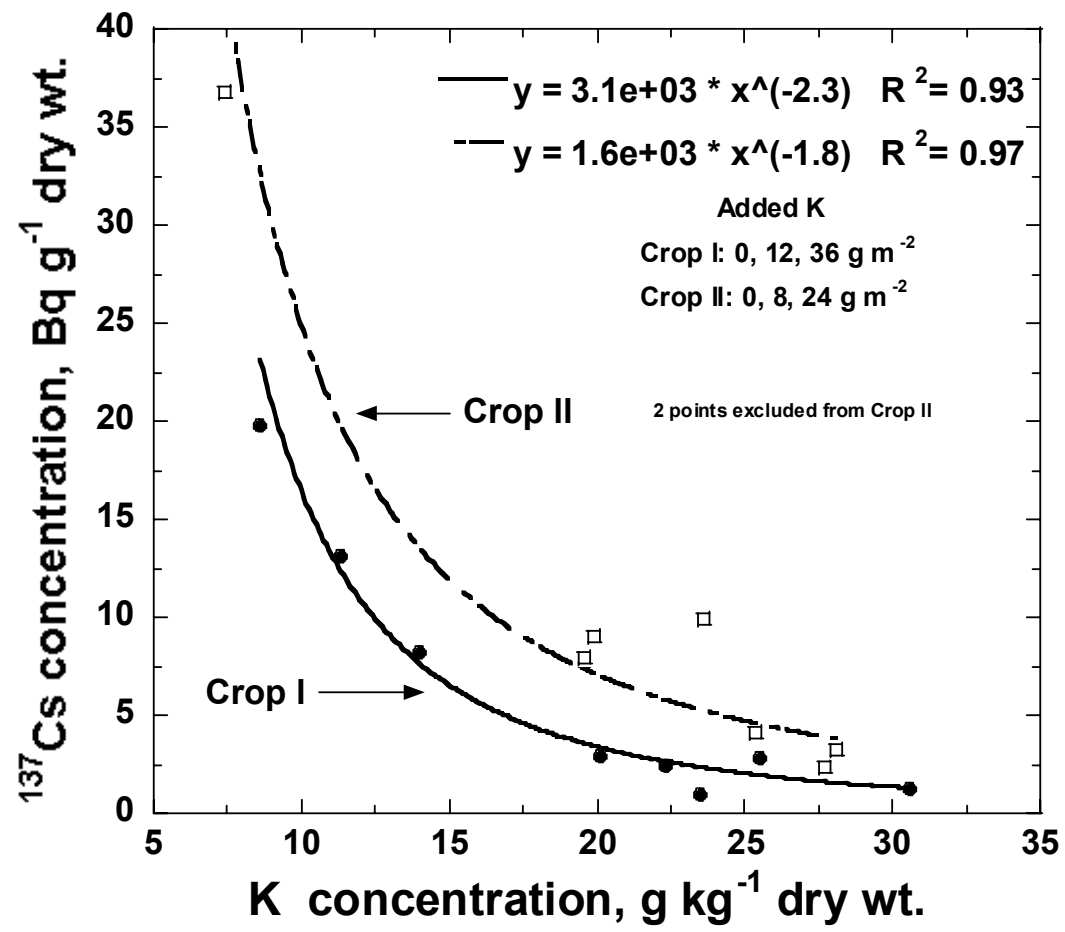

Figure 5-3. Correlation between ${ }^{137} \mathrm{Cs}$ and $\mathrm{K}$ concentrations in sorghum, Crops I and II. 


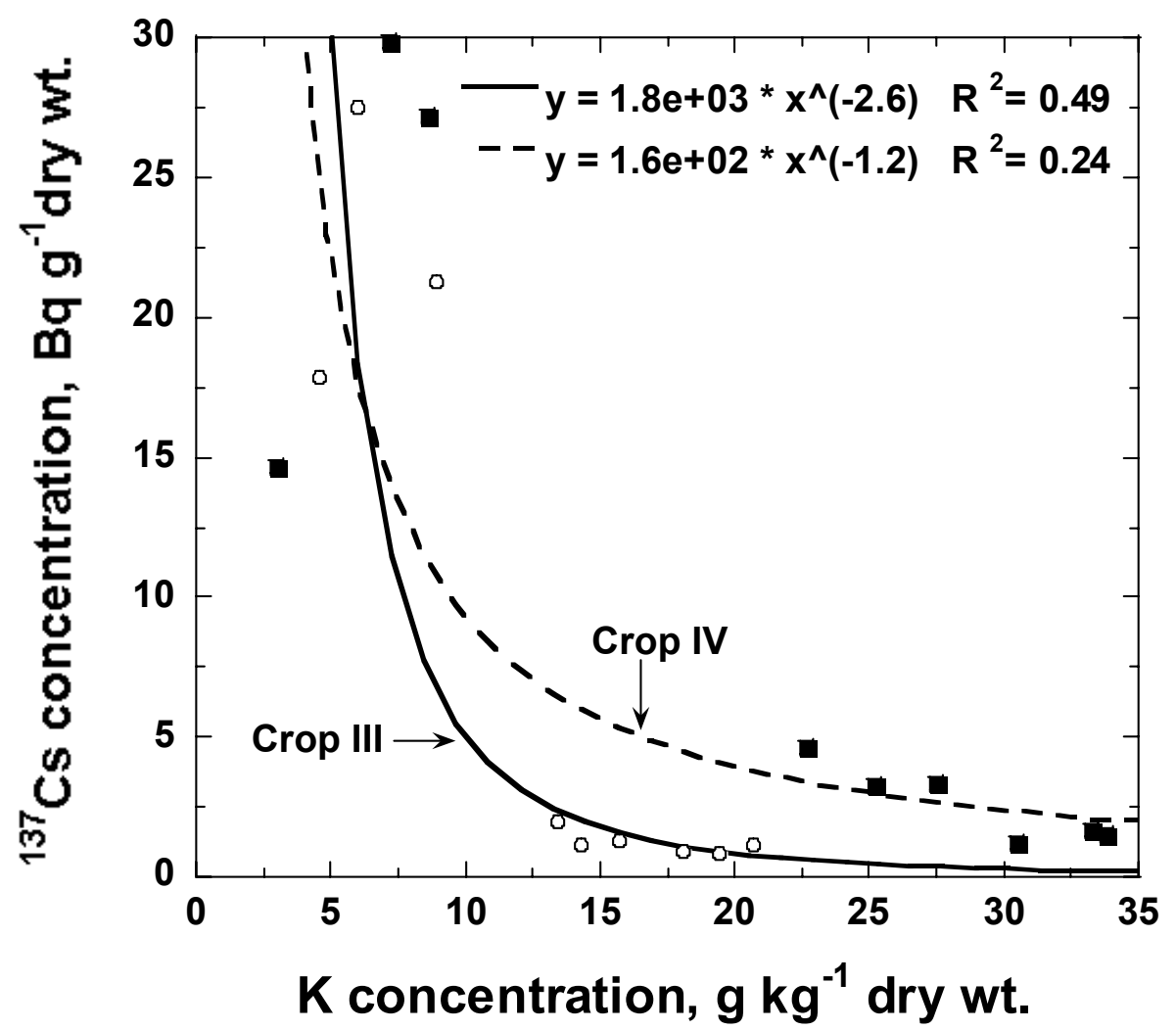

Figure 5-4. Correlation between ${ }^{137} \mathrm{Cs}$ and $\mathrm{K}$ concentrations in sorghum, Crops III and IV.

\section{Experiment 6: Spatial Distribution of Applied Potassium and the Uptake of ${ }^{137} \mathrm{Cs}$ by Plants}

It is now abundantly clear that potassium applied to atoll soils reduces plant uptake of ${ }^{137}$ Cs. But, how should that K be distributed spatially over the root system to maximize its effectiveness, and what would such findings suggest about how K exerts its suppressive effect?

An earlier explanation for this suppressive effect was that competition between ${ }^{137} \mathrm{Cs}$ and $\mathrm{K}$ in the soil solution determines root uptake. Such competition may be consequential in some solution cultures where concentrations are far greater than in the field. On Bikini Island, however, concentrations of ${ }^{137} \mathrm{Cs}$ in the $0-10 \mathrm{~cm}$ depth of soil average around $10^{-12}$ to $10^{-11} \mathrm{~mol}$ $\mathrm{kg}^{-1}$ soil, and diminish with depth. Only 5 to $10 \%$ of the total soil inventory seems available for plant uptake in a single year (Table 1-3). In contrast, exchangeable $\mathrm{K}$ in the upper layer of many soils commonly ranges from $10^{-4}$ to $10^{-3}$ mol kg-1 unless additions have been made. Thus, addition of 100 to $1000 \mathrm{~kg} \mathrm{ha}^{-1} \mathrm{~K}$ to untreated soils widens the ${ }^{137} \mathrm{Cs}$ : $\mathrm{K}$ molar ratio from about $10^{-8}$ to about $10^{-9}$. A mechanism whereby such a change would drastically increase the competitive ability in soil is not yet apparent.

Such an addition may increase the concentration of $\mathrm{K}$ in plants two- to five-fold and often increases plant mass. This suggests that uptake of 137Cs from soil is regulated more by internal $\mathrm{K}$ content than the $137 \mathrm{Cs} / \mathrm{K}$ ratio in soil, as much recent literature indicates (e.g., Zhu et al., 2000).

Further, as we have previously noted (Robison and Stone, 1992), the decrease of ${ }^{137} \mathrm{Cs}$ in coconuts from palms growing along the edge 
of K-treated plots was about $90 \%$ as great as that for palms in the plot interior. Yet, the edge palms had only $\sim 50 \%$ of their root systems in treated soil. Papaya (Carica papaya) growing at the edge of K-treated plots showed a similar reduction (Robison and Stone, unpublished data).

Thus, an alternative hypothesis appropriate for atoll soils lacking silicate clays is that $\mathrm{K}$ concentration within the plant controls ${ }^{137} \mathrm{Cs}$ uptake. If this is so, uniform distribution of applied $\mathrm{K}$, lowering the ${ }^{137} \mathrm{Cs} / \mathrm{K}$ ratio in all parts of the absorbing root system, would be unnecessary for large reductions of ${ }^{137} \mathrm{Cs}$ in plants. This study was designed to test this hypothesis, using annual plants growing in field conditions.

\section{Materials and Methods}

The present study employed the entire above ground portions of two plants, sweet corn (Zea mays), cv Silver Queen, and sorghum (Sorghum bicolor), cv Cargill \#40. Relatively moderate amounts of $\mathrm{K}$ were applied either to the entire rooting area, or to only portions of it, leaving the remainder comparable to the untreated controls.

The study area had been in grass and weeds for about five years after clearing a coconut grove. The grass was burned and the area shallowly chopped to destroy root clumps. Two contiguous treatment blocks were established; each consisted of eight single-row plots five meters long and one meter apart.

Figure 6-1 and Table 6-1 indicate the nature of the treatments. Treatment 5 consisted of two adjacent rows with $40 \mathrm{~g} \mathrm{~m}^{-2} \mathrm{~K}$ broadcast over the single row space between the two rows. Similarly, Treatments 3 and 4 were coupled in a three-row sequence with $20 \mathrm{~g} \mathrm{~m}^{2} \mathrm{~K}$ broadcast over the two meter-wide spaces between rows.

Thus, the same total amount of $\mathrm{K}$ was applied as in Treatment 5, but was shared by three plant rows rather than two; the center row, Treatment 4 , was rooted entirely in treated soil. Treatment 2 had the equivalent of $20 \mathrm{~g} \mathrm{~m}^{2}$ for one row space applied as a narrow band 15 to $20 \mathrm{~cm}$ away from one side of the row. Treatment 1 was a nominal control, but received a "starter" solution of 1.0 or $0.5 \mathrm{~g} \mathrm{~m}^{-2} \mathrm{~K}$ to avoid acute deficiency in the young plants.

The coupling of rows, however, prevented free randomization within the two small blocks. Accordingly, the coupled Treatments 3 and 4 were first established at random followed by randomizing Treatment 5 in suitable spaces. The other treatments were then fitted into remaining rows. Initially, we established an outside row at either end of the experimental sequence as guard rows; subsequently these were treated in all respects as controls, increasing $\mathrm{n}$ to 4 . Hence, the resulting data have been expressed only as individual treatment means with standard deviations.

Fertilizers were applied as follows: all plots received the same amounts of $\mathrm{P}$ and $\mathrm{N}$. With Crops I and II, treble superphosphate at the rate of $5 \mathrm{~g} \mathrm{~m}^{-2} \mathrm{P}$ was placed in a slit 8 to $10 \mathrm{~cm}$ away from the seed row. An initial application of $\left(\mathrm{NH}_{4}\right)_{2} \mathrm{SO}_{4}$ in solution was also placed in the slit before it was closed. Further applications of $\mathrm{N}$ as $\mathrm{NaNO}_{3}$ were made later at the time of $\mathrm{K}$ applications (Table 6-2).

Potassium chloride in solution was sprinkled over the indicated areas of Treatments 3,4 , and 5 (Table 6-1). For Treatment 2, the initial application was in a slit 15 to $20 \mathrm{~cm}$ away from the row. Later additions were in a shallow furrow over the slit location. Very small starter solutions of $\mathrm{K}$ were applied over all control rows at or after sowing, or in the case of Crop IV before sprouting.

Crop III, sorghum, was sown without addition of $\mathrm{K}$ except as noted above. Dissolved $\mathrm{NaNO}_{3}$ at the rate of $10 \mathrm{~g} \mathrm{~m}^{-2}$ was added once to all plots after germination. 


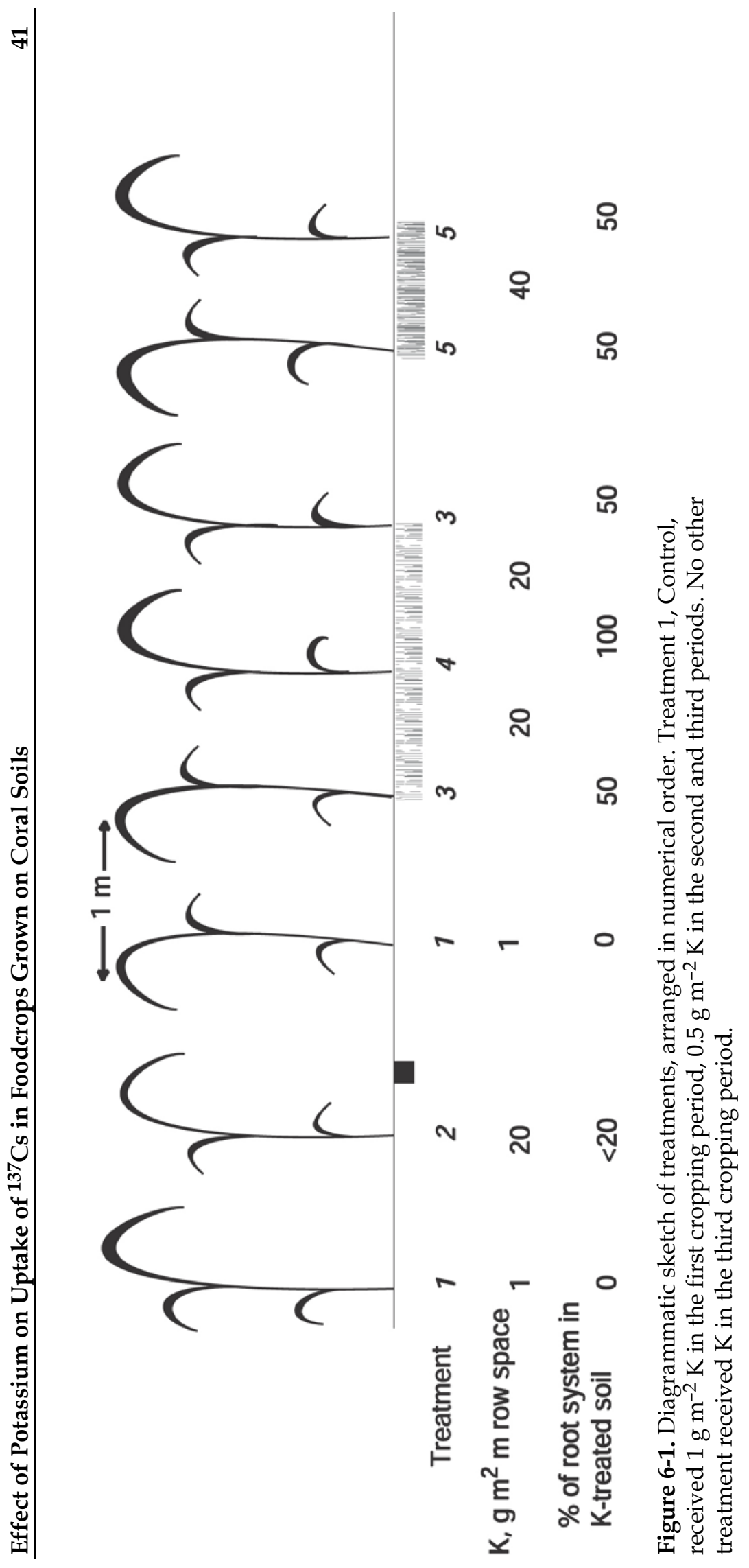


Table 6-1. Potassium added per treated row to Crops I and II, and assumed distribution.

\begin{tabular}{|c|c|c|c|c|c|}
\hline $\begin{array}{c}\text { Treatment } \\
\text { no. }\end{array}$ & $\begin{array}{l}\text { Amount } \\
\text { of } \mathrm{K} \text { per } \\
\text { row } \\
\mathrm{g} \mathrm{m}^{-1}\end{array}$ & $\begin{array}{l}\text { Proportion of } \\
\text { rooting } \\
\text { area } \\
\text { treated } \\
\% \\
\end{array}$ & $\begin{array}{l}\text { Concentration } \\
\text { within } \\
\text { K-treated } \\
\text { soil } \\
\mathrm{g} \mathrm{m}^{-2} \mathrm{~K} \\
\end{array}$ & $\begin{array}{l}\text { Rows of } \\
\text { K-treated } \\
\text { soil } \\
\text { no. }\end{array}$ & $\begin{array}{c}\text { Number of } \\
\text { replications } \\
\text { no. }\end{array}$ \\
\hline 1 Control & $0.5-1.0$ & $<5^{a}$ & $?$ & 1 & 4 \\
\hline 2 Band & 20 & $<20^{\mathrm{a}}$ & $80^{\mathrm{a}}$ & 1 & 2 \\
\hline Broadcast, one side & 20 & 50 & 20 & 3 & 4 \\
\hline 4 Broadcast, both sides & 20 & 100 & 20 & 3 & 2 \\
\hline 5 Broadcast, one side & 40 & 50 & 40 & 2 & 4 \\
\hline
\end{tabular}

a Estimated

Table 6-2. Details of four successive cropping periods of same row-plots described in Table 6-1. Phosphorus applied to Crops I and II; nitrogen applied to all.

\begin{tabular}{|c|c|c|c|c|c|c|c|c|c|}
\hline \multirow[b]{2}{*}{$\begin{array}{c}\text { Crop } \\
\text { no. }\end{array}$} & \multirow[b]{2}{*}{ Plant } & \multirow{2}{*}{$\begin{array}{l}\text { Growth } \\
\text { period } \\
\text { days }\end{array}$} & \multirow[b]{2}{*}{$\begin{array}{c}\text { Rainfall } \\
\mathrm{cm}\end{array}$} & \multicolumn{4}{|c|}{ Total K applied } & \multirow[b]{2}{*}{$\begin{array}{l}\# 5 \\
\mathrm{~g} \mathrm{~m}^{-2}\end{array}$} & \multirow{2}{*}{$\begin{array}{c}\mathrm{K} \\
\text { applications } \\
\text { no. }\end{array}$} \\
\hline & & & & $\begin{array}{l}\# 1 \\
\mathrm{~g} \mathrm{~m}^{-2}\end{array}$ & $\begin{array}{l}\# 2 \\
\mathrm{~g} \mathrm{~m}^{-2}\end{array}$ & $\begin{array}{l}\# 3 \\
\mathrm{~g} \mathrm{~m}^{-2}\end{array}$ & $\begin{array}{c}\# 4 \\
\mathrm{~g} \mathrm{~m}^{-2}\end{array}$ & & \\
\hline I & Corn & 64 & 49 & 1.0 & 20 & 20 & 20 & 40 & 4 \\
\hline II & Corn & 92 & 43 & 0.50 & 20 & 20 & 20 & 40 & 3 \\
\hline III & Sorghum & 131 & $37^{a}$ & 0.50 & 0 & 0 & 0 & 0 & 0 \\
\hline IV & Sorghum $b$ & 67 & $15^{\mathrm{C}}$ & 1.0 & 20 & 20 & 20 & 40 & 1 \\
\hline
\end{tabular}

a Rainfall $72 \mathrm{~cm}$ in 110 day interval between Crops II and III.

b Mostly new sowing supplementing ratooning of Crop III.

c Supplemented by watering during early growth.

At the beginning of Crop IV, it appeared that sprouting from Crop III would yield a ratoon crop in most plots, but seed was sown as a precaution. Potassium was applied as indicated in Table 6-2. In the event, however, most of the ratoon clumps died, and the harvest consisted largely of seedlings from incompletely stocked plots. Hence, only ${ }^{137} \mathrm{Cs}$ concentrations, without harvest weights, are reported for this crop.

Samples from all four crops were treated as described in the introduction except that the stalks of Crop I had lodged and so were cut 25 to $30 \mathrm{~cm}$ above ground to minimize soil contamination. The frozen samples were shipped to LLNL for processing and analysis. Potassium was determined by XRF.

\section{Results and Discussion}

It was assumed in the design of this study that the effective rooting radii of both corn and sorghum would be no greater than one meter, and that surface-applied K would not move laterally more than a few centimeters in these highly porous soils. Both assumptions are born out by the results obtained.

Table 6-3 gives the green weights of the first three crops grown on the same plots. The gross 
Table 6-3. Green weight yields of three successive crops.

\begin{tabular}{|c|c|c|c|c|c|}
\hline \multirow[b]{2}{*}{$\begin{array}{c}\text { Treatment } \\
\text { no. }\end{array}$} & \multirow[b]{2}{*}{$\begin{array}{l}\text { Treatment; K } \\
\text { applied to } \\
\text { Crops I \& II }\end{array}$} & \multicolumn{4}{|c|}{$\mathrm{kg} \mathrm{m}^{-2}$, green weight } \\
\hline & & $\begin{array}{l}\text { Crop I } \\
\text { corn }\end{array}$ & $\begin{array}{l}\text { Crop II } \\
\text { corn }\end{array}$ & $\begin{array}{l}\text { Crop III } \\
\text { sorghum }\end{array}$ & $\begin{array}{r}\text { Total } \\
\text { green } \\
\text { weight }\end{array}$ \\
\hline 1 & Control, $0.5-1.0 \mathrm{~g} \mathrm{~m}^{-2} \mathrm{~K}$ & $0.83 \pm .13$ & $0.56 \pm .10$ & $0.57 \pm .20$ & 2.0 \\
\hline 2 & $20 \mathrm{~g} \mathrm{~m}^{-2}$, band & $1.1 \pm .43$ & $0.85 \pm .14$ & $1.1 \pm .11$ & 3.1 \\
\hline 3 & $\begin{array}{l}20 \mathrm{~g} \mathrm{~m}^{-2} \text {, edge of } \\
\text { broadcast }\end{array}$ & $1.3 \pm .37$ & $1.0 \pm .30$ & $1.1 \pm .15$ & 3.3 \\
\hline 4 & $\begin{array}{l}20 \mathrm{~g} \mathrm{~m}^{-2} \text {, center of } \\
\text { broadcast }\end{array}$ & $1.3 \pm .11$ & $1.0 \pm .08$ & $0.87 \pm .11$ & 3.2 \\
\hline 5 & $\begin{array}{l}40 \mathrm{~g} \mathrm{~m}^{-2} \text { edge of } \\
\text { broadcast }\end{array}$ & $1.3 \pm .17$ & $1.0 \pm .19$ & $1.0 \pm .19$ & 3.4 \\
\hline
\end{tabular}

totals for corn and sorghum combined do not differ appreciably among treatments receiving 20 or $40 \mathrm{~g} \mathrm{~m}^{-2} \mathrm{~K}$. The yield of the control, however, was only $60 \%$ of the treated yield mean.

Potassium applied in amounts of 20 or $40 \mathrm{~g}$ $\mathrm{m}^{-2}$ greatly reduced ${ }^{137} \mathrm{Cs}$ uptake by all four crops (Figure 6-2), including Crop III, to which no additional application had been made. The greatest reduction of ${ }^{137} \mathrm{Cs}$ in all four crops was brought about by Treatment 4, $20 \mathrm{~g} \mathrm{~m}^{-2} \mathrm{~K}$, distributed over the entire rooting area. Nearly the same reduction was brought about $40 \mathrm{~g} \mathrm{~m}^{-2}$ $\mathrm{K}$ applied to only $50 \%$ of the rooting area. The latter amount was shared by the two adjourning rows (Figure 6-1). Potassium at the rate of $20 \mathrm{~g}$ $\mathrm{m}^{-2}$ row space, but applied in a narrow band, was as effective as Treatment 3 on Crop I, and more effective thereafter. Probably less than 20\% of the rooting area was affected by diffusion from the banded $\mathrm{K}$ in Treatment 2 .

These results support the hypothesis that the critical factor regulating plant uptake of ${ }^{137} \mathrm{Cs}$ is K concentration in the plant, rather than proportion of the root system in K-treated soil.

Figure 6-3 describes the relationship of ${ }^{137} \mathrm{Cs}$ to $\mathrm{K}$ in Crop III, mature sorghum. No K had been applied to this crop (except $0.5 \mathrm{~g} \mathrm{~m}^{2} \mathrm{~K}$ on the controls); hence yields (Table 6-1) and $\mathrm{K}$ concentrations reflect residual soil $\mathrm{K}$ from the two previous crops, plus any remaining native soil $\mathrm{K}$ and replenishment by salt spray. Figure 6-3 closely resembles Figures 2-6 and 4-3, which are comparable associations from nearby studies in different years. All demonstrate the large reduction of ${ }^{137} \mathrm{Cs}$ with initial increases in $\mathrm{K}$, followed by rapid decrease in the rate of ${ }^{137}$ Cs reduction.

The persistence of $\mathrm{K}$ residual from the Crop I and II applications in Crop III is surprising in view of $72 \mathrm{~cm}$ total rainfall in the 110 days between the Crop II harvest and sowing of Crop III. The Crop III Controls contained only $0.70 \pm .38 \mathrm{~g} \mathrm{~m}^{-2} \mathrm{~K}$ (green weight) in the harvested tops versus $3.30 \pm .67 \mathrm{~g} \mathrm{~m}^{-2}$ in plants of Treatment 3, and 3.75 to $5.0 \mathrm{~g} \mathrm{~m}^{-2}$ in those of the other treatments. Differences from the control suggest the minimum amounts of residual K. Some additional amounts may have remained in root clumps left after harvest of Crop III, but the widespread failure of effective ratooning for Crop IV suggests that any such $\mathrm{K}$ content was near minimal.

The removal of ${ }^{137} \mathrm{Cs}$ in harvested crops (Table 6-4) is of interest. The total soil inventory at this location was not determined, but presumably was similar to those already mentioned for adjacent study areas: $276 \mathrm{kBq} \mathrm{m}^{-2}$ (Experiments 4 and 5) and $210 \mathrm{kBq} \mathrm{m}^{-2}$ (Experiment 2), both to $50 \mathrm{~cm}$ depth. Hence, total harvest removals in the controls of Crops I, II, and III were around 5 to $7 \%$ of the soil inventory (or less, if the total inventory were greater than assumed). Although not determined, it is likely that increased growth resulting from the starter solutions $(0.5$ to $1.0 \mathrm{~g}$ $\mathrm{m}^{-2}$ ) applied to the controls more than compensated for any small reduction in ${ }^{137} \mathrm{Cs}$ concentrations. 


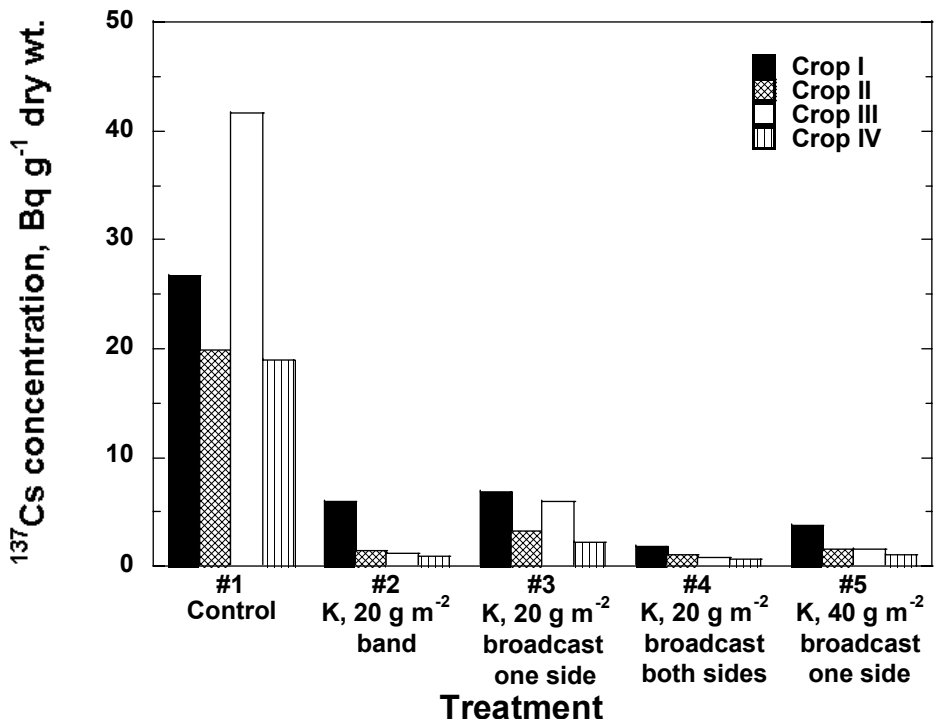

Figure 6-2. ${ }^{137} \mathrm{Cs}$ concentration in Crops I, II, III, and IV versus the amount of K added in various ways to the rows of sorghum.

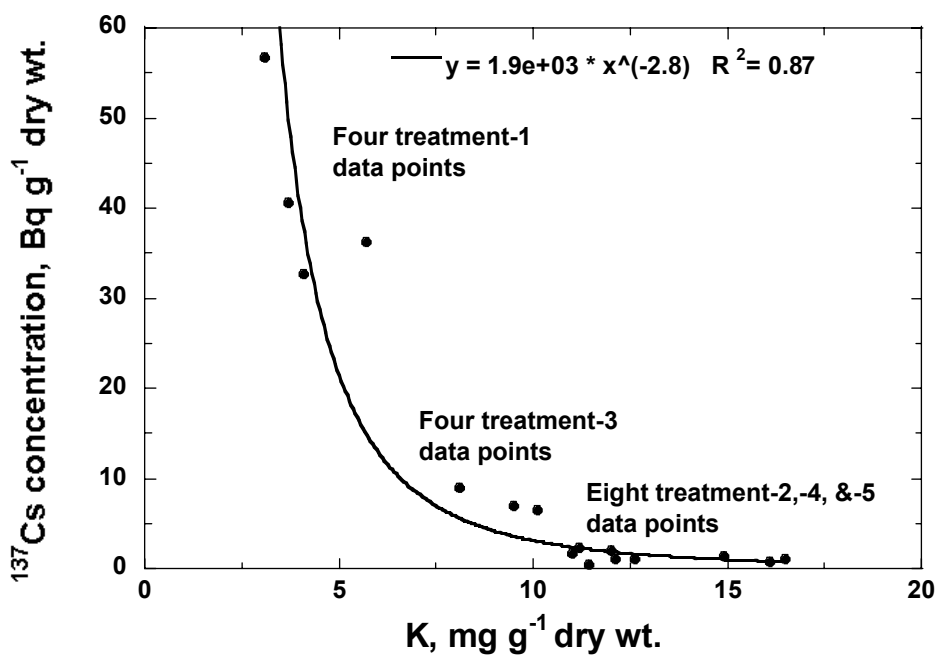

Figure 6-3. Correlation between the ${ }^{137} \mathrm{Cs}$ and $\mathrm{K}$ concentrations in sorghum, Crop III.

Table 6-4. Removal of ${ }^{137} \mathrm{Cs}$ from soil in three harvested crops from the same plots.

\begin{tabular}{ccccc}
\hline & \multicolumn{3}{c}{ Crop no. } & \\
\cline { 2 - 4 } Treatment no. & $\mathrm{I}$ & $\mathrm{II}$ & $\mathrm{III}$ & Total, I-III \\
\hline & \multicolumn{4}{c}{$137 \mathrm{Cs}, \mathrm{kBq} \mathrm{m}^{-2}$} \\
1 & 5.8 & 2.8 & 6.5 & \\
2 & 1.4 & 0.3 & 0.5 & 2.2 \\
3 & 2.2 & 1.0 & 2.1 & 5.3 \\
4 & 0.6 & 0.2 & 0.2 & 1.0 \\
5 & 1.2 & 0.4 & 0.5 & 2.1 \\
\hline
\end{tabular}




\section{Experiment 7: Potassium Release from Clinoptilolite Reduces ${ }^{137} \mathrm{Cs}$ in Food Crops}

\begin{abstract}
A possible means of reducing ${ }^{137} \mathrm{Cs}$ in plants grown on atoll soils would be to add a clay or zeolite that would immobilize the nuclide in soil. Such immobilization occurs to a greater or lesser extent in soils containing silicate clays and so reduces plant uptake. A compilation of plantsoil concentration factors from a variety of nonatoll soils ( $\mathrm{Ng}$ et al., 1982) revealed that such ratios commonly range between $10^{-5}$ and $10^{-2}$ when based on plant green weight. In contrast, our data from untreated soils on Bikini Atoll usually varied between $10^{0}$ to $10^{1}$.
\end{abstract}

Accordingly, we examined whether mixing a commercially available natural zeolite, clinoptilolite, into atoll soil would reduce uptake by annual food crops, both monocot and dicot.

Since this experiment was begun, November 1987, at least three studies have reported that addition of clinoptilolite reduced plant uptake of Cs (Shenber and Johanson, 1992; Campbell and Davies, 1997; Paasikallio, 1999). In none of these were the experimental circumstances or findings relevant to the Bikini experiment. All three investigations attributed the reductions chiefly to absorption of Cs by clinoptilolite, but recognized that $\mathrm{K}$ liberated from the mineral might have had some effect.

\section{Materials and Methods}

The Teague Mineral Products Company, Oregon, generously provided the clinoptilolite used. The product was food grade, mostly less than 20 mesh, and contained $4.1 \% \mathrm{~K}$. This is nearly half of the total cation charge contained in the mineral structure. Thus, addition at rates of 2,4 , and $8 \mathrm{~kg} \mathrm{~m}^{-2}$ included $82\left(266 \mathrm{mg} \mathrm{kg}^{-1}\right)$, $164\left(532 \mathrm{mg} \mathrm{kg}^{-1}\right)$, and $328 \mathrm{~g} \mathrm{~m}^{-2}\left(1064 \mathrm{mg} \mathrm{kg}^{-1}\right)$ total $\mathrm{K}$, respectively.

The site of this study paralleled that of Experiment 3, although about 40 meters away. The soils of both are Typic Rendolls and similar in morphology. The area was prepared by clearing grasses and Ipomea vines, and later removing roots. Fifteen $1.5 \times 1.5 \mathrm{~m}$ mini-plots were excavated to a depth of 28 to $30 \mathrm{~cm}$, and the spoil piled for subsequent mixing. Open plywood frames $30 \mathrm{~cm}$ deep were fitted into the excavated pits, thus preventing lateral root growth and water movement outside the frame boundaries.

The soil from each pit was then mixed thoroughly with the designated amount of clinoptilolite (Table 7-1), using a small gasolinepowered cement mixer. Only about one-third of the soil volume from a pit could be mixed at one time, so each frame was filled with three layers of the mixture that were similar in composition though not identical. Superphosphate, at the rate of $60 \mathrm{~g} \mathrm{~m}^{-2} \mathrm{P}$, was added during the mixing process, together with $20 \mathrm{~g} \mathrm{~m}^{-2} \mathrm{~K}$ in Treatment 2 (Control plus K).

Composited soil cores, $28 \mathrm{~cm}$ long, were taken from filled plots in two of the three blocks prior to sowing. Subsamples were analyzed for ${ }^{137}$ Cs at LLNL, and analyzed for organic matter and other elements at the University of Florida using $\left(\mathrm{NH}_{4}\right) \mathrm{H} \mathrm{CO}_{3}$ plus DTPA) as an extractant (Soltanpour and Schwab, 1977). Sampling was repeated at the end of the study, but $\left(\mathrm{NH}_{4}\right)_{2} \mathrm{CH}_{2}$ $\mathrm{COOH}$ was used as an extractant. For comparison, the two sets of results are presented in a single Table, 7-2.

Cesium-137 and organic matter in the mixed soil were closely correlated (Figure 7-1), as in Figure 3-1 also. (The present data represent high surface organic matter values equivalent to the linear portions of Figure 3-1, but now mixed with deeper soil.) The range in Figure 7-1 demonstrates an unexpectedly great variation in both ${ }^{137} \mathrm{Cs}$ and organic matter among $2.25-\mathrm{m}^{2}$ plots within a total experimental area of only $53 \mathrm{~m}^{2}$.

Potassium extracted by $\left(\mathrm{NH}_{4}\right) \mathrm{HCO}_{3}$ varied widely according to treatment. The mean difference between Treatments 1 and 2 (Control and Control plus K), initially, approximates that due to the $20 \mathrm{~g} \mathrm{~m}^{-2} \mathrm{~K}$ addition. Amounts of $\mathrm{K}$ in the added clinoptilolite can be converted to soil concentrations (taking depth of soil to be $28 \mathrm{~cm}$ and bulk density to be 1.10), to which the extractable amount in the untreated soil of 24 $\mathrm{mg} \mathrm{kg}^{-1}$ may be added. Surprisingly, the totals so calculated are close to the actual amounts extracted before cropping (Table 7-2B), i.e., 290 $\left(\mathrm{mg} \mathrm{kg}^{-1}\right)$ calculated vs 240 extracted, 556 vs 527, 
Table 7-1. Basic treatments and rates. (Potassium maintenance dressings shown in Table 7-3.)

Total $\mathrm{K}$ in

Treatment no. Treatment Rate Clinoptilolite, $\mathrm{g} \mathrm{m}^{-2}$

\begin{tabular}{lllr}
\hline 1 & Control & & 0 \\
2 & Control + K & $20 \mathrm{~g} \mathrm{~m}^{-2}$ on Crop I & 0 \\
& & $10 \mathrm{~g} \mathrm{~m}^{-2}$ on Crop V \\
3 & Clinoptilolite & $2 \mathrm{~kg} \mathrm{~m}^{-2}$ mixed to $28 \mathrm{~cm}$ & 82 \\
4 & Clinoptilolite & $4 \mathrm{~kg} \mathrm{~m}^{-2}$ mixed to $28 \mathrm{~cm}$ & 164 \\
5 & Clinoptilolite & $8 \mathrm{~kg} \mathrm{~m}^{-2}$ mixed to $28 \mathrm{~cm}$ & 328 \\
\hline
\end{tabular}

Table 7-2. Organic matter and extractable elements in soil.

A. Mean contents $( \pm \mathrm{SD})$ of treatment plots, other than $\mathrm{K}$, before Crop I. $\mathrm{n}=10$; each sample a composite of 5 cores per plot. Extracted with $\left(\mathrm{NH}_{4}\right) \mathrm{HCO}_{3}+$ DTPA.

\begin{tabular}{lccccccc}
$\begin{array}{l}\text { Organic } \\
\text { matter } \\
\mathrm{g} \mathrm{kg}^{-1}\end{array}$ & $\mathrm{P}$ & $\mathrm{Ca}$ & $\mathrm{Mg}$ & $\begin{array}{c}\mathrm{Zn} \\
\mathrm{mg} \mathrm{kg}^{-1}\end{array}$ & $\mathrm{Cu}$ & $\mathrm{Mn}$ & $\mathrm{Fe}$ \\
\cline { 2 - 5 } & & & & & & & \\
$43 \pm 1.1$ & $110 \pm 14$ & $1400 \pm 930$ & $90 \pm 25$ & $2.0 \pm .8$ & $0.94 \pm .50$ & $4.4 \pm 1.2$ & $33 \pm 18$
\end{tabular}

$B$ and C. Mean soil K $( \pm S D)$ of treatment plots before and after cropping.

B. $\mathrm{n}=2$, sampling and extractant as in A.

C. $n=3$; single core per plot; extracted with $\left(\mathrm{NH}_{4}\right) \mathrm{CH}_{2} \mathrm{COOH}$.

B before Crop I $0-28 \mathrm{~cm}$

Treatment

1. Control

2. Control $+\mathrm{K}$

3. Clinoptilolite, $2 \mathrm{~kg} \mathrm{~m}^{-2}$

4. Clinoptilolite, $4 \mathrm{~kg} \mathrm{~m}^{-2}$

5. Clinoptilolite, $8 \mathrm{~kg} \mathrm{~m}^{-2}$ $\mathrm{mg} \mathrm{kg}^{-1}$

$24 \pm 5$

$110 \pm 9$

$240 \pm 5$

$527 \pm 54$

$1207 \pm 18$
C

\begin{tabular}{cr}
\multicolumn{2}{c}{ after Crop VI } \\
\hline $0-15 \mathrm{~cm}^{-1}$ & $15-28 \mathrm{~cm}$ \\
$\mathrm{mg} \mathrm{kg}^{-1}$ & $\mathrm{mg} \mathrm{kg}^{-1}$
\end{tabular}

$9 \pm 4 \quad 6 \pm 1$

$10 \pm 2 \quad 9 \pm 3$

$15 \pm 2 \quad 11 \pm 3$

$50 \pm 11 \quad 62 \pm 20$

$160 \pm 83 \quad 210 \pm 70$ 


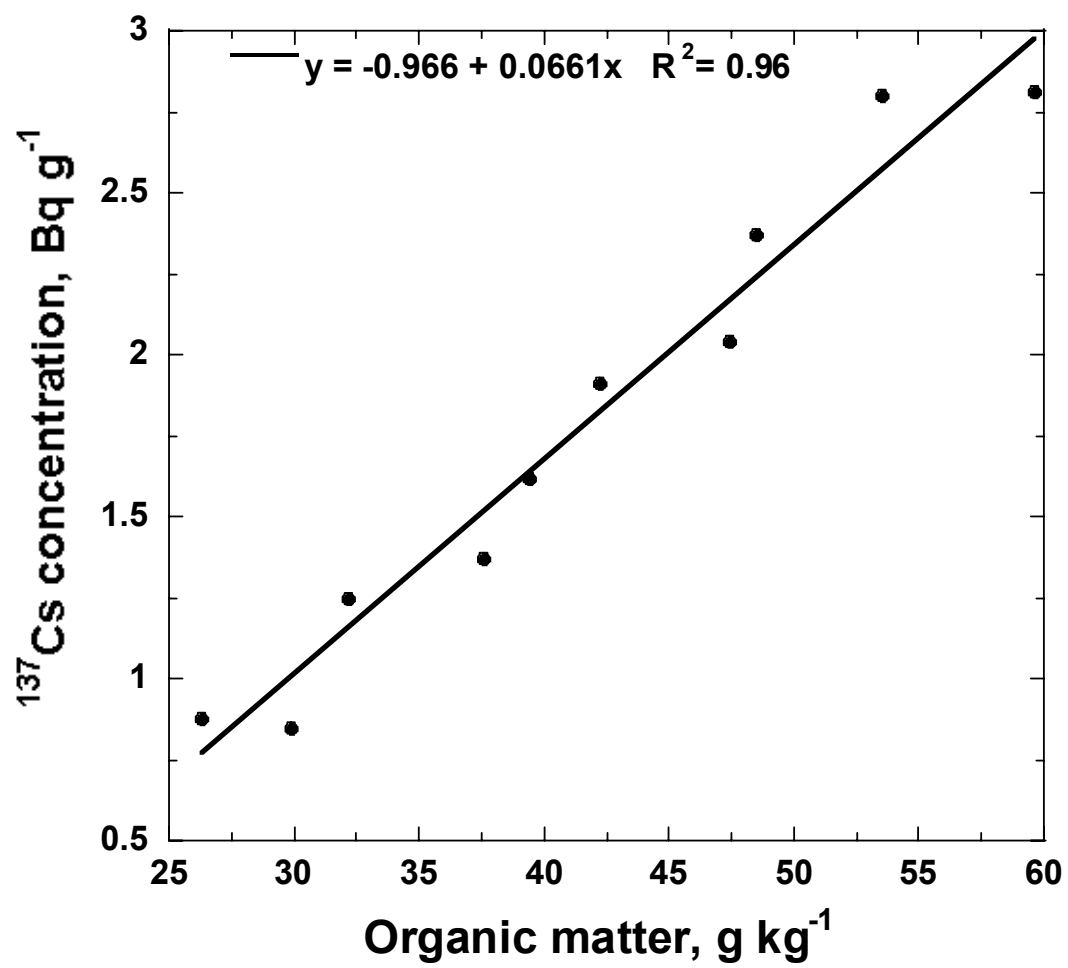

Figure 7-1. Relationship of ${ }^{137} \mathrm{Cs}$ to organic matter in $28 \mathrm{~cm}$ depth of well-mixed soil.

and 1088 vs 1207, respectively, for the three rates of clinoptilolite. The likelihood of such complete extraction was not foreseen when the study began.

Mean total ${ }^{137} \mathrm{Cs}$ activity in the upper $28 \mathrm{~cm}$ of soil was estimated to be $554 \pm 56$ (SEM) kBq $\mathrm{m}^{-2}$. This is about twice as much as estimated for the nearby sites of Experiments 3 and 4, but is near that of an adjacent area on the opposite side, $462 \pm 29$ (SEM), in the $20 \mathrm{~cm}$ deep surface.

The experimental design was a randomized block with three replications of five treatments (Table 7-1). Six successive crops were grown (Table 7-3), including sweet corn (Zea mays cv Silver Queen) and Chinese cabbage (Brassica rapa cv Bok-choi) together as Crop I. Other species were sweet potato (Ipomea batatas cv unknown; local) and sorghum (Sorghum bicolor cv Cargill \#40).

All plots received $\mathrm{N}$ and very small maintenance "dressings" of K applied 4 to 6 times to each crop (Table 7-3). The amount of K thus applied to each plot over the experimental period, however, totaled $13.86 \mathrm{~g} \mathrm{~m}^{-2}$.

Additionally, a second application of $\mathrm{K}, 10 \mathrm{~g} \mathrm{~m}^{2}$, was broadcast on Treatment 2 at the beginning of Crop V.

Crops were sown and harvested during visits of LLNL personnel, and hence samples varied in stage of growth (Table 7-3). Harvested samples were frozen and shipped to LLNL as described previously. Cesium-137 was determined on all crops or components, but the results for sweet corn components have been combined in some calculations. Potassium was determined on entire sorghum plants, but only on the stover component of sweet corn Crops III and IV.

During cropping periods I and II, green weight yields of sweet corn, Chinese cabbage and sweet potato from Block I were commonly only one half or much less than those from Blocks II and III, and ${ }^{137}$ Cs concentrations were also much lower. The reduction disappeared after Crop II. The cause of this reduction is unknown, but inadvertent application of a 
Table 7-3. Sequence of crops, fertilizer addition, and growth conditions for all plots. Rainfall supplemented by hand watering in dry periods. (Does not included additional K applied to Treatment \#2.)

\begin{tabular}{|c|c|c|c|c|c|c|}
\hline & \multirow[b]{2}{*}{ Crop } & \multicolumn{2}{|c|}{ Fertilizer added } & \multirow[b]{2}{*}{$\begin{array}{c}\text { Applications } \\
\text { no. }\end{array}$} & \multirow[b]{2}{*}{$\begin{array}{c}\text { Cropping } \\
\text { period } \\
\text { days }\end{array}$} & \multirow[b]{2}{*}{$\begin{array}{l}\text { Periodic } \\
\text { rainfall } \\
\mathrm{cm}\end{array}$} \\
\hline & & $\begin{array}{c}\text { Maintenance } \\
\mathrm{K} \\
\mathrm{g} \mathrm{m}^{-2}\end{array}$ & $\begin{array}{c}\mathrm{N} \\
\mathrm{g} \mathrm{m}^{-2}\end{array}$ & & & \\
\hline I & Sweet corn & & & & & \\
\hline \multirow[t]{2}{*}{ I } & Chinese cabbage & -3.0 & 19 & 6 & 55 & 24 \\
\hline & (Fallow) & - & - & - & 31 & 3 \\
\hline II & Sweet potato & 4.1 & 22 & 6 & 160 & 16 \\
\hline III & Sweet corn & 1.7 & 18 & 4 & 84 & 46 \\
\hline \multirow[t]{2}{*}{ IV } & Sweet corn & 1.9 & 18 & 5 & 66 & 43 \\
\hline & (Fallow) & - & - & - & 188 & 24 \\
\hline $\mathrm{V}$ & Sorghum & 1.4 & 17 & 4 & 59 & 45 \\
\hline \multirow[t]{2}{*}{ VI } & Sorghum ratoon & 1.8 & 15 & 5 & 84 & 49 \\
\hline & Total & 14 & 110 & & 727 & 250 \\
\hline
\end{tabular}

persistent herbicide is suspected. Accordingly, data from Crops I and II grown in Block I were deleted from subsequent statistical analyses.

Green weight, ${ }^{137} \mathrm{Cs}$ concentration in either the whole plant or an index component, and total ${ }^{137}$ Cs removed in a plot harvest were subject to ANOVA using the StatView program. Analysis of differences was based on Fisher's PLSD (Protected Least Significant Difference) test. It included all comparisons but only those between the Control and individual treatments are considered relevant here.

\section{Results and Discussion}

Mean green weights, ${ }^{137} \mathrm{Cs}$ concentration in the whole plant or component, and total ${ }^{137} \mathrm{Cs}$ removed by each crop and treatment are given in Table 7-4 together with the significance of the differences from the Controls. As noted in Table 7-3, the controls as well as all other treatments received maintenance dressings of $K$, the amounts of which were reduced from Crop III onward.

Crop III, sweet potato, was grown during a prolonged drought (Table 7-3) only by means of hand watering. Insufficient water and variability in its application to individual plots probably contributed to a high variability which rendered even large mean differences nonsignificant with $\underline{n}=2$.

Otherwise, the clinoptilolite treatments $(3,4$, and 5) increased green weight, reduced ${ }^{137} \mathrm{Cs}$ concentration, and hence greatly reduced total uptake of ${ }^{137} \mathrm{Cs}$ in each crop.

Treatment 2 (Control plus K) generally increased growth and reduced ${ }^{137} \mathrm{Cs}$ uptake. The total amount of $\mathrm{K}$ provided by this treatment was very much less than that released from the lowest rate of clinoptilolite addition, and the total removal of ${ }^{137} \mathrm{Cs}$ in all six crops combined was not greatly different from that removed by the full Controls, $\sim 41$ vs $56 \mathrm{kBq} \mathrm{m}^{-2}$ (Table 7-4).

The data in Table 7-2 demonstrate the initial amounts of extractable soil $\mathrm{K}$ before cropping and applying any maintenance dressing, and also the extractable $\mathrm{K}$ remaining after harvesting Crop VI. It is evident that repeated cropping reduced extractable soil $\mathrm{K}$ to very low levels in both Control and Control plus K treatments (Table 7-2). Successive crops from the lowest rate of clinoptilolite (Treatment 3 ) indicate the gradual increase of ${ }^{137} \mathrm{Cs}$ as $\mathrm{K}$ was depleted (Table 7-4, Figure 7-2 \& 3). There is no evidence here of an independent action of clinoptilolite through immobilizing ${ }^{137}$ Cs. 


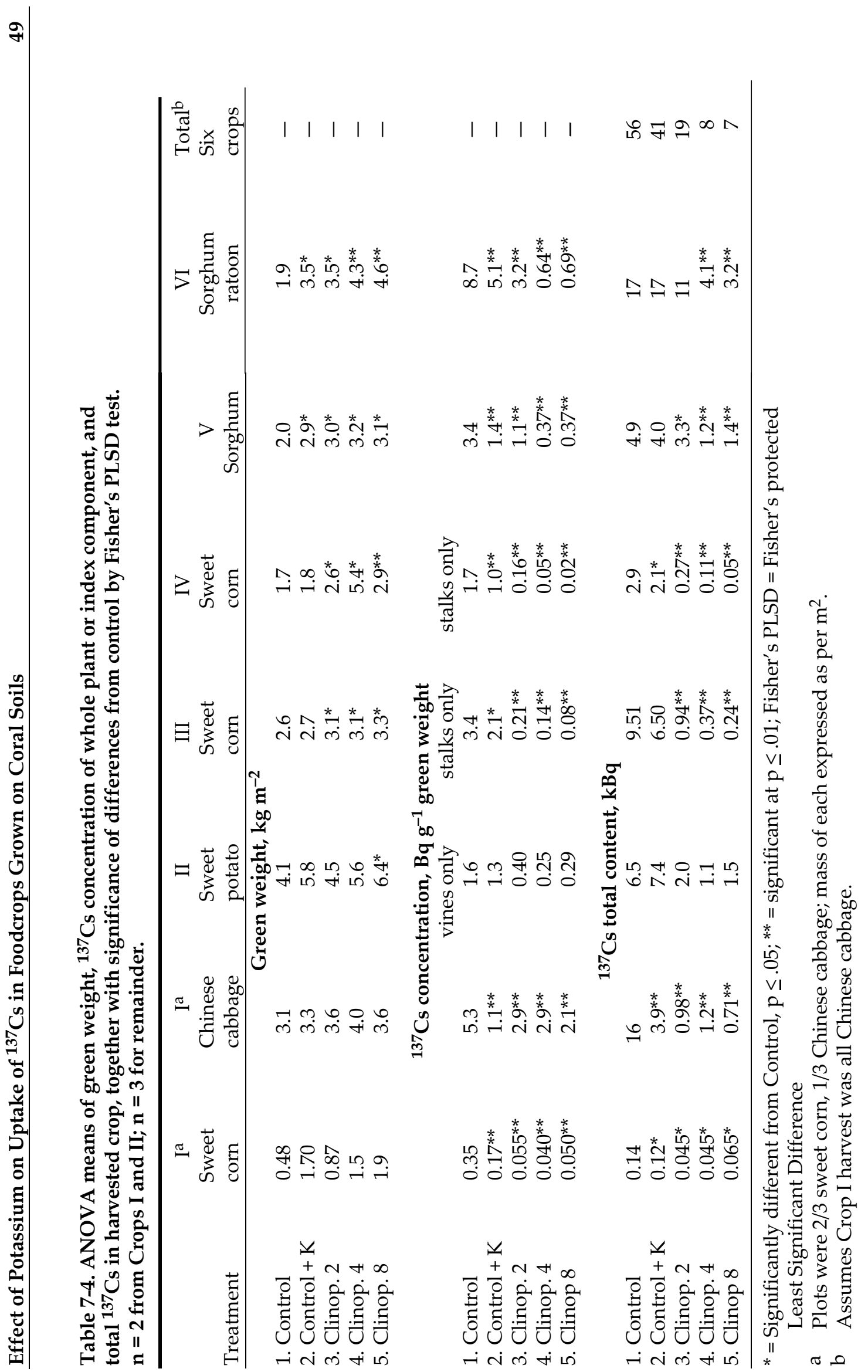




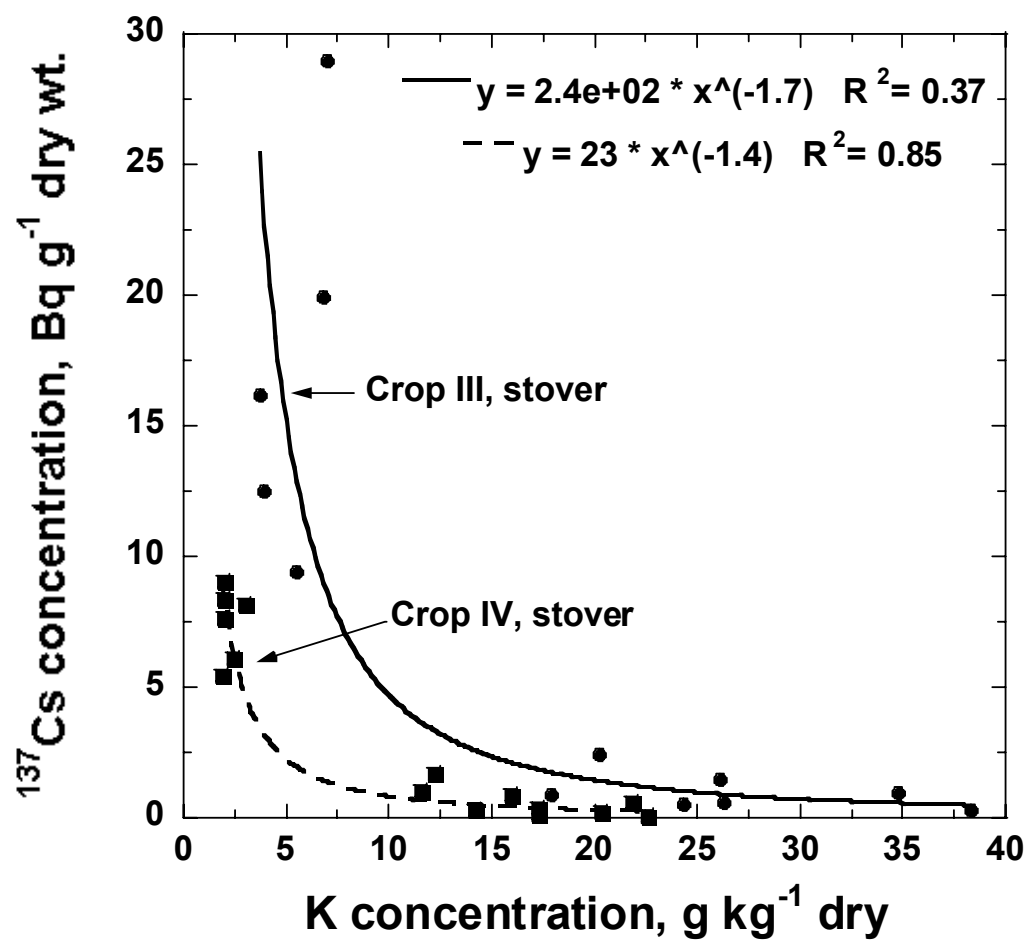

Figure 7-2. Relationship of ${ }^{137} \mathrm{Cs}$ to $\mathrm{K}$ in stover of sweet corn.

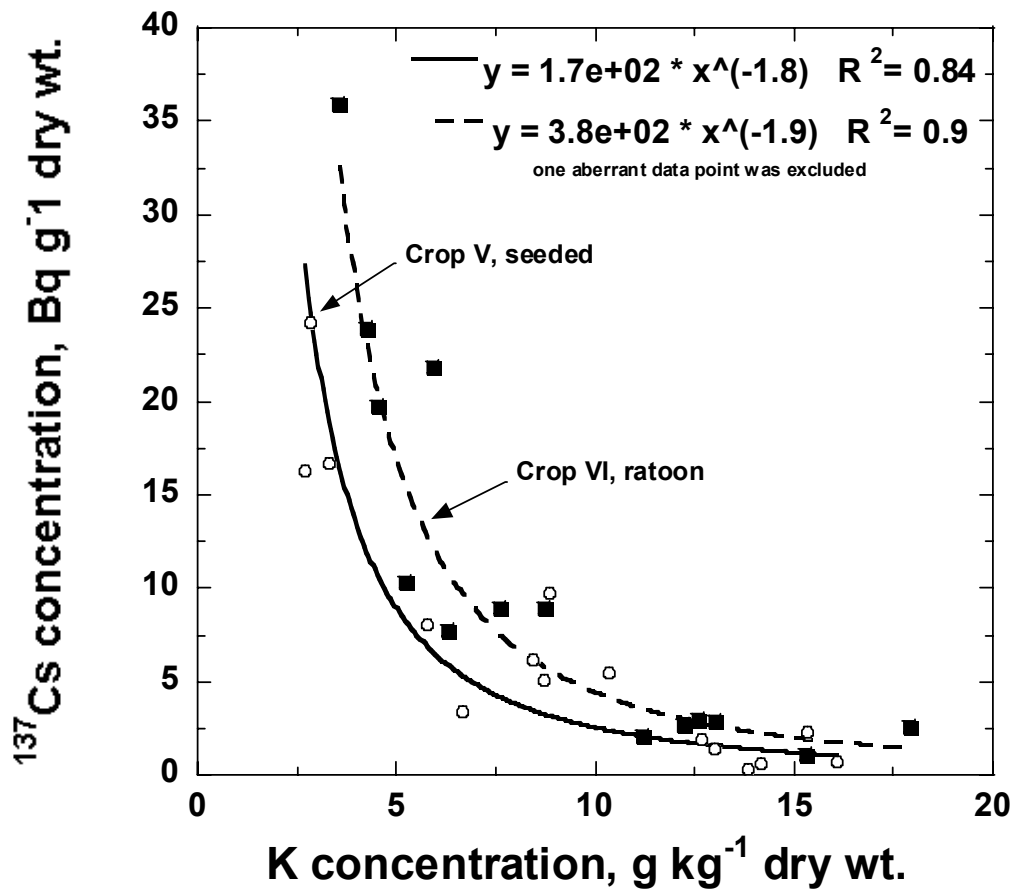

Figure 7-3. Relationship of ${ }^{137} \mathrm{Cs}$ to K in sorghum plants (Crop VI is a ratoon crop from Crop V).

Potassium was not determined in Crops I and II, but it is likely that these crops depleted much of the initial soil supply seen in the Controls plus that added in maintenance 
dressings. Subsequent crop uptake from Treatments 1 and 2 then depended on any residual amounts plus the indicated further additions. In contrast, plants grown on the clinoptilolite-treated soils continued to absorb K released from the mineral. Hence, there is a near equality between the summed "additions" (including initial supply) and removals of $\mathrm{K}$ by Crops III through VI in Treatments 1 and 2 (Control, and Control plus K). Likewise, the much greater uptake from the clinoptilolitetreated plots (Table 7-5) agrees with the reductions in extractable soil $\mathrm{K}$ (Table 7-2). These large removals are products of a 50 to $70 \%$ increase in green matter, as compared with the controls, coupled with greater plant $\mathrm{K}$ concentration.

Table 7-2 also indicates the ready mobility of $\mathrm{K}$ in the added clinoptilolite. The values given under Tables 7-2B and $\mathrm{C}$ are products of different extractants with the same cation. The ( $\left.\mathrm{HH}_{4}\right) \mathrm{CH}_{2} \mathrm{COOH}$ applied to $\mathrm{C}$ would not have remained such, however, in this highly calcareous soil. Comparison of the respective mean concentrations in $C$ with those in $B$ suggests the magnitude of the combined losses of $\mathrm{K}$ due to plant uptake and leaching over the two-year cropping period (Table 7-3).

In sum, the foregoing results indicate that the large reductions of ${ }^{137} \mathrm{Cs}$ in plants grown on these clinoptilolite-treated soils (Table 7-4) are due to ready uptake of $\mathrm{K}$ from the mineral rather than any immobilization of ${ }^{137} \mathrm{Cs}$. The profound mixing and loosening of the upper soil at installation would have facilitated intensive root development through the entire mass. Possibly the lack of such absorption in such soils is related to the extreme dilution of ${ }^{137} \mathrm{Cs}$ in the soil solution (see Table 1-1) and its saturation with $\mathrm{Ca}^{++}$and $\mathrm{Mg}^{++}$, or with the abundance of $\mathrm{Na}^{+}$.

As noted earlier, ${ }^{137} \mathrm{Cs}$ in the upper $28 \mathrm{~cm}$ of soil averaged $554 \pm 54(\mathrm{SEM}) \mathrm{kBq} \mathrm{m}^{-2}$.

Cesium-137 removed in six crops from the Control plots-assuming that Chinese cabbage made up the whole of Crop I-totaled $57 \mathrm{kBq} \mathrm{m}^{-2}$. Although both of these values have appreciable error terms, comparison suggests about $10 \%$ removal of ${ }^{137} \mathrm{Cs}$.

The plant growth required for such removal from the Controls was made possible only by the small maintenance dressings of $\mathrm{K}$. These were empirically based, however, and any appropriate balance between providing enough $\mathrm{K}$ for edible growth while not greatly reducing ${ }^{137}$ Cs concentration is unknown.

As in other experiments (Figures 1-3, 2-6, 4-2, 6-3, etc.) concentration of ${ }^{137} \mathrm{Cs}$ in plants is negatively and curvealinearly related to $\mathrm{K}$ concentrations (Figures 7-2, 7-3). This relationship appears independent of how the $\mathrm{K}$ was provided or of species, within the range tested.

Table 7-5. Total potassium in Crop III, IV, V, and VI harvests ${ }^{*}$ as compared with added $\mathrm{K}$, and with $\mathrm{K}$ contained in clinoptilolite before cropping (also see Table 7-2) .

\begin{tabular}{|c|c|c|c|c|c|}
\hline \multirow[t]{2}{*}{ Variable } & \multicolumn{5}{|c|}{ Treatment no. } \\
\hline & 1 & 2 & 3 & 4 & 5 \\
\hline \multicolumn{6}{|c|}{ Crops I and II Only } \\
\hline $\mathrm{K}$ in clinoptilolite, $\mathrm{g} \mathrm{m}^{-2}$ & 0 & 0 & 82 & 164 & 328 \\
\hline K added, Crops I \& II, $\mathrm{g} \mathrm{m}^{-2}$ & 7.0 & 27.0 & 7.0 & 7.0 & 7.0 \\
\hline \multicolumn{6}{|c|}{ Crops III, IV, V, and VI } \\
\hline Harvested, green wt., $\mathrm{kg} \mathrm{m}^{-2}$ & 7.2 & 9.9 & 11 & 12 & 13 \\
\hline $\mathrm{K}$ in harvest ${ }^{\mathrm{a}}, \mathrm{g} \mathrm{m}^{-2}$ & 6.6 & 17.1 & 40 & 60 & 76 \\
\hline K added, Crops III, IV, V,VI, g m-2 & 6.7 & 16.7 & 6.7 & 6.7 & 6.7 \\
\hline $\mathrm{K}$, difference, $\mathrm{g} \mathrm{m}^{-2}$ & +0.1 & -0.4 & +34 & +53 & +70 \\
\hline Difference as $\%$ of $\mathrm{K}$ in clinoptilolite & - & - & 41 & 39 & 21 \\
\hline
\end{tabular}

a Total $\mathrm{K}$ in sweet corn Crops III and IV assumed proportional to K concentrations in stalks only. 


\section{Experiment 8: Soil Fumigation Increases ${ }^{137}$ Cs Concentration in Sweet Corn}

The mechanism of ${ }^{137} \mathrm{Cs}$ retention in atoll soils lacking clay is unknown, although obvious sinks are one or more components of soil organic matter, and soil organisms. Prolonged leaching with seawater (Robison and Stone, 1999), or cation exchange reactions (Koranda and Robison, unpublished data; Wong and Robison, unpublished data), or repeated plant harvests (Experiments 2, 3,4) removed only small fractions of the total ${ }^{137}$ Cs inventory present in Bikini soils. The extracted fraction was replaced over time, although there have been no systematic studies of the process.

Many soil fungi, from a variety of taxonomic groups, can absorb relatively large concentrations of Cs (Avery, 1995; Gillette and Croat, 2000; Witkamp, 1968), as well as Rb and $\mathrm{K}$. The actual mass of hyphae present in the calcareous sands of atolls is unknown, and may be far less than that in acid forest soils where fleshy fungi abound. Even less is known about the mass of actinomycete tissue (Johnston, 1947). Nevertheless, hyphal strands are abundant in all atoll soils, even below the organic horizon (Figure 8-1). Small masses of mycelium and entrapped sand often can be winnowed from surface soils by gentle shaking. Successive screening and removal of sand grains from the fungal mass gave the following results in a preliminary examination:

\begin{tabular}{lcrr}
\multicolumn{1}{c}{ Location } & $\begin{array}{c}\text { Depth } \\
\text { cm }\end{array}$ & $\begin{array}{c}\text { Mycelial } \\
\text { weight } \\
\text { mg }\end{array}$ & $\begin{array}{c}\mathbf{1 3 7}^{\mathbf{1 3 7}} \mathbf{\text { Bq }} \\
\text { B }\end{array}$ \\
\hline Exp. B-4 (N) & $17-22$ & 87 & 2.74 \\
KNPK R-S/9-10 & $0-6$ & 581 & 11.89 \\
KNPK R-S/9-10 & $30-40$ & 80 & 3.53 \\
S of Tree 90 & $19-31$ & 860 & 3.44 \\
\hline
\end{tabular}

Hence, absorption of ${ }^{137} \mathrm{Cs}$ by fungi in soil, and its release as hyphae decline or die may represent an appreciable sink-source couplet in atoll soils.

We therefore examined the possibility that fumigating soil in the field might increase plant uptake of ${ }^{137} \mathrm{Cs}$. The null hypothesis was that plants grown on untreated or fumigated soil would not differ in ${ }^{137} \mathrm{Cs}$ concentration.

\section{Methods and Materials}

The edge of this study was about $15 \mathrm{~m}$ from the edge of Experiment 2, and one end was adjacent to the Experiment 7 plots. Hence, the soil is similar to that described for those studies. Two rows, each containing five contiguous $3 \times 3$ meter plots, were established. The vegetation of grasses, Ipomea, and other forbs was removed by shallow hand grubbing. The soil surface area was then roughly smoothed and the plots separated by shallow trenches. Superphosphate equivalent to $14.6 \mathrm{~g} \mathrm{~m}^{-2} \mathrm{P}$ was raked into the surface, and shallow planting furrows made at $50 \mathrm{~cm}$ intervals. The aim was to minimize disruption of the surface soil structure.

The paired plot design consisted of five pairs of fumigated and control plots. Those to be fumigated were covered with polyethylene plastic, sealed at the plot edges. They were treated with $97.7 \mathrm{~g} \mathrm{~m}^{-2}$ methyl bromide for a period of 28 hours. This rate was chosen because the soil is highly porous, with LOI values of $56 \mathrm{~g}$ $\mathrm{kg}^{-1}$ in the $0-10 \mathrm{~cm}$ layer and $25 \mathrm{~g} \mathrm{~kg}^{-1}$ in the next $20 \mathrm{~cm}$.

Forty-eight hours after removal of the covering, all plots were sown with soaked seed of sweet corn (Zea mays, cv Silver Queen), spaced about $10 \mathrm{~cm}$ apart in the preformed rows. 


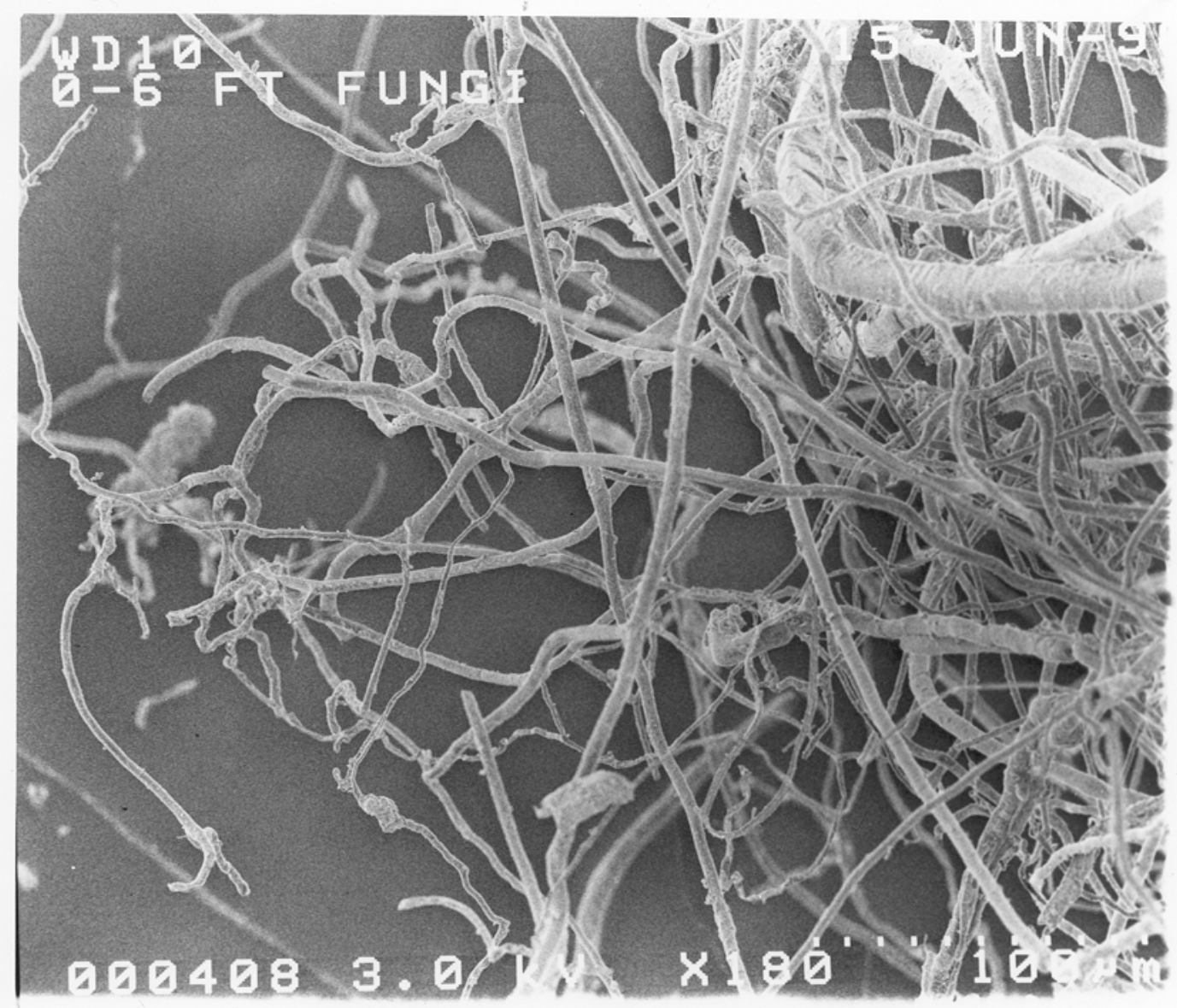

Figure 8-1. Fungal (hyphae separated) from Bikini soil. $19-30 \mathrm{~cm}$ deep (uncoated). Scale dots at lower right are $10 \mu$ apart.

Nitrogen and $\mathrm{K}$ fertilizers were broadcast in four equal applications $3,13,33$, and 47 days after sowing. The total amount of $\mathrm{N}$ as $\left(\mathrm{NH}_{4}\right)_{2}$ $\mathrm{SO}_{4}$ was high, $24 \mathrm{~g} \mathrm{~m}^{-2}$, because of expected losses from volatilization, and also to reduce any differential effect of fumigation on $\mathrm{NH}_{4}$ concentration in soil. Potassium applications totaled $4.8 \mathrm{~g} \mathrm{~m}^{-2}$. The fertilizers were applied in solution and the plots sprinkled after application.

The soil profile was near field capacity at time of sowing, having received $114 \mathrm{~cm}$ rainfall in the preceding $3 \frac{1 / 2}{2}$ months. Rainfall in the following month was only $5.4 \mathrm{~cm}$ but was supplemented by hand watering.

The two harvests were confined to $2 \times 2$ meter interior plots. The first, at 28 days, consisted of young plants cut $5 \mathrm{~cm}$ above the soil surface. Their removal left residual seedlings spaced 80 to $90 \mathrm{~cm}$ apart to form the second harvest. This consisted only of somewhat immature ears harvested at 62 days because water for further irrigation was lacking.

At LLNL the ears were separated into kernels, cobs and husks before analysis for ${ }^{137} \mathrm{Cs}$. Differences in crop yields and ${ }^{137} \mathrm{Cs}$ concentrations were examined by paired " $\mathrm{t}$ " tests.

\section{Results and Discussion}

Fumigation of the soil had no significant effect on the mass of the 28-day harvest (young stems), nor the 62-day harvest (ears only) (Table 8-1). 
Table 8-1. Effect of methyl bromide fumigation on harvested mass of young sweet corn (Paired " $t$ " comparison, $n=5$ ).

\begin{tabular}{lccc}
\hline & \multicolumn{2}{c}{ Treatment } & \\
\cline { 2 - 3 } Age and component & \multicolumn{2}{c}{$\begin{array}{c}\text { Control } \\
\mathrm{g} \mathrm{m}^{-2}, \text { dry weight }\end{array}$} & “ $\mathrm{t}$ " \\
\hline 28 days; whole plant & $24 \pm 8$ & $28 \pm 9$ & $0.82 \mathrm{~ns}^{\mathrm{a}}$ \\
62 days; whole ears only & $270 \pm 48$ & $310 \pm 63$ & $1.84 \mathrm{~ns}^{\mathrm{a}}$ \\
\hline a $\quad$ ns = difference not significant at $<.10$. &
\end{tabular}

The effect of fumigation, however, increased ${ }^{137}$ Cs concentrations in both harvests (Table 8-2). This increase amounted to $56 \%$ in the young stalks cut at 28 days.

In the second harvest, the increase was significant at $\mathrm{p}=.05$ only for the kernels, and at $p=.10$ for husks. This increase was about $20 \%$ for both husks and cobs, although the latter was not significant. Cesium-137 concentrations of all three tissues varied appreciably within treatments, as shown in Figure 8-2. Those for any one plot are closely correlated with each other, however, implying a consistent response of the three tissues to fumigation.

The only plausible interpretation for the results in Table 8-2 is that methyl bromide fumigation killed soil fungi containing ${ }^{137} \mathrm{Cs}$ and so increased the amounts readily available for plant uptake. Abundant literature documents Cs concentration in a variety of fungi (Avery, 1995; Gillette and Crout, 2000; Bruckmann and Wolters, 1994) as well as the release of plant nutrients from microbial populations killed by fumigation (Jenkinson and Powlson, 1976; Anderson and Domseh, 1980; Brookes, et al., 1985).

Two features of the present study may have reduced the full effects of fumigation. First, the addition of $\mathrm{K}$ at rates of 2.4 and $4.8 \mathrm{~g} \mathrm{~m}^{-2}$ to corn harvested at 28 and 62 days, respectively, would have lessened ${ }^{137} \mathrm{Cs}$ uptake, with greater effect on plants exposed to higher amounts of soluble Cs in the soil. Second, redevelopment of soil mycelium, and hence competition for the nuclide, might have been enough to reduce the amounts available to plants of the second harvest. Foot traffic associated with fertilization and watering may have facilitated reinoculation.

Consideration of the total soil inventory of ${ }^{137} \mathrm{Cs}$ and the magnitude of crop uptake in Experiments 3 and 7, however, indicate that fumigation here effectively released only a small fraction of the total inventory. It appears likely that the major sink for ${ }^{137} \mathrm{Cs}$ after 30 years equilibration may lie elsewhere in soil organic matter rather than in live mycelium.

Table 8-2. Effect of methyl bromide fumigation on ${ }^{137} \mathrm{Cs}$ concentration in sweet corn (Paired " $\mathrm{t}$ " comparison; $\mathrm{n}=5$ ).

\begin{tabular}{|c|c|c|c|}
\hline & & Treatment & \\
\hline Age and component & Control & $\begin{array}{c}\text { Fumigated } \\
{ }^{137} \mathrm{Cs}, \mathrm{Bq} \mathrm{g}^{-1}, \text { green weight }\end{array}$ & "t" \\
\hline $\begin{array}{l}28 \text { days } \\
\text { whole plant } \\
62 \text { days }\end{array}$ & $0.42 \pm .09$ & $0.66 \pm .23$ & $2.93^{a}$ \\
\hline $\begin{array}{l}\text { Husk } \\
\text { Kernels } \\
\text { Cobs }\end{array}$ & $\begin{array}{l}0.79 \pm .19 \\
0.61 \pm .17 \\
0.71 \pm .15\end{array}$ & $\begin{array}{l}0.94 \pm .29 \\
0.79 \pm .30 \\
0.84 \pm .28\end{array}$ & $\begin{array}{l}2.34^{\mathrm{b}} \\
2.87^{\mathrm{a}} \\
1.50 \mathrm{~ns}^{\mathrm{c}}\end{array}$ \\
\hline
\end{tabular}




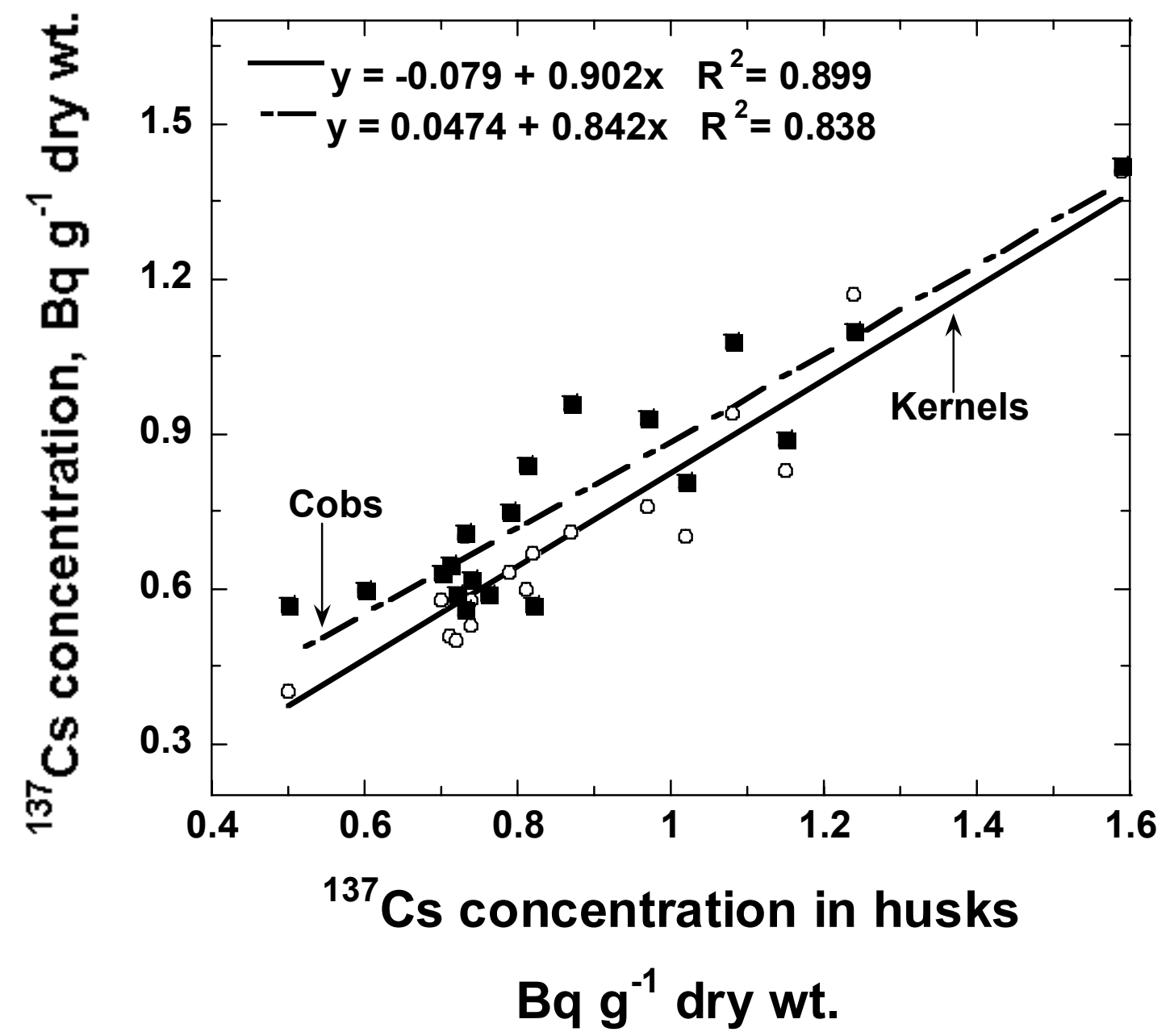

Figure 8-2. ${ }^{137} \mathrm{Cs}$ concentrations in sweet corn kernels and cobs versus those in 62 day-old stalks.

\section{Summary Discussion}

Expressing ${ }^{137} \mathrm{Cs}$ in terms of radioactivity is necessary but may conceal how exceedingly minute the amounts held in soil are, and so obscure the processes involved in cycling through plant systems or interacting with $\mathrm{K}$. Even in the center of Bikini Island, ${ }^{137} \mathrm{Cs}$ in the surface soil commonly averages only 1 to $4 \mathrm{~Bq} \mathrm{~g}^{-1}$, which is only $\sim 3$ to $12 \times 10^{-13} \mathrm{~g}$ ${ }^{137} \mathrm{Cs} \mathrm{g}^{-1}$ soil. The average amounts in a square meter of soil 20 to $30 \mathrm{~cm}$ deep are seldom greater than $600 \mathrm{kBq}$, equivalent to less than $2 \mathrm{mg} \mathrm{ha}^{-1}$. Possibly its great dilution in a $\mathrm{Ca}$ and $\mathrm{Mg}$ matrix accounts for the lack of absorption by added clinoptilite (Experiment 7).
The amounts of ${ }^{137} \mathrm{Cs}$ are miniscule when compared with those of added potassium. For example, $600 \mathrm{kBq} \mathrm{m}{ }^{-2}{ }^{137} \mathrm{Cs}$ represents only $1.36 \times 10^{-9}$ mols whereas $10 \mathrm{~g} \mathrm{~m}^{-2} \mathrm{~K}$ applied to the same area, as in some of our experiments, amounts to $2.58 \times 10^{-1}$ mols. The effect of added $\mathrm{K}$ appears to be reduction of $\mathrm{K}$ stress in plants a condition which seems general on atolls. As evident in all of the preceding experiments, increasing $\mathrm{K}$ concentration in plants greatly reduce ${ }^{137}$ Cs uptake. Cesium-137 is retained in the soil by organic matter (including soil organisms). In the few instances examined, concentrations of organic matter and ${ }^{137} \mathrm{Cs}$ were 
closely correlated (Figures 3-1 and 7-1). Both are remarkably variable over scales of a few square meters and averages from adjacent small plots have 20 to $50 \%$ coefficients of variation.

At the beginning of these studies, the original fallout ${ }^{137} \mathrm{Cs}$ had already "aged" or equilibrated with soil for more than 30 years. Only a small fraction could be removed by laboratory exchange procedures (Koranda and Robison, unpublished data; Wong and Robison, unpublished data), or by growth of successive crops. Figures 1-5A and B demonstrate that plant uptake of such ${ }^{137} \mathrm{Cs}$ is closely correlated with uptake of newly added ${ }^{133} \mathrm{Cs}$, as would be expected. The ratio ${ }^{137} \mathrm{Cs} /{ }^{133} \mathrm{Cs}$ in plants, however, is only 5 to $10 \%$ of the ratio in soil, indicating that most of the total ${ }^{137} \mathrm{Cs}$ present is not readily accessible to plant roots. Such findings concur with the very limited removal (4 to $5 \%$ ) of total ${ }^{137} \mathrm{Cs}$ in the soil column of a 1-hectare plot by prolonged leaching with seawater totaling $20 \mathrm{~m}$ over a 3 month period (Robison and Stone, 1999). The uptake of ${ }^{137} \mathrm{Cs}$ into food plants and grass was very low over the first year and a half after the irrigation with seawater and only gradually increased over the next 2 years. It appears to take some time to deplete the soil of K added with the seawater or to establish an exchangeable (available) pool of ${ }^{137}$ Cs after such extensive leaching.

Again, cumulative removal of ${ }^{137} \mathrm{Cs}$ by continuous cropping experiments amounts to no more than $10 \%$ of the estimated soil totals (Experiments 1, 2, 3, 4, 7). These and other studies give no certain indication that such removals have diminished availability to subsequent crops, although some suggest this (e.g., Experiment 4). Such reduction may become apparent after greater or more rapid removals. However, the studies do show that the $\mathrm{K}$ supply is depleted within two or three successive crops. To grow any further crops at this stage requires the addition of $\mathrm{K}$ which, in turn, greatly reduces the uptake of ${ }^{137} \mathrm{Cs}$ in any crops that we have grown on atoll soils.

Release of $\mathrm{K}$ from the mineral components of weathered atoll soils appears vanishingly small. The presumed long-term source is oceanic spray; a consequence of which is that soil $\mathrm{Na}$ exceeds $\mathrm{K}$ in untreated soil. Although $\mathrm{K}$ is retained by soil organic matter, the total extractable amounts are small and readily depleted by cropping. As noted, reduced growth and K deficiency symptoms commonly mark the second or third crop grown with adequate $\mathrm{N}$ and P. Possibly, the high levels of $\mathrm{Ca}$ and $\mathrm{Mg}$ in the soil solution decrease rates of K uptake (Dibb and Thompson, 1985).

Addition of $\mathrm{K}$ increased crop growth in all of the field experiments where such comparisons were made (e.g., Figures 2-2, 2-8, 4-1, 6-3, Table 7-2). The only exception was sweet potato, Crop 6 of Experiment 2, where insufficient water restricted growth and allowed salt injury. In many instances, the apparent response was limited by application of "starter" or "maintenance" amounts of $\mathrm{K}$ to all treatments, including the nominal zero-K controls. As already noted, such applications were not always small relative to minimal plant requirements.

The major concern of most of these experiments, however, was reduction of ${ }^{137} \mathrm{Cs}$ in foodcrops. Such reductions were large and universal, as shown in numerous figures and tables. Here the crops included tomato, sweet potato, Chinese cabbage, squash, and the monocots, pearl millet, sorghum, and sweet corn - both kernels and stover. Other studies, not reported here, would add other crucifers, beans, melons, tree crops, and wild plants to this list. Where studies included increasing rates of $\mathrm{K}$, the greatest absolute reductions in ${ }^{137} \mathrm{Cs}$ uptake occurred at the lowest or low rates, with progressively smaller reductions as more $\mathrm{K}$ was added (e.g., Figures 2-1, 2-2, 2-3, 2-8B).

As plant nutrition studies have long demonstrated, the range of $\mathrm{K}$ concentration between acute deficiency and toxicity is wider than with other nutrients that remain soluble in plants. In particular, plants may continue to accumulate $\mathrm{K}$ well above the concentrations associated with maximum growth, an effect sometimes described as "luxury consumption." In our studies, the dry weight range in sorghum and sweet corn stover is at least 10-fold, from around $3 \mathrm{~g} \mathrm{~kg}^{-1}$ to more than $30 \mathrm{~g} \mathrm{~kg}^{-1}$. Usually the highest concentrations occur with the highest rates of addition to soil, although variation occurs among plots.

Where plant $\mathrm{K}$ concentrations were determined in field experiments, curvilinear relationships between concentrations of ${ }^{137} \mathrm{Cs}$ and $\mathrm{K}$ are similar in all (e.g., Figures 2-6, 4-2 and 4-3, 5-3 and 5-4, 6-3, 7-2 and 7-3). Cesium 
decreased abruptly as $\mathrm{K}$ increased initially from its lowest levels. Further increases in $\mathrm{K}$ brought progressively smaller decreases in ${ }^{137} \mathrm{Cs}$, ending in a near-asymptotic approach to a low level of ${ }^{137}$ Cs. Complete exclusion of ${ }^{137} \mathrm{Cs}$ has not occurred in these studies. Even the greatest rates of $\mathrm{K}$ application, above $300 \mathrm{~g} \mathrm{~m}^{-2}$, although probably reduced by initial leaching, lowered

${ }^{137} \mathrm{Cs}$ in sweet corn only to $0.2 \mathrm{~Bq} \mathrm{~g}^{-1}$, green weight (Figure 6-3).

These observations concur with the response patterns displayed in numerous nutrient culture studies, usually over short periods. Thus, Handley and Overstreet (1961), using excised barley roots, and an hour-long absorption period, demonstrated an abrupt hyperbolic decrease in ${ }^{137} \mathrm{Cs}$ uptake as $\mathrm{K}$ in the nutrient solution increased from zero to $50 \mu \mathrm{M}$. Much later, Baligar et al. (1979) confirmed this pattern with 20-day-old intact corn seedlings. Recently, Smolders et al (1996), reviewing previous short-term investigations, noted that ${ }^{137}$ Cs uptake by plants in such studies showed the greatest response to K supply between 20 and $500 \mu \mathrm{M} \mathrm{K}$, with about 10 -fold reductions for each 10 -fold increase in solution $\mathrm{K}$ concentration. Their own work with 18-day-old wheat seedlings demonstrated that a 5-fold increase in solution $\mathrm{K}$ concentrations, from 50 to $250 \mu \mathrm{M}$, reduced ${ }^{137} \mathrm{Cs}$ concentration in these plants by 42 -fold. As K concentration increased from 250 to $1000 \mu \mathrm{M}$, however, the reduction in ${ }^{137}$ Cs was only 1.9-fold. Moreover, growth of these young plants was unaffected over the entire range, from 25 to $1000 \mu \mathrm{M}$.

In a more recent study (Zhu et al., 2000), week-old wheat seedlings were grown for three days in nutrient cultures with or without added K. When subsequently exposed to test solutions containing Cs, the previously K-starved seedlings absorbed ${ }^{137} \mathrm{Cs}$ far more rapidly than the unstarved seedlings, with a linear range in solution concentration from 700 to $6500 \mathrm{~Bq} \mathrm{~L}^{-1}$. Such uptake was greatly lessened as $\mathrm{K}$ in the test solutions increased from 2 to $12 \mathrm{mg} \mathrm{L}^{-1}$ ( 50 to $300 \mu \mathrm{M})$. Thus, the authors concluded that Cs influx was controlled not only by external concentrations of $\mathrm{K}$ and $\mathrm{Cs}$, but also by internal $\mathrm{K}$.

Such evidence that internal K concentration controls ${ }^{137} \mathrm{Cs}$ influx concurs with the results of Experiment 6. Here ${ }^{137} \mathrm{Cs}$ uptake was determined not by the proportion of the root system in untreated soil, but by the amount of $\mathrm{K}$ absorbed by the plant (Figure 6-3), whatever K distribution in the soil might be.

Thus, the ${ }^{137} \mathrm{Cs} / \mathrm{K}$ response curves seen in the crop plants grown on Bikini over severalweek periods are similar in form to the nutrient culture results mentioned above. This suggests a similarity in the operating uptake mechanisms, as well as extremely low concentrations of $\mathrm{K}$ in the soil solutions of unfertilized plots.

In the Bikini soils, $\mathrm{K}$ unused by one crop plus that retained in unharvested root systems remains available to the next crop, except as leached by heavy rain or irrigation. Increased growth and reduced ${ }^{137} \mathrm{Cs}$ following $\mathrm{K}$ additions as small as $2.0 \mathrm{~g} \mathrm{~m}^{-2}$ focus attention both on minor differences in soil $\mathrm{K}$ and on any "carryover" effect of K added to one crop upon the next.

Adding $\mathrm{K}$ to a crop in several split applications, as in most of these experiments, lessens the time for root uptake before harvest, but also lessens the opportunity for leaching before the next crop. The influence of residual $\mathrm{K}$ was made apparent when one crop in a series was grown without added $K$, as shown in Figures 2-9A and B, 4-1, 4-2, and Tables 6-2 to $6-4$. The latter instance is particularly striking because heavy rainfall occurred in a fallow period before the crop without added $\mathrm{K}$ was sown.

The high porosity of these soils and the water solubility of the supposedly exchangeable $\mathrm{K}$ should favor leaching. On the other hand, removal of K may be retarded by the abundance of organic-bound aggregates and the channelized flow of water (seen in one study with dye). The increase in plant ${ }^{137} \mathrm{Cs}$ after preliminary leaching followed by $2 \mathrm{~m}$ of rainfall, as shown in Figure 3-3, however, demonstrated that excess rainfall over a period of months can remove even extraordinarily large additions of K.

It is now abundantly clear that $\mathrm{K}$ addition is a highly effective and consistent countermeasure against ${ }^{137} \mathrm{Cs}$ in atoll soils. The only exceptions would arise where surface applications of $\mathrm{K}$ fail to penetrate to root systems during prolonged rainless periods, or when sustained heavy rains fall on already moist soil. Such rains, in fact, occur occasionally on Bikini, as illustrated in Figures 0-3 and 3-3. 
It is also clear that relatively small applications of $\mathrm{K}$, if absorbed, cause large decreases in ${ }^{137} \mathrm{Cs}$ uptake, although the response curve is far from linear. Hence the apparent soilplant concentration ratio (or transfer factor) for a given plant genotype and soil type may vary greatly according to small, often localized, differences in either $\mathrm{K}$ or ${ }^{137} \mathrm{Cs}$ content of soil.

Removal of soil ${ }^{137}$ Cs pollution by continuous cropping, or "bioremediation" obviously depends on plant mass production as well as its ${ }^{137} \mathrm{Cs}$ concentration. Addition of $\mathrm{K}$ has opposing effects on the two parameters, as illustrated by estimated total removals in Experiment 2. In the absence of added $\mathrm{K},{ }^{137} \mathrm{Cs}$ concentration is high in any annual crop, but mass production declines to some low level or may fail entirely.

In principle, very small initial applications of $\mathrm{K}$ that would be exhausted as the plants developed might favor a moderate level of mass production together with relative high ${ }^{137} \mathrm{Cs}$ concentration, thus maximizing total removal in successive crops. The difficulty and uncertainties in regulating an appropriate $\mathrm{K}$ status, however, as well as the absolute lack of water for irrigating more than small plots, renders this prospect of only academic interest.

The practical applications of these studies may be summarized thus:

1. Soil concentrations of ${ }^{137} \mathrm{Cs}$ vary substantially even among small plots within a confined area (Figures 3-1, 7-1). This must be taken into account when sampling soil. In some areas, at least, ${ }^{137} \mathrm{Cs}$ is related to soil organic matter contents (Figures 3-1, 7-1).

2. Plant-available $\mathrm{K}$ is low or very low in most atoll soils. The result is low or minimal concentrations in crop plants. Removal of $\mathrm{K}$ by one or a very few harvests leads to reduced yields and acute $\mathrm{K}$ deficiency unless $\mathrm{K}$ is applied (Figures 2-2, 6-3).

3. Additions of $\mathrm{K}$ fertilizer to soil reduce ${ }^{137} \mathrm{Cs}$ in plants (Experiments 2, 3, 4, 5, 6, 7). The relationship between the two is almost hyperbolic. Much of the achievable maximum decrease occurs after relatively moderate applications of
K-say, 40 to $100 \mathrm{~kg} \mathrm{ha}^{-1}$. Progressively larger additions of $\mathrm{K}$ lead to further, but progressively smaller, reductions in ${ }^{137} \mathrm{Cs}$.

Annual crops require very much smaller applications of $\mathrm{K}$ to effectively reduce ${ }^{137} \mathrm{Cs}$ than do bearing coconut palms (Robison and Stone, 1992). The reason is the much greater total green mass of a coconut plantation, which commonly has ten times or more green mass than a well-grown annual crop. Almost all K and $\mathrm{Cs}$ in plants occurs in solution.

4. The amount and sequence of rains following broadcast addition of $\mathrm{K}$ affect both growth response and ${ }^{137} \mathrm{Cs}$ reduction. Plants developing on already moist soil during a rainless period may not reach $\mathrm{K}$ remaining at or near the soil surface (Figure 4-2).

On the other hand, prolonged heavy rains (or excessive watering) will leach much of the added $\mathrm{K}$ below rooting depth before uptake occurs (Figure 3-3). "Split application," that is, dividing the total $\mathrm{K}$ into two or more additions, is a defense against loss by heavy rains, but not against limited penetration.

5. Unless rainfall is high, potassium not absorbed by one crop remains in the soil for uptake by subsequent plants. In the case of sorghum, $\mathrm{K}$ in re-sprouting rootstocks also is available to the ratoon crop, adding to the total carryover.

6. It follows from 4 and 5 above that concentration of $\mathrm{K}$ in the plant is a better indicator of ${ }^{137} \mathrm{Cs}$ reduction than the amount applied to a crop.

7. As indicated by Experiment 7, increased plant concentration of $\mathrm{K}$ after soil additions is the critical factor reducing ${ }^{137}$ Cs uptake, rather than the pattern or uniformity of distribution over the rooting area. An evident reservation to this generality is that $\mathrm{K}$ addition should not be so great at any point as to damage roots or be heavily leached before absorption occurs. 


\section{References}

Anderson, J. P. E., and K. H. Domsch (1980), "Quantities of Plant Nutrients in the Microbial Biomass of Selected Soils," Soil Sci.: 211-216.

Avery, S. V. (1995), “Caesium Accumulation by Micro Organisms: Uptake Mechanisms, Cation Competition, Compartmentalization, and Toxicity," J. Indust. Micobiol. 14: 17-84.

Baligar, V. C., N. E. Neilson, and S. A. Barber (1979), "Kinetics of Absorption of K, Rb and Cs from Solution Culture by Intact Plant Roots," J. Plant Nutr. 1: 25-37.

Ball, D. F. (1964), “Loss-on-Ignition as an Estimate of Organic Matter and Organic Carbon in Non-Calcareous Soils," J. Soil Science: 1584-1592.

Brookes, P. C., J. F. Kragt, D. S. Powlson, and D. S. Jenkinson (1985), "Chloroform Fumigation and the Release of Soil Nitrogen: The Effects of Fumigation Time and Temperature," Soil Biol. Biochem.17: 83-835.

Brückmann, A., and V. Wolters (1994), "Microbial Immobilization and Recycling of ${ }^{137} \mathrm{Cs}$ in Organic Layers of Forest Ecosystems: Relationship to Environmental Conditions, Humification, and Invertebrate Activity," Sci. Total Environ.157: 249-256.

Brunk, J. L. (1995a), Gamma Analysis of Environmental Samples from the Marshall Islands, Lawrence Livermore National Laboratory, Livermore, CA, UCRL-ID122251.

Brunk, J. L. (1995b), Instructions for Calibrating Gamma Detectors Using the CanberraNuclear Data Genie Gamma Spectroscopy System, Lawrence Livermore National Laboratory, Livermore, CA, UCRL-ID120428.
Campbell, L. S. and D. E. Davies (1997), “Experimental Investigation of Plant Uptake of Ceasium from Soils Amended with Clinoptilolite and Calcium Carbonate," Plant Soil 189: 65-79.

Cheshire, M. V. and C. Shand (1991), "Translocation and Plant Availability of Radio Ceasium in an Organic Soil," Plant Soil 134: 287-296.

Davies, B. E. (1974), “Loss-on-Ignition as an Estimate of Soil Organic Matter," SoilSci. Soc. of Am Proc., 38: 150-151.

Dibb, D. W. and W. R. Thompson Jr. (1985), "Interaction of potassium with other nutrients," in Potassium in Agriculture (R. D. Munson, Ed.) Am. Soc. Agronomy, Crop Sci. Soc. Am., Soil Sci. Soc. Am., Madison, Wisconsin, p. 515-533.

Dunn, P. H. and Don Reynolds (1987), "Fungi of Enewetak Atoll," in The Natural History of Enewetak Atoll, Vol. II, Office of Scientific and Technical Information, U.S. Department of Energy, DOE/EV/00703Ti-Vol. 2, p. 11-15.

Etherington, J. R. (1967), "Studies of Nutrient Cycling and Productivity in Oligiotrophic Ecosystems. I. Soil Potassium and WindBlown Sea Spray in A South Wales Dune Grassland," J. Ecol. 55: 743-752.

Fosberg, F. R., and D. Carroll (1965), “Terrestrial Sediments and Soils of the Northern Marshall Islands," Atoll Research Bulletin 113: 1-156.

Gessel, S. P., and R. B. Walker (1992), "Studies of Soils and Plants in the Northern Marshall Islands," Atoll Research Bulletin 359, p. 70.

Gillette, A. G., and N. M. J. Crout (2000), “A Review of ${ }^{137} \mathrm{Cs}$ Transfer to Fungi and Consequences for Modelling Environmental Transfer," J. Environ. Radioactivity 48: 95-121. 
Gudiksen, P. H., T. R. Crites, and W. L. Robison (1976), External Dose Estimates for Future Bikini Atoll Inhabitants, Lawrence Livermore National Laboratory, Livermore, CA, UCRL-51879 Rev. 1.

Handley, R. and R. Overstreet (1961), "Effect of Various Cations on Absorption of CarrierFree Cesium," Plant Physiol. 36: 66-69.

Jenkinson, D. S., and D. S. Powlson (1976), “The Effects of Biocidal Treatments on Metabolism in Soils I. Fumigation with Chloroform," Soil Biol. Biochem. 8: 167-177.

Johnston, D. B. (1947), “Soil Actinomycetes of Bikini Atoll and Special Reference to their Antagonistic Properties," Soil. Sci. 64: 453458.

Kehl, S. R., M. E. Mount, and W. L. Robison (1995), The Northern Marshall Islands Radiological Survey: a Quality Control Program for Radiochemical and Gamma Spectroscopy Analysis, Lawrence Livermore National Laboratory, Livermore, CA, UCRL-ID-120429.

Koranda, J. J., W. L. Robison, C. L. Conrado, and M. L. Stuart, Laboratory Studies Related to the Cycling of Radionuclides at Enewetak Atoll, (Unpublished data)

Ng, Y. C., C. S. Colsher, and S. E. Thompson (1982), Soil-to-Plant Concentration Factors for Radiological Assessments, U. S. Nuclear Regulatory Commission, NUREG/CR2975.

Paasikallio, A. (1999), "Effect of Biotite, Zeolite, Heavy Clay, Bentonite and Apatite on the Uptake of Radiocaesium by Grass from Peat Soil," Plant Soil 206: 213-222.

Robison, W. L. (1983). “Radiological Dose Assessments of Atolls in the Northern Marshall Islands, "Nineteenth Annual Meeting of the National Council on Radiation Protection and Measurements: Environmental Radioactivity No. 5, Bethesda, MD, National Council on Radiation Protection and Measurements, p. 40-82.
Robison, W. L. and E. L. Stone (1999), “The Evaluation of Critical Pathways, Radionuclides, and Remedial Measures for Reducing the Radiological Dose to Returning Population at A Former Nuclear Test Site," in HLW, LLW, Mixed Wastes and Environmental Restoration Working Towards A Cleaner Environment, Session 17, ER Progress in Cleaning Up Nuclear Weapons Test Sites-II, WM'98 Symposium, Tucson, Arizona, March 1-5, 1998, p. 17-02: 1-9

(file:/ / /WM98PRO/html/sess17/1702/17-02.htm).

Robison, W. L. and E. L. Stone (1992), “The Effect of Potassium on the Uptake of 137 Cs in Food Crops Grown on Coral Soils: Coconut at Bikini Atoll," Health Physics 62: 496-511.

Robison, W. L., K. T. Bogen, and C. L. Conrado. (1997), “An Updated Dose Assessment for Resettlement Options at Bikini Atoll-A U.S. Nuclear Test Site." Health Physics 73: 100-114.

Rogers, D. P. (1947), "Fungi of the Marshall Islands, Central Pacific Ocean," Pacific Sci. 1: 92-107.

Shenber, M. A. and K. L. Johansen (1992), "Influence of Zeolite on the Availability of Radiocaesium in Soil to Plants," Sci. Total Environ. 113: 287-295.

Shinn, J. H., D. N. Homan, W. L. Robison (1997), "Resuspension Studies in the Marshall Islands," Health Physics 73: 248-257.

Sltanpour, P. N., and A. P. Schwab (1977), “A New Test for Simultaneous Extraction of Macro-and Micro-Nutrients in Alkaline Soils," Commun. Soil. Sci. Plant. Anal. 8: 195-207.

Smolders, E., and G. Shaw (1995), "Changes in Uptake and Distribution in the Wheat Plant During Plant Development: A Solution Culture Study," Plant Soil 176: 1-6. 
Smolders, E., L. Kiebooms, J. Buysse, and R. Merek (1996), "137Cs Uptake in Spring Wheat (Triticum aestivum L. cv Tonic) at Varying K Supply I. The Effect in Solution Culture," Plant Soil 181: 205-208.

Sparrow, F. K. (1948), “Soil Phycomycetes from Bikini, Eniwetok, Rongerik, and Rongelap Atolls," Mycologia 40: 445-453.

Stone, E. L. (1951), “The Soils of Arno Atoll, Marshall Islands," Atoll Research Bull. 6: 1-46.

Stuart, M. L. (1995), Collection and Processing of Plant, Animal, and Soil Samples from Bikini, Enewetak, and Rongelap Atolls, Lawrence Livermore National Laboratory, Livermore, Livermore, CA, UCRL-ID120427.

Tipton, W. J., and R. A. Meibaum (1981), An Aerial Radiological and Photographic Survey of Eleven Atolls and Two Islands within the Northern Marshall Islands, EG\&G, Las Vegas, NV, EGG-1183-1758 (available through the National Technical Information Service).

Walker, R. B., S. P. Gessel, and E. E. Held (1997), "The Ecosystem Study of Rongelap Atoll," Health Physics 73: 223-233.
Walker, R. B., E. E. Held, and S.P. Gessel (1961), "Radiocesium in Plants Grown on Rongelap Atoll Soils," in Advances in Botany, University of Toronto Press, $\mathrm{p}$. 1363-1367.

Wallace, A., E. M. Romney, and R. A. Wood (1982), "The Role of Stable Cesium on Plant Uptake of Cesium-137," Soil Science 134: 71-75.

Witkamp, M. (1968), “Accumulation of ${ }^{137}$ Cs by Trichoderma Viride Relative to ${ }^{137} \mathrm{Cs}$ in Soil Organic Matter and Soil Solution," Soil Sci. 106: p. 309-311.

Wong, K. M., T. A. Jokela, and V. E. Noshkin (1994), Radiochemical Procedures for Analysis of Pu, Am, Cs, and Sr in Water, Soil, Sediments, and Biota Samples, Lawrence Livermore National Laboratory, Livermore, CA, UCRL-ID-116497.

Zhu, Y. G., G. Shaw, A. F. Nisbit, and B. T. Wilkins (2000), "Effect of Potassium Starvation on the Uptake of Radiocaesium by Spring Wheat (Triticum aestivum $\mathrm{cv}$ Tonic)," Plant Soil 220: 27-34. 




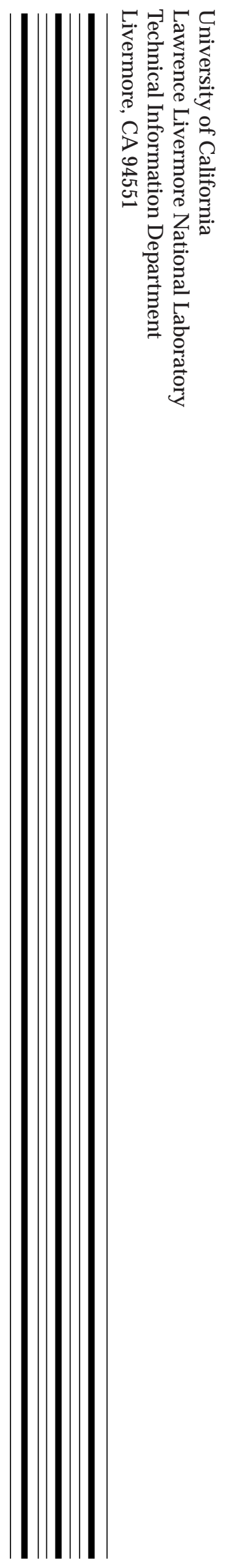

